ANDRÉ LUIZ NEVES DE SOUZA

AVALIAÇÃO DE QUALIDADE CARTOGRÁFICA E EXTRAÇÃO DE BORDAS DE OBJETOS NÃO PERTENCENTES AO TERRENO EM PRODUTOS GERADOS PELO SISTEMA DE VARREDURA A LASER AEROTRANSPORTADO

SÃO PAULO 
ANDRÉ LUIZ NEVES DE SOUZA

\begin{abstract}
AVALIAÇÃO DE QUALIDADE CARTOGRÁFICA E EXTRAÇÃO DE BORDAS DE OBJETOS NÃO PERTENCENTES AO TERRENO EM PRODUTOS GERADOS PELO SISTEMA DE VARREDURA A LASER AEROTRANSPORTADO
\end{abstract}

Dissertação apresentada à Escola Politécnica da Universidade de São Paulo para obtenção do título de Mestre em Engenharia

SÃO PAULO 
ANDRÉ LUIZ NEVES DE SOUZA

\title{
AVALIAÇÃO DE QUALIDADE CARTOGRÁFICA E EXTRAÇÃO DE BORDAS DE OBJETOS NÃO PERTENCENTES AO TERRENO EM PRODUTOS GERADOS PELO SISTEMA DE VARREDURA A LASER AEROTRANSPORTADO
}

\author{
Dissertação apresentada à Escola \\ Politécnica da Universidade de São \\ Paulo para obtenção do título de \\ Mestre em Engenharia \\ Área de Concentração: Engenharia \\ de Transportes \\ Orientador: Professor Livre-Docente \\ Jorge Pimentel Cintra
}

SÃO PAULO 
Este exemplar foi revisado e alterado em relação à versão original, sob responsabilidade única do autor e com a anuência de seu orientador.

São Paulo, de junho de 2009.

Assinatura do autor

Assinatura do orientador

FICHA CATALOGRÁFICA

Souza, André Luiz Neves de

Avaliação de qualidade cartográfica e extração de bordas de objetos não pertencentes ao terreno em produtos gerados pelo sistema de varredura a laser aerotransportado / A.L.N. de Souza. -- ed.rev. -- São Paulo, 2009. $103 \mathrm{p}$.

Dissertação (Mestrado) - Escola Politécnica da Universidade de São Paulo. Departamento de Engenharia de Transportes.

1.Cartografia 2.Modelagem de dados 3.Controle da qualidade 4.Detecção de bordas 5.Dispositivos de varredura (Topografia) I.Universidade de São Paulo. Escola Politécnica. Departamento de Engenharia de Transportes II.t. 


\section{AGRADECIMENTOS}

Ao Professor Cintra pela orientação, incentivo e, principalmente, motivação no decorrer deste trabalho;

Ao Professor Jorge Centeno, da Universidade Federal do Paraná, pela cessão dos dados utilizados neste trabalho;

Aos meus pais pela educação e valores que me fizeram alcançar esta conquista;

A minha esposa Keilla pelo incentivo e paciência;

Aos meus colegas de graduação e pós-graduação pelas opiniões e discussões que enriqueceram em muito este trabalho. 


\section{RESUMO}

O sistema de varredura a LASER aerotransportado é uma tecnologia competitiva para levantamentos que visam à geração de modelos digitais de superfície (MDS) e modelos digitais de terreno (MDT). Esta tecnologia sofreu certa resistência por parte das empresas de aerolevantamento e de alguns usuários, porém vem conquistando o mercado, graças à grande quantidade de trabalhos recentemente publicados. Uma das limitações associadas ao levantamento a LASER é a correta deteç̧ão de objetos não pertencentes ao terreno como árvores e edificações. Esses objetos, quando devidamente identificados, são essenciais para várias aplicações como cadastro e avaliação da qualidade cartográfica. Este trabalho propõe uma metodologia de identificação de edificações através da detecção de suas bordas, em uma rede triangular (TIN) construída sobre a nuvem de pontos. A utilização da TIN preserva os valores originais da amostra e, representa o universo real com melhor fidelidade que os modelos matriciais. A detecção é realizada calculando-se as declividades para todos os triângulos da TIN. Após esta etapa, são segmentados todos os triângulos que possuem valor de declividade acima de um limiar, pois representam variações abruptas no terreno, condizentes com edificações. A definição do limiar depende da resolução da nuvem de pontos, padrão de varredura e natureza do terreno. $O$ trabalho apresenta ferramentas preliminares para automatizar a vetorização das bordas detectadas. As edificações extraídas pela metodologia e ferramentas apresentadas, podem ser utilizadas para avaliação da qualidade cartográfica do MDS/MDT. Para isso, compara-se o MDS a um documento cartográfico de referência, e realizam-se testes para: detecção e eliminação de erros grosseiros, detecção de tendências e minimização de erros sistemáticos, testes de precisão e de atendimento ao Padrão de Exatidão Cartográfico (PEC). Após análises, conclui-se que a metodologia de detecção de bordas propostas é eficiente, porém as ferramentas de automatização precisam ser aperfeiçoadas. Conclui-se também que o MDS oriundo do levantamento a LASER tem qualidade cartográfica compatível com o produto cartográfico de referência. Recomenda-se aplicação das metodologias propostas em outros conjuntos de dados.

Palavras-Chave: varredura a LASER, modelo digital de superfície, detecção de bordas. 


\section{ABSTRACT}

The airborne LASER scanner is competitive technology for surveys that generates digital surface models (DSM) and Digital Terrain Models (DTM). This technology suffered some resistance by the aerosurvey enterprise (and some users), but is conquering its market share due the amount of papers recently published in this field. A limitation associated with this technique is the correct detection of the offterrain objects, like trees and buildings. These objects, when well identified, are essential to a sort of applications like cadastre e map quality evaluation. This dissertation proposes a methodology to identify buildings by the edge detection of a triangular irregular net (TIN) built over the point cloud. The utilization of TIN preserves the original values, representing the real $3 \mathrm{D}$ universe with fidelity despite the raster models. The detection is done calculating the slopes for all triangles of the TIN. After that, the triangles with slope values above a threshold are segmented. The Threshold definition depends on resolution of the point cloud, scan pattern and target behavior. Triangles with high slope values represent hard variation and may mean buildings. This work shows preliminary tools to automate the vectorization of the detected edges. The extracted buildings may be used for map quality evaluation of the DSM/DTM, by comparing it with a reference map. This means: test for detection e elimination of bundles, test for detection and minimization of systematic errors, precision tests and evaluate the meeting the Brazilian cartographic accuracy standard (PEC). Theses analysis concludes that the proposed methodology of edge detection is efficient but the developed tools of automation may be sharpened. Also, concludes that the DSM built with LASER scanner survey is compatible with reference map. It's recommended the application of the methodology on other collections of data.

Key-words: LASER scan, digital surface model, edge detetcion. 


\section{SUMÁRIO}

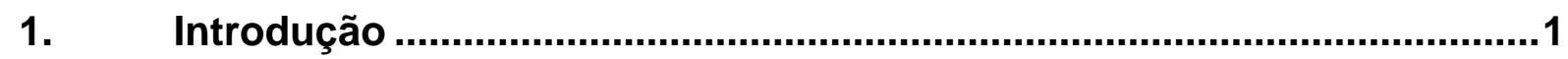

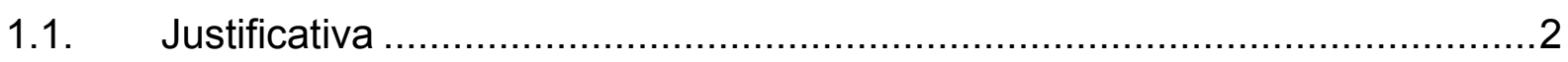

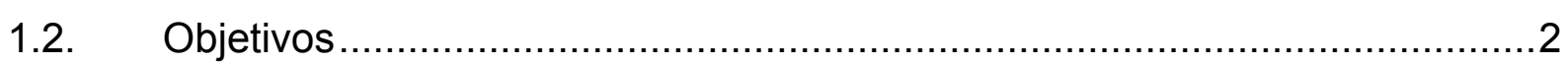

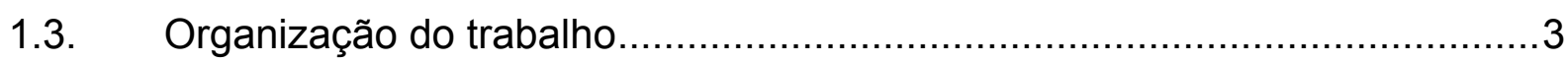

2. Revisão Bibliográfica .................................................................4

2.1. Componentes e funcionamento do sistema de varredura a LASER

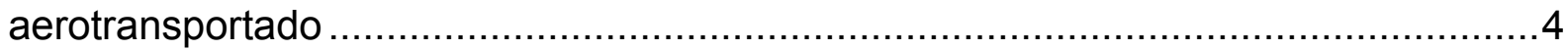

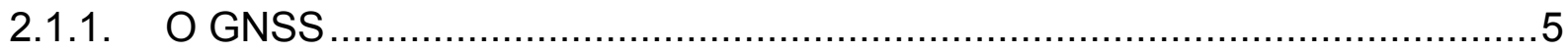

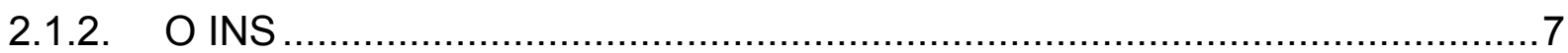

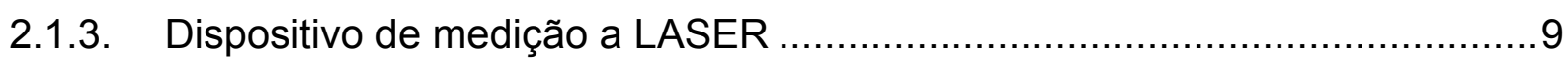

2.1.4. Mecanismos de Varredura .............................................................. 13

2.1.5. Sincronização e determinação dos pontos ........................................... 16

2.2. Processamento dos dados do sistema de varredura a LASER .................19

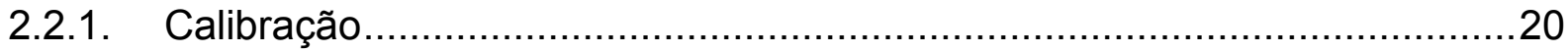

2.2.2. Filtragem de pontos não-pertencentes ao terreno ...............................29

2.3. Modelos digitais de terreno e dados de varreduras a LASER ...................34

2.3.1. Amostragem e redução de pontos redundantes ................................... 35

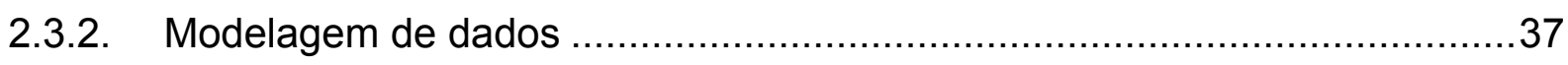

2.3.3. Avaliação da Qualidade Cartográfica de um MDT ou MDS .......................39

2.4. Detecção de bordas e dados de varredura a LASER. ............................40

3. Proposta de metodologia para a avaliação da qualidade cartográfica de produtos gerados a partir de levantamentos a LASER.....................................44

3.1. Processamento dos dados e delimitação da área de estudo......................46

3.2. Geração do MDS e detecção de bordas de edificações ...........................46

3.3. Coleta de pontos de controle planimétricos e altimétricos ........................52

3.4. Cálculo de estatísticas, detecção e eliminação de erros grosseiros ............53

3.5. Testes de tendência e eliminação de erros sistemáticos .............................55

3.6. Teste de precisão (padrão americano) …............................................56

3.7. Satisfação ao PEC (padrão brasileiro) ................................................. 57

3.8. Ajustamento com transformação afim ............................................ 58 


\section{Avaliação da qualidade do levantamento a LASER realizado no}

Campus da UFPR

4.1. Local de testes, equipamentos e programas computacionais utilizados.....61

4.2. Processamento dos dados e coletas de pontos de controle .......................62

4.3. Geração do MDS e coleta de pontos de controle planimétrico .....................65

4.4. Detecção e eliminação de erros grosseiros na planimetria, sobre o conjunto

de dados vetorizados manualmente .68

4.5. Testes de tendência e minimização de erros sistemáticos na planimetria, sobre o conjunto de dados vetorizados manualmente .70

4.6. Teste de precisão (padrão americano) e satisfação ao PEC (padrão brasileiro) sobre o conjunto de dados vetorizados manualmente. 73

4.7. Ajustamento com transformação afim e avaliação da qualidade planimétrica, sobre o conjunto de dados vetorizados manualmente .76

4.8. Eliminação de erros grosseiros, minimização de erros sistemáticos, teste de precisão e satisfação ao PEC sobre o conjunto de dados vetorizados pelo método semi-automático

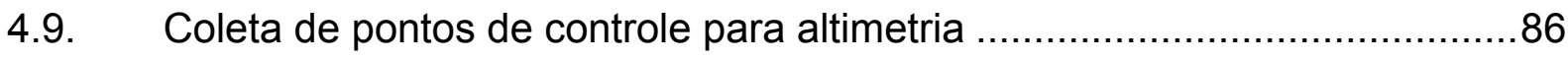

4.10. Detecção e eliminação de erros grosseiros e sistemáticos na altimetria .....89

4.11. Teste de satisfação ao PEC (padrão brasileiro) na altimetria......................92

4.12. Ajustamento com polinômio de $1^{\circ} \mathrm{grau}$ na altimetria.................................93

5. Conclusões e recomendações ……….................................................97 


\section{Introdução}

Conhecer o espaço sempre foi de fundamental importância para o desenvolvimento tecnológico. Dispondo de informações espaciais sobre áreas de interesse é possível realizar bons planejamentos, importantes tanto para a concepção quanto para implantação de projetos de engenharia.

No levantamento de áreas extensas, seja para geração de base cartográfica ou execução de grandes obras, dispõem-se hoje de várias técnicas concorrentes em determinadas aplicações que requerem certa qualidade posicional. Concorrem o levantamento topográfico/geodésico terrestre, o levantamento aerofotogramétrico e a tecnologia de varredura a LASER aerotransportada.

O sistema de varredura a LASER tem-se apresentado bastante competitivo, entre outras aplicações, em mapeamentos que visam à geração de modelos digitais de superfície. Estes modelos contêm, além das informações de elevação do terreno, a representação altimétrica de árvores e construções e são fundamentais para projetos nas áreas de transmissão de energia elétrica, telecomunicações, urbanismo etc.

Na Europa, Canadá e Estados Unidos da América onde grande parte dos estudos sobre esta tecnologia é realizada, há soluções comerciais, entre outras, para:

- Cadastro urbano e atualização de área construída;

- Mapeamento costeiro (até 50m de lâmina d'água);

- Mapeamentos em áreas florestais;

- Mapeamento de lavras a céu aberto;

- Atualização altimétrica de mapeamentos sistemáticos. 
Há cerca de 10 anos, no Brasil, havia certo ceticismo por parte das empresas de aerolevantamento e consumidores de informação georreferenciada Essa resistência, que vem diminuindo, pode ser explicada pelo fato de ser uma tecnologia ainda não popular no Brasil, onde se nota ausência de domínio em operação e processamento de resultados pelos técnicos.

Não dispomos de metodologias definitivas para processamento de dados ou classificação quanto à qualidade cartográfica.

\subsection{Justificativa}

Os produtos de levantamentos de varredura a LASER, atualmente não contam com uma metodologia própria para classificação de qualidade cartográfica. Isso se deve, em grande parte, à dificuldade em detectar e comparar elementos planimétricos presentes nesses produtos com produtos cartográficos de referência.

A área de processamento de nuvens de pontos ainda é muito incipiente. Várias abordagens de detecção de bordas de objetos são baseadas em métodos de processamento de imagem, que impõem interpolação aos dados e efeitos de suavização (aliasing).

\subsection{Objetivos}

Este trabalho tem por objetivos gerais, propor uma metodologia de detecção de bordas de edificações e avaliação da qualidade cartográfica dos produtos gerados pelo sistema de varredura a LASER aerotransportado. 
Como objetivos específicos tem-se:

a) A geração de modelos digitais de terreno e modelos digitais de superfície e seu controle de qualidade posicional, para enquadrá-los em uma das classes previstas na Norma Brasileira, ou seja, determinar a classe segundo o Padrão de Exatidão Cartográfica (PEC);

b) O desenvolvimento de uma metodologia para identificação de edificações e regiões planas, a partir de grades triangulares irregulares, dos modelos digitais de terreno; metodologias que estão associadas à detecção de bordas e fronteiras através de triângulos com declividade superior (ou inferior) a certos limiares definidos pela experiência;

c) O desenvolvimento de ferramentas preliminares de automação para extração de bordas sobre grades triangulares irregulares, para posterior aperfeiçoamento.

\subsection{Organização do trabalho}

O capítulo 2 apresenta uma revisão de bibliografia sobre: componentes do sistema de varredura a LASER aerotransportado, seus princípios de funcionamento, calibração desse sistema, processamento de dados, construção e avaliação de modelos digitais de terreno e detecção de bordas.

O capítulo 3 apresenta a metodologia adotada para extração de edificações e avaliação de qualidade cartográfica de levantamentos a LASER aerotransportado.

O capítulo 4 apresenta e analisa os resultados de um levantamento a LASER sobre o campus da Universidade Federal do Paraná.

O capítulo 5 apresenta conclusões finais e recomendações. 


\section{Revisão Bibliográfica}

\subsection{Componentes e funcionamento do sistema de varredura a LASER aerotransportado}

O sistema de varredura a LASER aerotransportado é um sistema de sensoriamento remoto ativo composto por uma unidade de varredura a LASER (LASER scanner), um receptor GPS e um INS (do inglês, Inertial Navigation System, sistema de navegação inercial), integrados e montados sobre uma plataforma. Este sistema permite a determinação de pontos tridimensionais sobre o terreno (Huising, 1998).

A unidade de varredura LASER usa um feixe ótico de alta potência e bem direcionado, coerente no espaço e no tempo, para medir esta distância. Ela pode ser instalada em diferentes plataformas, tal como aeronaves e serve para medir a distância entre os objetos da superfície e o sensor. A determinação da posição do sensor no momento da medição de cada ponto é possível graças ao uso de um sistema de GPS diferencial (DGPS), encarregado de calcular a posição $(X, Y, Z)$ da aeronave/sensor no espaço. Um segundo sistema de apoio, o sistema de navegação inercial (INS) é encarregado de calcular a inclinação do sensor nessas três direções. A precisão da medição de distância do LASER é cerca de 0,1m, por isso os sistemas de apoio devem ter uma precisão igual ou melhor. Na prática, conta-se com sistemas com precisão melhor que 0,1m e 0,02graus (Wehr; Lohr, 1999).

O conjunto de medições de apoio, os dados do INS e do GPS diferencial são coletados e armazenados simultânea e paralelamente à medição da distância pelo sistema LASER (Huising, 1998). Em etapa posterior, as séries de dados coletados são sincronizadas e a posição exata de cada ponto é calculada. Cada componente do sistema será comentado nos itens a seguir. 


\subsubsection{O GNSS}

Os sistemas de navegação global por satélite (GNSS, do inglês Global Navigation Satellite System) são desenvolvidos para se obter cobertura mundial, sendo operacional 24 horas por dia, proporcionando latitude, longitude, altura e tempo, independente das condições meteorológicas. Por ser citado na maioria dos artigos consultados, ser o mais maduro e o mais utilizado para navegação e vôos georreferenciados, o sistema de posicionamento global (GPS, do inglês Global Position System) será mais bem detalhado e será utilizado, neste trabalho, como equivalente do termo GNSS para simplificação do entendimento.

Os satélites GPS fornecem sinais codificados (códigos C/A, P e efemérides transmitidas) que são processados por receptores, permitindo o cálculo de posições em 3 dimensões e tempo. Os códigos são transportados por duas freqüências portadoras: L1 e L2, de 1575,4 MHz e 1227,60 MHz, respectivamente.

Para calcular as coordenadas da antena do receptor, o sistema GPS utiliza uma solução conhecida como Trilateração Espacial. Os satélites, ao emitirem os códigos $\mathrm{C} / \mathrm{A}$ e $\mathrm{P}$, fornecem os elementos necessários para os receptores calcularem a distância entre satélite e receptor. Esta, muitas vezes chamada de pseudodistância, é uma aproximação da verdadeira distância, pois não foi corrigida dos erros inerentes ao processo: atraso ionosférico, falta de sincronismo dos relógios do receptor e do satélite, ruídos e outros. (Pessoa, 1998)

Como a precisão obtida a partir das pseudo-distâncias, não é suficiente para várias aplicações, é utilizada a fase da onda portadora transmitida pelo satélite. A fase da portadora é igual à diferença entre a fase do sinal do satélite recebido pelo receptor e a fase do sinal gerado no receptor. Os receptores medem a parte fracionária da portadora e, mediante a resolução de equações, efetuam o cálculo do número inteiro de ciclos (comprimentos de onda) contidos entre a antena do satélite e a antena do receptor. A esse número de ciclos, inicialmente desconhecido, dá-se o nome de ambigüidade inteira $(\mathrm{N})$. A resolução de $\mathrm{N}$ fornece a solução de posicionamento. 


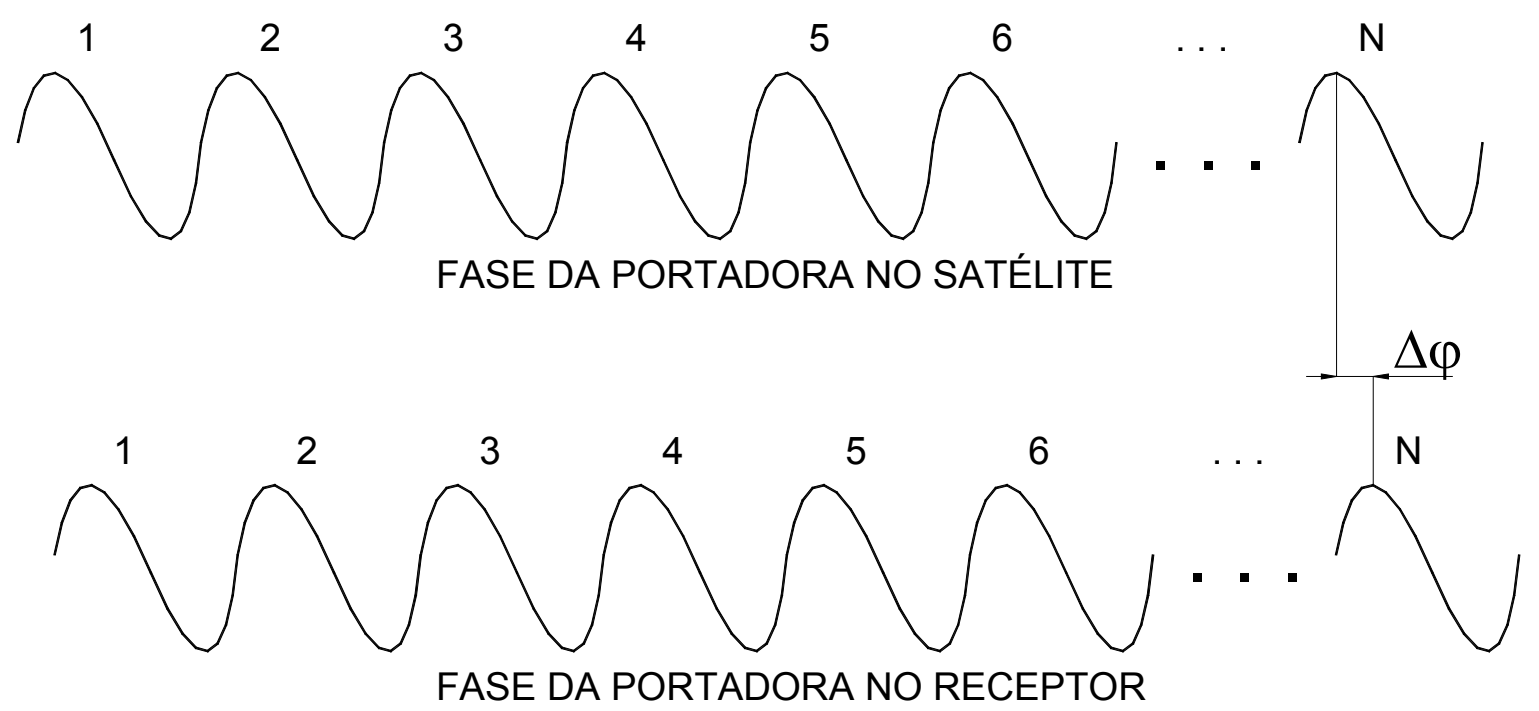

Figura 2.1 - Diferenças de fase e número de ciclos.

As principais fontes e efeitos de erros ao qual o GPS está sujeito são apresentados na tabela 2.1. Assunto bastante tratado na literatura; para maiores informações podem ser consultadas as referências (Mônico, 2008) e (Pessoa, 1998).

Tabela 2.1 - Fontes de erros do GPS

\begin{tabular}{|c|c|}
\hline Fontes & Efeitos \\
\hline Satélite & Erro do relógio \\
& Erro da órbita \\
\hline Propagação do sinal & Refração troposférica \\
& Refração ionosférica \\
& Perda de ciclos \\
& Multicaminhamento \\
\hline Receptor & Erro do relógio \\
& Variação do centro de fase da antena \\
\hline Estação & Erros nas coordenadas \\
& Multicaminhamento \\
\hline
\end{tabular}

A determinação de coordenadas por métodos absolutos não garante a acurácia necessária para o sistema de varredura a LASER. Mesmo utilizando técnicas de posicionamento relativo, os resultados obtidos através do processamento somente pelo código não atingem precisão compatível com a medição de distância da varredura a LASER. A técnica de posicionamento relativo, utilizando a fase da onda portadora para a determinação da diferença de posicionamento entre as estações, é a metodologia mais indicada para a determinação do sensor/aeronave no sistema de varredura a LASER. Com essa metodologia, muitos dos erros sistemáticos são removidos na diferença das 
observáveis. Os erros na posição relativa são inferiores ao centímetro até distâncias de poucas dezenas de quilômetros.

Essa técnica utiliza um equipamento estacionado (base) sobre um ponto com coordenadas conhecidas e outro no ponto em que se deseja obter coordenadas (móvel). É a técnica mais precisa proporcionada pelo GPS, podendo-se obter precisões centimétricas ou melhores e por isso de maior aplicação em projetos de alta precisão. A precisão alcançada é compatível com o levantamento a LASER e para sua aplicação são utilizadas uma ou várias bases, ao longo da região a ser mapeada.

\subsection{2. $\quad O$ INS}

Os receptores GPS podem ser definidos como sensores de posição e velocidade discretos no tempo. Porém, tal sistema não é muito sensível à atitude da aeronave, sendo necessária a instalação de arranjos de receptores e antenas. Mais comumente, utilizam-se sistemas complementares, dentre os quais se destacam os sensores inerciais.

Um conjunto de sensores inerciais, montados sobre uma plataforma, com intuito de modelar e predizer a posição e a velocidade de um movimento é chamado de sistema de navegação inercial ou INS (do inglês, Inertial Navigation System). Sensores de atitude, utilizados em voos georreferenciados, são chamados de unidades inerciais de movimento ou IMU (do inglês, Inertial Motion Unit). Por coerência a bibliografia consultada, será utilizado o termo INS, mesmo quando este não for usado somente para predição da posição. 
O INS conta com giroscópios para detectar e medir todas as variações angulares experimentadas pelo sistema em relação a um sistema de coordenadas de referência inercial e acelerômetros para detectar e medir todas as acelerações específicas, incluindo a gravidade. Atualmente, os sensores inerciais (giroscópios e acelerômetros) convencionais vem sendo substituídos por sistemas microeletromecânicos (MEMs), que apresentam menor tamanho, peso, consumo de energia e custo (Lima, 2005). No entanto, tais sensores não atingem níveis de precisão dos sensores convencionais não sendo indicados para levantamentos de alta precisão ou navegação de alta dinâmica.

Conhecendo a variação angular o INS calcula a inclinação da aeronave com relação à referência geográfica sob forma de atitude. Conhecendo a aceleração na direção de cada eixo o INS calcula a posição sob a forma de variação de latitude, longitude e altitude. Esta característica permite ao INS determinar complementar as informações de posição do GPS. A integração de dados do GPS e do INS garante uma predição contínua da posição da aeronave. Esta integração é realizada com técnicas de processamento de sinais, como o filtro de Kalman. Para maiores detalhes consultar Kaplan (1996).

Para a correta determinação da atitude, o INS deve considerar a atração gravitacional, a força centrífuga e a força de Coriolis na direção do movimento. Deve-se, também, subtrair o efeito da velocidade de rotação da Terra ( $15^{\circ}$ por hora) das variações angulares aparentes.

A tabela 2.2 apresenta as principais fontes de erros dessa tecnologia. Muitos dos erros do INS podem ser atribuídos aos sensores inerciais (erros instrumentais/sistemáticos). São erros residuais exibidos pelos giroscópios e acelerômetros, mesmo após calibração. 
Tabela 2.2 - Principais fontes de erros do INS. Fonte: Kaplan (1996)

\begin{tabular}{|c|c|c|}
\hline Tipo/Fonte & Descrição & Magnitude Típica \\
\hline Erros de alinhamento & Erros em $\omega, \varphi$ e $\mathrm{K}$ & Não disponível \\
\hline Viés do acelerômetro & $\begin{array}{l}\text { Um valor constante adicionado à leitura de } \\
\text { aceleração e que varia a cada vez que o } \\
\text { acelerômetro é acionado. }\end{array}$ & $50-100 \mu \mathrm{gal}$ \\
\hline $\begin{array}{l}\text { Erro de fator de escala do } \\
\text { acelerômetro }\end{array}$ & $\begin{array}{l}\text { Resulta em um erro de aceleração } \\
\text { proporcional a aceleração sentida. }\end{array}$ & 75-200 ppm \\
\hline $\begin{array}{l}\text { Não-Ortogonalidade do } \\
\text { acelerômetro e do giroscópio }\end{array}$ & $\begin{array}{l}\text { Desalinhamento e incertezas nos eixos do } \\
\text { sistema de coordenadas da plataforma }\end{array}$ & $5 "-25 "$ \\
\hline $\begin{array}{c}\text { Viés do giroscópio e deriva em } \\
\text { função de mudança de } \\
\text { temperatura }\end{array}$ & $\begin{array}{l}\text { Valor constante somado à leitura da } \\
\text { variação angular, que aumenta com o } \\
\text { tempo. }\end{array}$ & $0,002-0,01 \% / h$ \\
\hline $\begin{array}{l}\text { Erro de fator de escala do } \\
\text { giroscópio por mudança de } \\
\text { temperatura }\end{array}$ & Erro na leitura da variação angular & $<10$ ppm \\
\hline
\end{tabular}

\subsubsection{Dispositivo de medição a LASER}

Segundo Wehr e Lohr (1999), os sistemas de varredura a LASER levam vantagem em medições de distância, quando comparados com radares de microondas, pois podem emitir pulsos de alta energia em curtos intervalos de tempo. O curto comprimento de onda do LASER pode ser altamente colimado através de pequenas aberturas. Assim que geradores de LASER de alta freqüência de repetição de pulso chegaram ao mercado, os sistemas de varredura começaram a ser desenvolvidos.

Segundo Wehr e Lohr (1999), esses sistemas foram conhecidos como LASER radar e as abreviaturas comumente usadas são: LADAR (LASER Detection And Ranging) e LIDAR (Llght Detection And Ranging). No Brasil, a maioria dos autores utiliza o termo LIDAR. Porém, todos os sistemas comerciais utilizam luz LASER em sistemas de varredura. 
A abreviatura LASER corresponde a Light Amplification by Stimuled Emission of Radiation (amplificação de luz por emissão de radiação estimulada). Usando esse processo pode-se gerar um feixe de luz poderoso, altamente direcionado e coerente no espaço e no tempo. LASERs são, normalmente, gerados por diodos de semicondutores. Há tipos de LASER que utilizam fontes de luz como lâmpadas de xenônio ou vapor de metal, para estimular o LASER principal. Comercialmente, os LASER mais usados são os de estado sólido, dentre os quais se destacam o Nd:YAG ou Neodímio sobre granada Ítrio-Alumínio (Wehr; Lohr, 1999).

Nas medições de distância com o LASER dois princípios são aplicados: a medição por pulso (diferença de tempo) e a medição por diferença de fase entre o sinal emitido e o sinal recebido após a interação com o alvo. O método de diferença de fase é aplicado com LASERs que emitem luz continuamente. Esses LASERs são chamados de CW (Continuous Wave) LASERs. Segundo Wehr e Lohr (1999), teoricamente a acurácia da medição de distância de um sistema LASER a pulso é 85 vezes superior a do sistema CW-LASER, porém necessita de uma potência 2.000 vezes maior. Porém, como a duração dos pulsos é curta e as freqüências de repetição são altas, a potência média do LASER a pulso se aproxima da ordem de grandeza da potência média do CW-LASER.

A tecnologia para geração de LASERs, tipos de LASER utilizados comercialmente e o princípio de funcionamento de medidores a LASER são detalhadamente explorados por Gonçales (2006).

A forma mais direta de medição da distância (L) é determinar o tempo de percurso do pulso luminoso, medindo o intervalo de tempo $\left(t_{L}\right)$ entre a emissão e recepção do pulso, como mostrado na figura 2.2 e nas equações 2.1 e 2.2. 


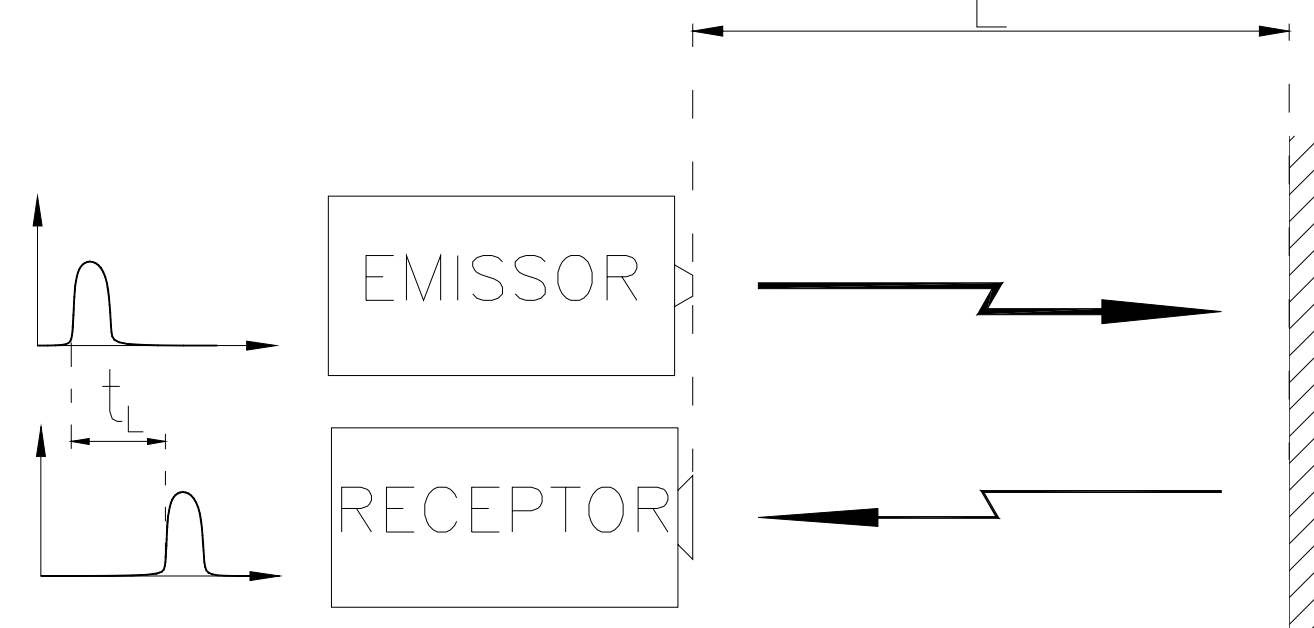

Figura 2.2 - Esquema de funcionamento do medidor de distância a pulso. (Adaptado de Wehr e Lohr, 1999)

O tempo de percurso ( $\left.\mathrm{t}_{\mathrm{L}}\right)$ é dado pela equação:

$$
t_{L}=2 \cdot \frac{L}{c}
$$

Onde $L$ é a distância entre o equipamento e o alvo e c é a velocidade da luz. Dessa equação, tem-se que a resolução da distância é proporcional à resolução da medição de tempo e pode ser definida como:

$$
\Delta L=\frac{1}{2} \cdot c \cdot \Delta t_{L}
$$

No LASER a pulso, a distância máxima ou alcance é, teoricamente, limitado pelo intervalo máximo de tempo que pode ser medido pelo relógio do LASER. $\mathrm{Na}$ prática, esse intervalo é grande o suficiente para que o alcance seja limitado, apenas, pelas perdas de energia durante a trajetória e pela refletividade do alvo (Baltsavias, 1999). Um melhor desempenho é obtido numa atmosfera fria, com o mínimo de umidade, dióxido de carbono e aerossóis. Com relação à hora do dia, são preferíveis levantamentos noturnos, evitando a radiação difusa do Sol.

Além do alcance, a acurácia $E$ na medição é um parâmetro importante. Segundo Wehr e Lohr,(1999), a acurácia é diretamente proporcional à duração do pulso ( $\delta \mathrm{t})$ e a raiz quadrada da largura de espectro associada a ruídos $(K)$ e inversamente proporcional a potência do sinal recebido $\left(P_{r}\right)$. 
$\mathrm{E} \propto \frac{c}{2} \cdot \delta t \cdot \frac{\sqrt{K}}{P_{r}}$

Eq. 2.3 (Wehr; Lohr, 1999)

Quanto maior a potência do pulso recebido, melhor a acurácia. Quanto menor a duração do pulso, maior a qualidade alcançada. Como não se consegue medir exatamente a duração do pulso, mede-se um componente do pulso, chamado tempo de subida (do inglês rise time) que é a duração da parte do pulso até atingir um limiar de energia (figura 2.3). Esta componente, além da maior facilidade de detecção possui duração da ordem de $10^{-1}$ do ciclo do pulso, aumentando a acurácia nas medições de distância. Na maioria dos sensores do mercado, o tempo de subida opera na faixa de 1 ns de duração.

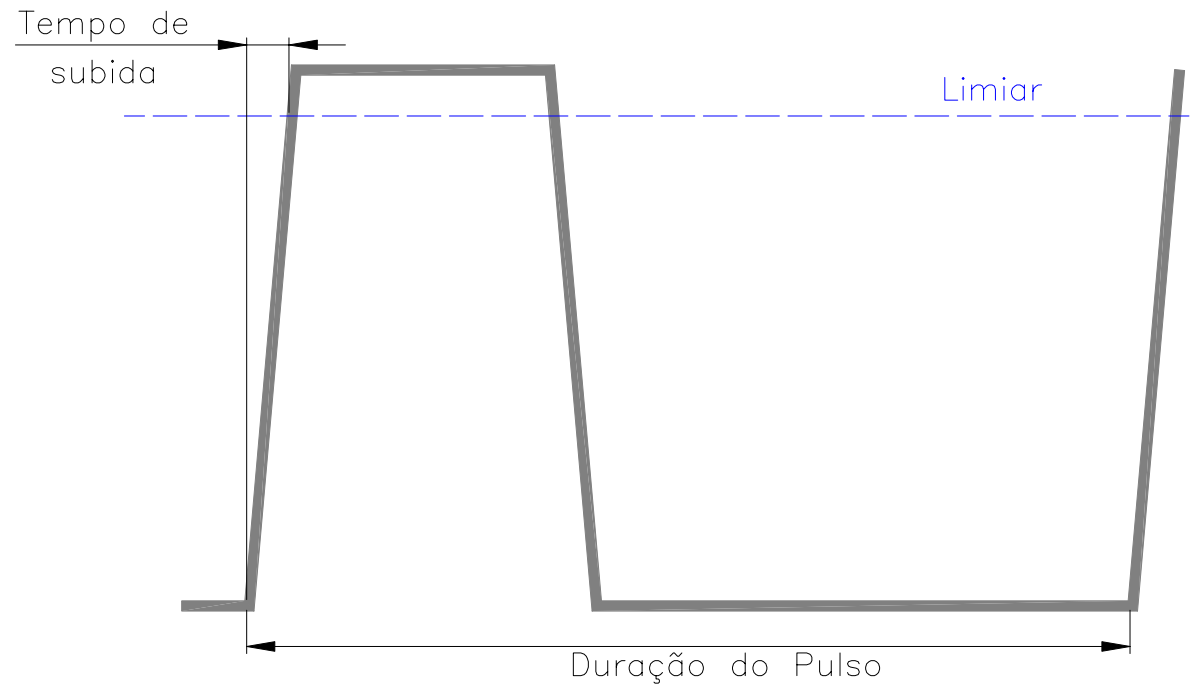

Figura 2.3 - Relação entre o tempo de subida e a duração do pulso.

Segundo Baltsavias (1999), a potência recebida $\left(P_{r}\right)$ é dada pela equação:

$$
P_{r}=\rho \cdot \frac{M^{2} \cdot A_{r}}{\pi \cdot L} \cdot P_{T}
$$

Onde: $\rho$ é a refletividade do alvo, $M$ é a transmissão atmosférica, $A_{r}$ é a área de recepção do sensor, $L$ é a distância entre sensor e alvo e $\mathrm{P}_{\mathrm{T}}$ é a potência emitida. Através dessa equação nota-se que para garantir uma potência recebida satisfatória, em vôos altos, a potência emitida e a área de recepção devem ser aumentadas. Note-se que, na prática, a área de recepção é igual área de abertura/emissão do LASER e que aumentá-la, significa diminuir a divergência do mesmo. 
Como visto na equação 2.4, a refletividade do alvo é de suma importância para a quantidade de potência recebida e, conseqüentemente, para a acurácia da medição. Como não se pode impor valores de refletividade aos objetos, esta deve ser considerada no momento da definição do alcance do LASER.

Os fabricantes de equipamentos devem sempre especificar para qual porcentagem de refletividade e tipo de reflexão (especular, difusa, etc...) o valor de alcance divulgado é válido. Em alguns casos, com $20 \%$ de refletividade dos alvos, alcança-se, apenas, 50\% do alcance nominal do sensor (Wehr; Lohr, 1999). Essa restrição do alcance impõe limites à altura de vôo.

Outros fatores que influenciam na acurácia na medição são os ruídos na aquisição do sinal entre os quais se destacam a radiação difusa, temperatura das superfícies e sensibilidade do detector (Weh; Lohr, 1999).

\subsubsection{Mecanismos de Varredura}

As medições LASER determinam a distância do sensor até a superfície-alvo. Para levantamentos de áreas devem ser feitas sucessivas medições para de que toda faixa de interesse, seja mensurada. O feixe LASER é deslocado, longitudinalmente, pelo movimento da aeronave e, transversalmente, por algum mecanismo de deflexão, realizando assim uma varredura.

O processo de varredura para uma dada seção é representado na figura 2.4. A largura da faixa levantada (LF) é função da altura de vôo (h) e da amplitude do ângulo de varredura $(\theta)$. Para uma dada altura de vôo $(h)$, a projeção do LASER no terreno ou footprints $\left(A_{L}\right)$ depende da divergência do LASER $(\gamma)$ e do ângulo de varredura instantâneo $\left(\theta_{\text {inst }}\right)$.

$$
\begin{aligned}
& L F=2 \cdot h \cdot \tan \left(\frac{\theta}{2}\right) \\
& A_{L}=\frac{h}{\cos ^{2}\left(\theta_{i n s t}\right)} \cdot \gamma
\end{aligned}
$$




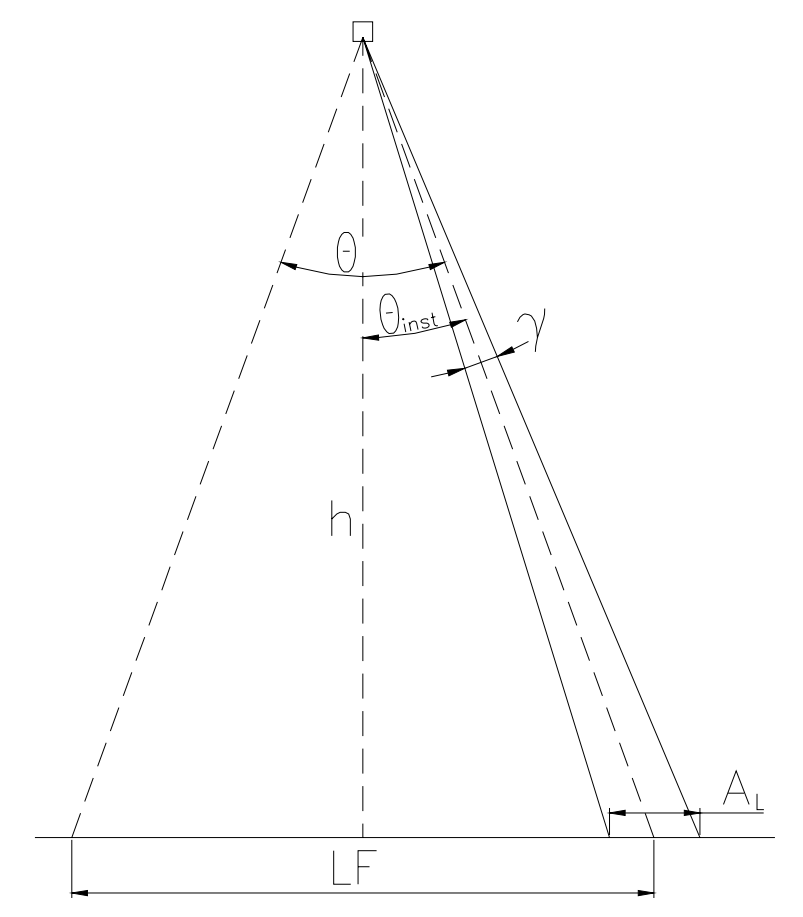

Figura 2.4 - Projeção do LASER e faixa levantada.

Varreduras podem ser unidirecionais ou bidirecionais. Típicos mecanismos de varredura empregados em aerolevantamentos são apresentados na figura 2.5. 0 mecanismo de espelhos oscilantes é um exemplo de mecanismo bidirecional. Este gera um padrão em zig-zag e é utilizado em muitos dos equipamentos do mercado.
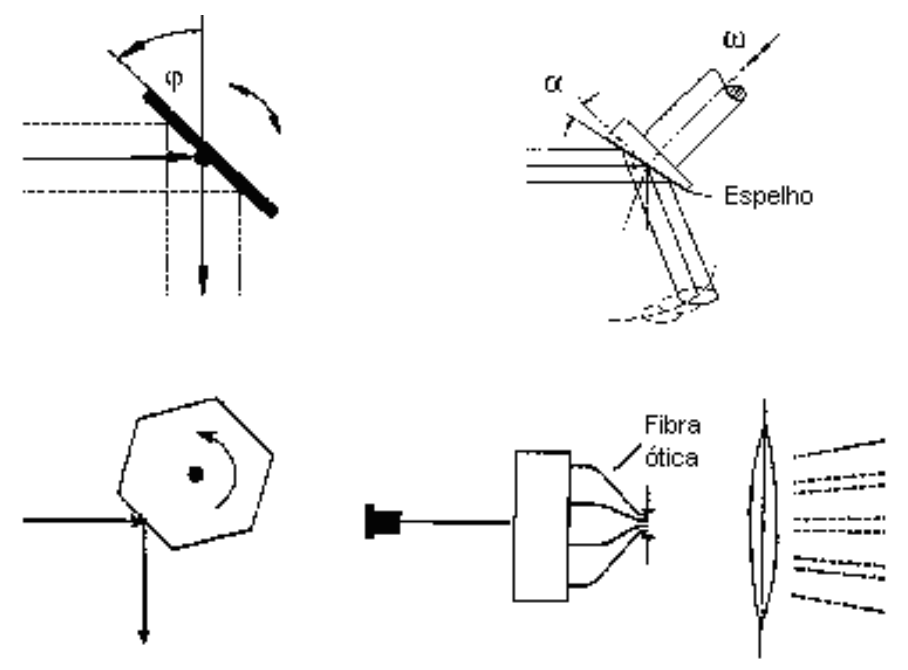

Figura 2.5 - Mecanismos de Varredura. Do canto superior esquerdo em sentido horário: espelho oscilante, Palmer scan, arranjo de fibras óticas e polígono giratório. Fonte: Wehr e Lohr, 1999

Polígonos giratórios e espelhos multifacetados são exemplos de mecanismos unidirecionais que produzem linhas paralelas. O Palmer scan, também unidirecional, produz um padrão elíptico e o arranjo de fibras óticas gera linhas 
paralelas. Alguns padrões de levantamento são apresentados na figura 2.6. 0 padrão depende além do tipo de mecanismo, da direção e velocidade de vôo e da topografia do terreno (Wehr; Lohr, 1999).
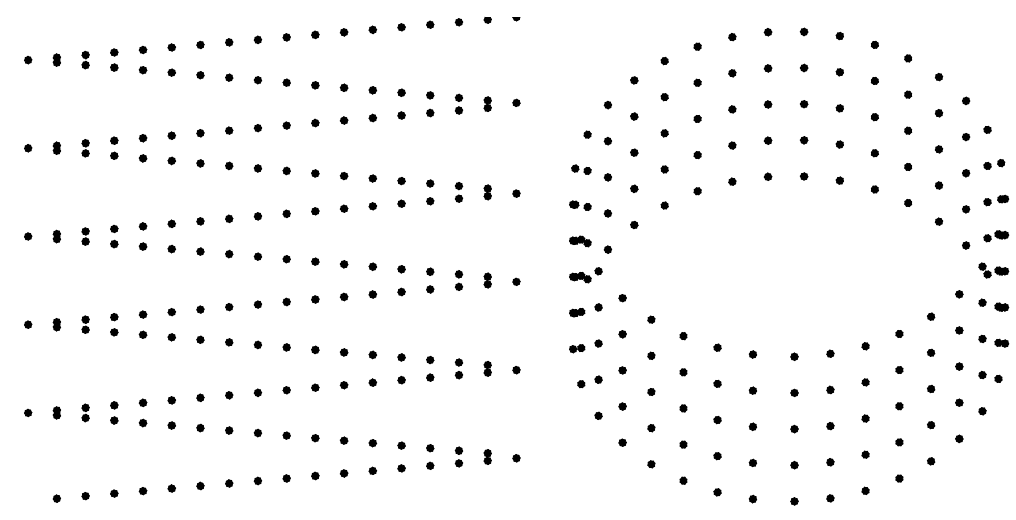

Figura 2.6 - Padrões de Varredura. Da esquerda para direita: espelho oscilante, Palmer Scan e polígono giratório.

O padrão de varredura é importante para o conhecimento da densidade de pontos do levantamento. A densidade de pontos depende da altura de vôo, do tipo de mecanismo de varredura utilizado e da velocidade do avião. Para o mecanismo de varredura de espelho oscilante, o espaçamento transversal ( $d x)$ é dado por: $d x=\frac{h}{\cos ^{2}\left(\theta_{\text {inst }}\right)} \cdot \frac{v_{\text {ang }}}{f}$

Eq. 2.7 (Wehr; Lohr, 1999)

Onde $v_{\text {ang }}$ é a velocidade angular de varredura em rad/s e $f$ é a freqüência de repetição do pulso. Os demais elementos foram definidos nas equações anteriores.

Na direção do vôo, o espaçamento longitudinal (dy) é calculado em função da velocidade da aeronave $(v)$ e do período de varredura de uma linha $\left(T_{v}\right)$, conforme a equação 2.8 :

$d y=v \cdot T_{v}$

Eq. 2.8 (Wehr; Lohr, 1999) 


\subsubsection{Sincronização e determinação dos pontos}

Georreferenciar as medições de distância do sistema de varredura requer uma perfeita sincronização de todos os componentes: o GPS, o INS e o dispositivo de varredura.

As leituras dos sensores são gravadas de forma independente, normalmente, por dois processadores distintos. Isto gera duas contagens de tempo diferentes: o tempo GPS, altamente preciso, ao qual os dados do sistema de posicionamento estão referenciados e o tempo do relógio do computador, onde são descarregados os dados do sistema de varredura (Wehr; Lohr, 1999).

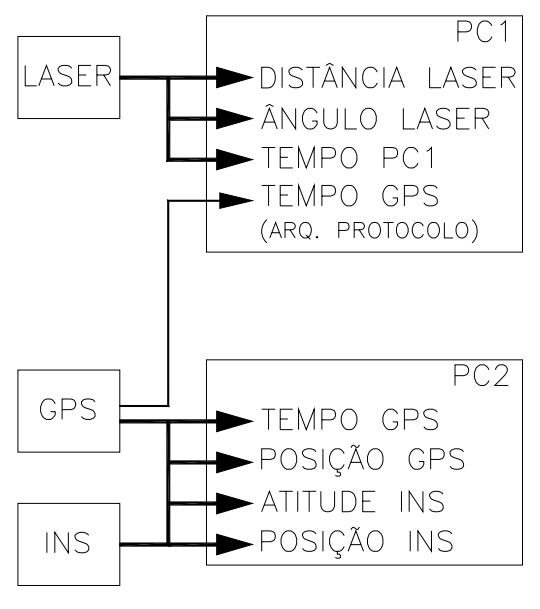

Figura 2.7 - Esquema do registro e sincronização das observações (Adaptado de Wehr e Lohr, 1999).

Em cada medição do sistema de varredura, o tempo do relógio do computador PC1 (figura 2.7) é armazenado na linha correspondente a aquela observação. No mesmo instante, a época GPS é gravada junto com a hora de PC1, num arquivo independente, chamado arquivo de protocolo. Para evitar atrasos na hora de armazenamento das informações de tempo, utilizam-se duas interrupções (IRQ) diferentes. Graças ao arquivo de protocolo, os dados GPS podem ser pósprocessados independentemente e depois sincronizados época a época (Wehr; Lohr, 1999). 
A essa taxa, possíveis erros do relógio do computador PC1, podem ser corrigidos pelo tempo do GPS. A qualidade da sincronização é da ordem de $10 \mathrm{~ns}$ (Wehr; Lohr, 1999).

Após a sincronização, os dados do sistema de varredura ficam relacionados com as respectivas posições do sensor, dadas pelo GPS/INS, e com os respectivos ângulos de atitude, dados pelo INS. Para cada leitura de distância (-d), tem-se um ângulo de varredura $\left(\theta_{\text {inst }}\right)$, uma posição pós-processada do centro ótico do sistema de varredura $\left(X_{0}, Y_{0}, Z_{0}\right)$ e ângulos de atitude instantâneos $(\varphi, \omega, K)$. Outros parâmetros também devem ser considerados como, a posição do centro do sensor $\mathrm{e}$ do centro do INS, com relação ao centro de fase da antena do receptor GPS. Esses parâmetros sistemáticos podem ser determinados durante a calibração. Através desses parâmetros obtêm-se as coordenadas no terreno $\left(X_{T}, Y_{T}, Z_{T}\right)$, conforme a equação 2.9 , expressa em notação matricial simplificada:

$$
\left|\begin{array}{l}
X_{T} \\
Y_{T} \\
Z_{T}
\end{array}\right|=\left|\begin{array}{l}
X_{0} \\
Y_{0} \\
Z_{0}
\end{array}\right|+R_{I N S} \cdot\left(\left(\begin{array}{l}
\delta_{x} \\
\delta_{y} \\
\delta_{z}
\end{array}\right)+R_{m} R_{\alpha} \cdot\left|\begin{array}{c}
0 \\
0 \\
-d
\end{array}\right|\right) \quad \text { Eq.2.9 } \quad \text { (Burman, } 2002 .
$$

Adaptada)

Onde: $\left(X_{0}, Y_{0}, Z_{0}\right)^{\top}$ é a posição do centro de fase da antena GPS, R $R_{\text {INS é a }}$ matriz-rotação da atitude da aeronave (função de $\varphi, \omega$ e $k$ ), $\left(\delta_{X}, \delta_{Y}, \delta_{Z}\right)^{\top}$ é a excentricidade entre o centro de fase da antena GPS e o sensor LASER, $R_{M}$ é a rotação de montagem entre o INS e o sensor LASER, $R_{\alpha}$ é o ângulo de varredura do espelho do mecanismo de varredura (função de $\theta_{\text {inst }}$ ) e d é a distância entre o sensor e o alvo. 


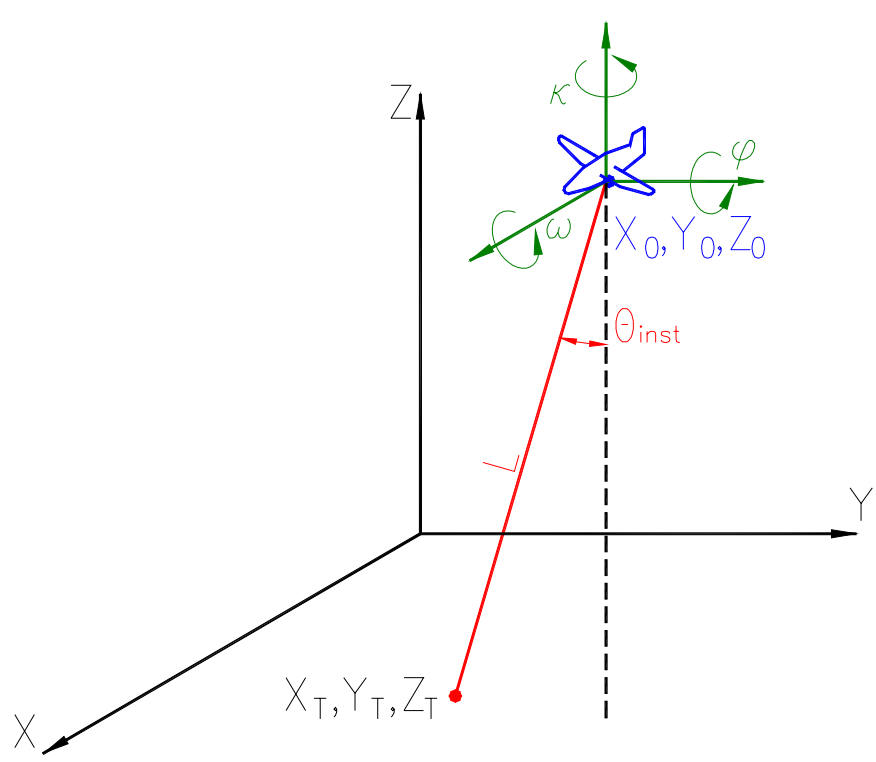

Figura 2.8 - Sistema de coordenadas do sistema de varredura.

A acurácia das coordenadas tridimensionais depende de vários fatores. Os principais são a acurácia na medição da distância, no posicionamento e na orientação. Erros de registro de tempo e sincronização, também afetarão o resultado (Baltsavias, 1999).

Como o resultado das determinações é usualmente expresso no sistema WGS-84, a transformação para o sistema de coordenadas desejado, incluindo a correção das ondulações geoidais, degrada um pouco mais a acurácia. Por exemplo, transformações de coordenadas obtidas por GPS, no Referencial WGS-84 para o Referencial topocêntrico SAD-69, pode acarretar deslocamentos, que são causados principalmente pela incerteza associada aos parâmetros de translação entre os sistemas. $\mathrm{O}$ erro relativo, entre os pontos da região levantada, é menor e na prática é desconsiderado.

Alguns sistemas podem medir diferentes ecos do sinal emitido, refletido por diferentes objetos dentro da projeção do feixe no terreno (Centeno, 2000). A maioria dos sensores comerciais pode medir o primeiro e o último eco do pulso (first/last pulse). Isto permite estudar a interação do feixe do LASER com os alvos, pois ao incidir na superfície da Terra, ele não atinge um único objeto e pode ser refletido por diferentes pontos localizados a diferentes distâncias do sensor. $O$ ponto mais próximo retorna mais rapidamente. Já o ponto mais distante origina o último eco. 
Também existe a possibilidade de registrar a intensidade do sinal de retorno para derivar informação a respeito da natureza da superfície do objeto de maneira similar ao imageamento por RADAR. Como a maioria dos sensores a LASER utiliza comprimento de onda na faixa do infravermelho próximo, a intensidade do sinal de retorno permite boa interpretação de feições.

\subsection{Processamento dos dados do sistema de varredura a LASER}

O levantamento por sistema de varredura a LASER é um método eficiente para a medição de altimetria do terreno. Porém, o resultado primário (dados brutos) dos levantamentos executados com esse método é uma nuvem de pontos desestruturada e disposta em faixas, com observações indistintas do terreno, de objetos sobre o terreno e ruído. Segundo Huising e Gomes (1998), existem diversos problemas relativos a essa tecnologia, entre eles: dados errôneos, mal filtrados e falta de dados (buracos nos dados ou data gaps). Atualmente, vários esforços estão sendo feitos para tornar o processamento mais eficiente e menos demorado.

$\mathrm{Na}$ construção de modelos digitais de terreno com dados do sistema de varredura a LASER, existem dois erros principais:

a) Os erros sistemáticos no georreferenciamento do sensor, observáveis nas faixas sobrepostas. Esses erros podem ser minimizados através de pontos de amarração e controle, como na Fotogrametria.

b) Os erros referentes à captura de pontos não-pertencentes ao terreno. Nesse caso, uma filtragem é indicada para a seleção de pontos úteis para a geração da superfície.

Sem os devidos cuidados e procedimentos de processamento, os produtos gerados não atingem a qualidade potencial da tecnologia, nem atendem aos requisitos do usuário. 
Os dados do sistema de varredura a LASER possuem, dependendo do planejamento da missão, uma grande densidade de pontos. Tal característica obriga procedimentos adicionais para a geração de MDT a partir desses dados. Muitas vezes, para a armazenagem e processamento de grande volume de dados, é preciso utilizar técnicas de redução de pontos redundantes, como apresentadas em capítulos posteriores.

\subsubsection{Calibração}

Apesar da crescente melhora na acurácia do GPS, do INS e da medição de distância obtida pelo sistema de varredura, ainda ocorrem erros na posição dos pontos. Esses erros são associados à complexidade do sistema e alinhamento entre seus componentes. Para minimizar esses erros é necessário um processo de calibração, que gera parâmetros de correção a serem utilizados na integração dos dados ou no pós-processamento.

Há uma série de erros que podem ser modelados antes, durante ou após a missão. Entre eles têm-se os erros provocados pela refração atmosférica, atrasos na medição do tempo de viagem do pulso, resposta dos alvos e os decorrentes dos mecanismos ópticos e mecânicos do sistema de varredura. A refração é função das condições atmosféricas, do comprimento de onda e do comprimento do percurso do pulso LASER, que por sua vez é função do ângulo de varredura e da altura de vôo. O contador de tempo do medidor de distância é outra fonte potencial de erros. Qualquer atraso gera um erro sistemático que se propaga por todas as distâncias medidas. O sinal recebido, devido à sua baixa potência, pode ser confundido com ruído e filtrado antes de atingir o detector, criando buracos ou falhas (gaps) nos dados. Os erros mecânicos dizem respeito ao registro do ângulo de varredura instantânea de cada medição (Huising; Gomes, 1998), (Wehr; Lohr, 1999), (Morin, 2002).

Todavia, os maiores erros encontrados no sistema de varredura a LASER são incoerências entre os ângulos de atitude informados pelo INS e os realmente 
experimentados pelo sensor. Estes erros podem ser vistos ao se comparar os dados do sistema de varredura a LASER com outras fontes de dados ou mesmo entre faixas sobrepostas. A figura 2.9, apresenta o perfil de uma linha levantado através de faixas distintas. Podem ser observados os deslocamentos na elevação e na posição horizontal existentes entre os dados das duas faixas (Morin, 2002). Essa incoerência pode impossibilitar a obtenção de uma informação acurada. Porém, a partir dela pode-se estabelecer pontos de enlace (tie-points), que junto com pontos de controle coletados em campo, permitem gerar produtos em um sistema de coordenadas homogêneo e coerente com o sistema de coordenadas exterior.

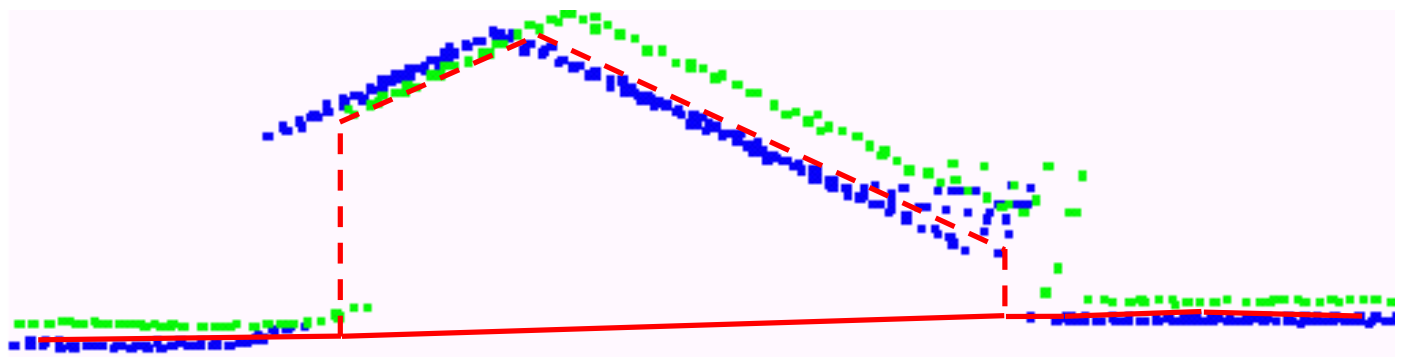

Figura 2.9 - Perfil levantado através de duas faixas distintas (verde e azul) em uma área de sobreposição correspondente a uma edificação (em vermelho, sua posição real). (Morin, 2002)

Para um controle ideal e obtenção de melhores resultados, todos os componentes do sistema deveriam passar por uma calibração antes e depois do levantamento. Isso, porém, é inviável, dado o custo e o tempo necessários e a estabilidade de algumas das fontes de erros (Morin, 2002). Certos procedimentos, contudo, são essenciais à garantia da qualidade do levantamento. Esses procedimentos podem ser divididos em: calibração pré-vôo e calibração pós-vôo.

\subsubsection{Calibração pré-vôo}

Esta calibração inclui certos procedimentos que devem ser executados, com certa freqüência, como a verificação de erros sistemáticos dos medidores de distância e outros que devem ser executados a cada missão, como a inicialização do sistema de navegação. 
Os parâmetros de calibração do medidor de distância a LASER podem ser determinados em terra, através de um processo descrito por Vaughn (1996). Este consiste em manter a plataforma fixa no solo enquanto o LASER é dirigido a um alvo fixo. A distância precisa até o alvo é medida com trena de aço ou distanciômetro independente. Variando a potência da onda emitida do mínimo detectável (limiar de detecção) até a saturação, pode-se construir uma curva para corrigir a distância aparente de acordo com a potência recebida. As correções podem ser aplicadas durante a aquisição dos dados ou após o vôo, na integração dos dados. Para modelar a deriva do relógio, esse método pode ser executado a partir de várias distâncias. Diferenças entre as várias curvas de correção podem ser associadas aos atrasos do relógio (Morin, 2002).

O equipamento de navegação deve ser inicializado para cada missão. Devese ligar o GPS da aeronave próximo à estação de referência, até solucionar a ambigüidade inteira da fase da onda portadora. (Morin, 2002). A reativação do GLONASS proporcionou aos vôos georreferenciados, maior disponibilidade de satélites e melhor distribuição da constelação. A maioria dos sistemas do mercado opera com satélites das duas constelações: GPS e GLONASS. O início de operação do sistema Galileo (GNSS desenvolvido pela União Européia) e do Compass (GNSS desenvolvido pela China) aumentará a disponibilidade de sinal e redundância de observações, com conseqüente melhora na exatidão na navegação e posicionamento.

Durante o vôo, deve se evitar a perda do sinal, que acarreta a perda da resolução da ambigüidade inteira. Para tal, devem-se evitar vôos de alta dinâmica. Isso inclui reduzir variações angulares bruscas da aeronave (maiores que $10^{\circ}$ ), altas velocidades e vôos em regiões de turbulência (Morin, 2002).

Na prática, é comum um vôo inteiro sem perda de resolução da ambigüidade (Morin,2002). Se uma perda de sinal (loss of lock) ocorrer durante a missão, a aquisição de dados deve ser interrompida até que se consiga restabelecer a ambigüidade em vôo através do método OTF (on-the-fly). A utilização de dados do INS pode ajudar no restabelecimento do valor da ambigüidade. Durante a perda de sinal, a posição é determinada pelo INS, utilizando a última posição confiável do GPS e as leituras de aceleração e variação angular nos três eixos. 
O INS precisa ser inicializado a cada missão, para que possa detectar e estabelecer a orientação e o nível (altitude) locais. Isso é atingido, com a aeronave em repouso, permitindo que os giroscópios orientem a plataforma. Em áreas de grande variação da ondulação geoidal, o INS pode ser afetado pelo desvio da vertical, gerando um erro sistemático propagado para toda a navegação. Variações de ondulação geoidal maiores que $5 \mathrm{~cm} / \mathrm{km}$, podem introduzir erros superiores a um segundo na determinação de atitude. Para compensar, correções do desvio da vertical podem ser introduzidas durante a integração dos dados ou no pósprocessamento (Morin, 2002).

As diferenças entre o centro ótico do sistema de varredura, o INS e o centro de fase da antena GPS, devem ser medidos com trena de aço ou distanciômetro. Todo o erro resultante dessas diferenças é propagado para as coordenadas do alvo. Recomenda-se, assim, uma precisão de 1 a $3 \mathrm{~cm}$ nessas medições, para minimizar seus efeitos na solução. Os desalinhamentos ou diferenças angulares entre os sistemas componentes (INS e sistema de varredura) são um desafio e não é possível uma solução pré-vôo (Morin, 2002).

\subsubsection{Calibração pós-vôo}

Esta etapa da calibração visa, principalmente, a minimização do desalinhamento entre os eixos do INS, definidos pelos três giroscópios, e os eixos do sistema de varredura, definidos pela origem e orientação do medidor LASER (Morin, 2002). Isto significa que se devem corrigir os ângulos de atitude informados pelo INS com a atitude real do sistema de varredura. Este é um dos principais erros sistemáticos e não pode ser medido diretamente. Apesar desses parâmetros serem fundamentais para a obtenção de bons resultados, ainda não existe uma metodologia padrão para essa calibração.

Um método bastante comum de calibração é o ajustamento manual. Este método consiste em sobrevoar uma série de pontos de controle ou uma superfície conhecida. São levantados perfis e comparados com os dados de controle. Os 
efeitos dos desalinhamentos são facilmente identificáveis, como mostra a figura 2.10. Os deslocamentos entre o perfil de controle (linha vermelha) e o perfil levantado a partir dos dados sistema de varredura a LASER (linha azul), podem ser quantificados e aplicados como correções. Essas correções são aplicadas manualmente e os dados são reprocessados. Normalmente, correções nos ângulos de atitude $\omega$ e $\varphi$ são determinadas comparando perfis levantados sobre áreas planas (Figura 2.11). Os parâmetros são modificados até que todas as áreas de sobreposição coincidam.

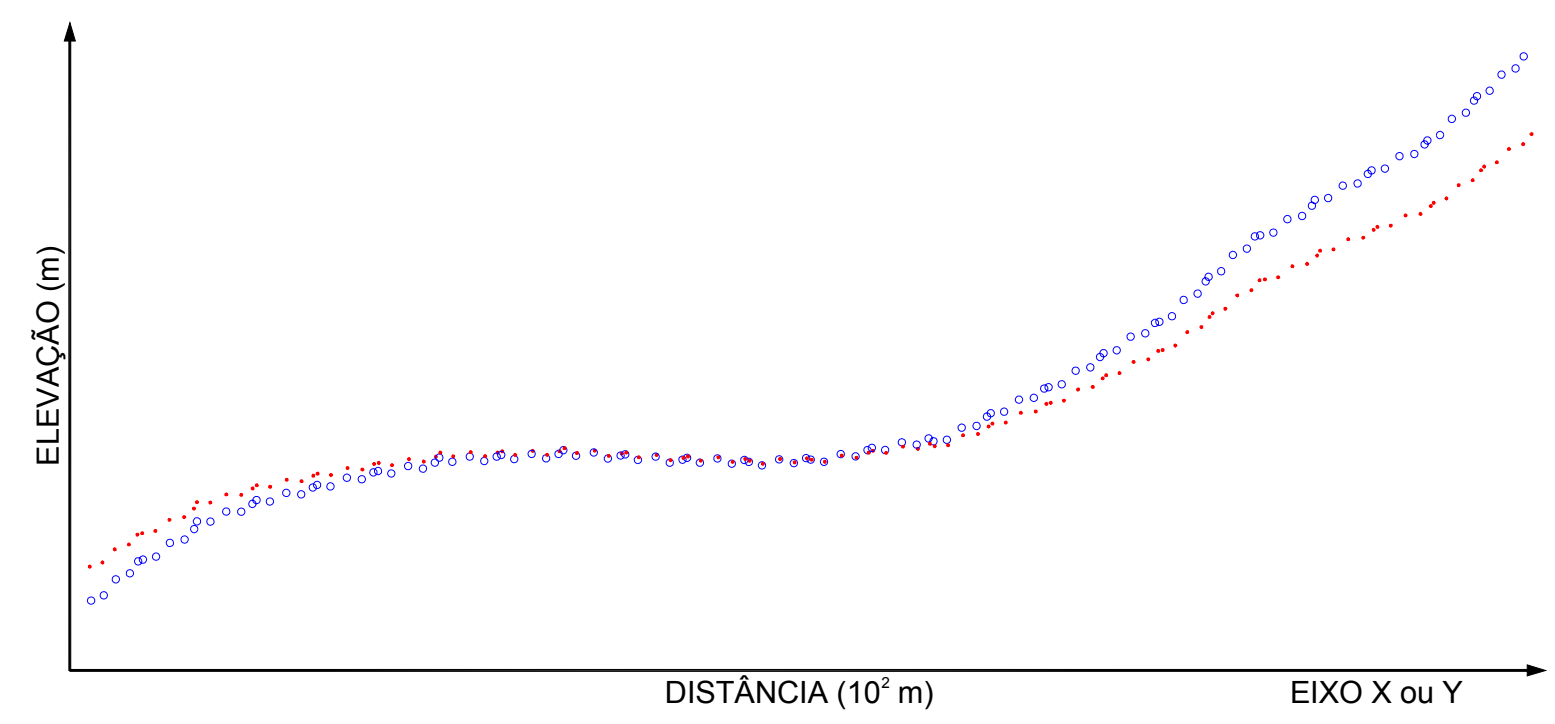

Figura 2.10 - Efeitos dos desalinhamentos em $\omega$ e $\varphi$

A correção em $\mathrm{k}$ pode ser determinada examinando regiões com variação abrupta de elevação como edifícios ou pontes. Isso se torna mais acentuado se um edifício for capturado por duas faixas adjacentes, ou seja, em uma aparece na posição extrema da direita e na outra na posição extrema da esquerda. Erros em $\kappa$ induzem a uma distorção na posição do edifício (Figura 2.11). Modificando este parâmetro, a distorção muda até que os cantos do edifício coincidam. 
Figura 2.11 - llustração do efeito do desalinhamento em K

Segundo Morin (2002), o ajustamento manual requer várias iterações e tempo considerável. Os resultados finais não produzem nenhuma informação estatística sobre a solução. Além disso, como a calibração é feita observando pequenos trechos dos dados, a solução pode ser influenciada por erros ou variações locais, que podem ser insatisfatórios para o conjunto inteiro dos dados.

Para tentar dinamizar o processo e diminuir a tendenciosidade da operação manual, vários autores desenvolveram técnicas de ajustamento automáticas. A seguir, serão apresentadas, resumidamente, algumas dessas técnicas.

Vaughn (1996) propõe sobrevoar uma superfície nivelada ou muito bem conhecida, variando os ângulos $\omega$ e $\varphi$ da plataforma entre $-10^{\circ}$ e $10^{\circ}$. Os parâmetros de calibração podem ser derivados, desenhando os ângulos de $\omega$ e $\varphi$ contra a distância medida (Figura 2.12). Adequando os dados a uma parábola, consegue-se uma curva com um mínimo que se supõe ser a observação a $0^{\circ}$.

A diferença entre o valor onde foi observado o mínimo da parábola e o zero do eixo dos ângulos é o desalinhamento em $\omega$ e $\varphi$. A desvantagem desse método é a impossibilidade de determinação de erros em $\mathrm{k}$. 


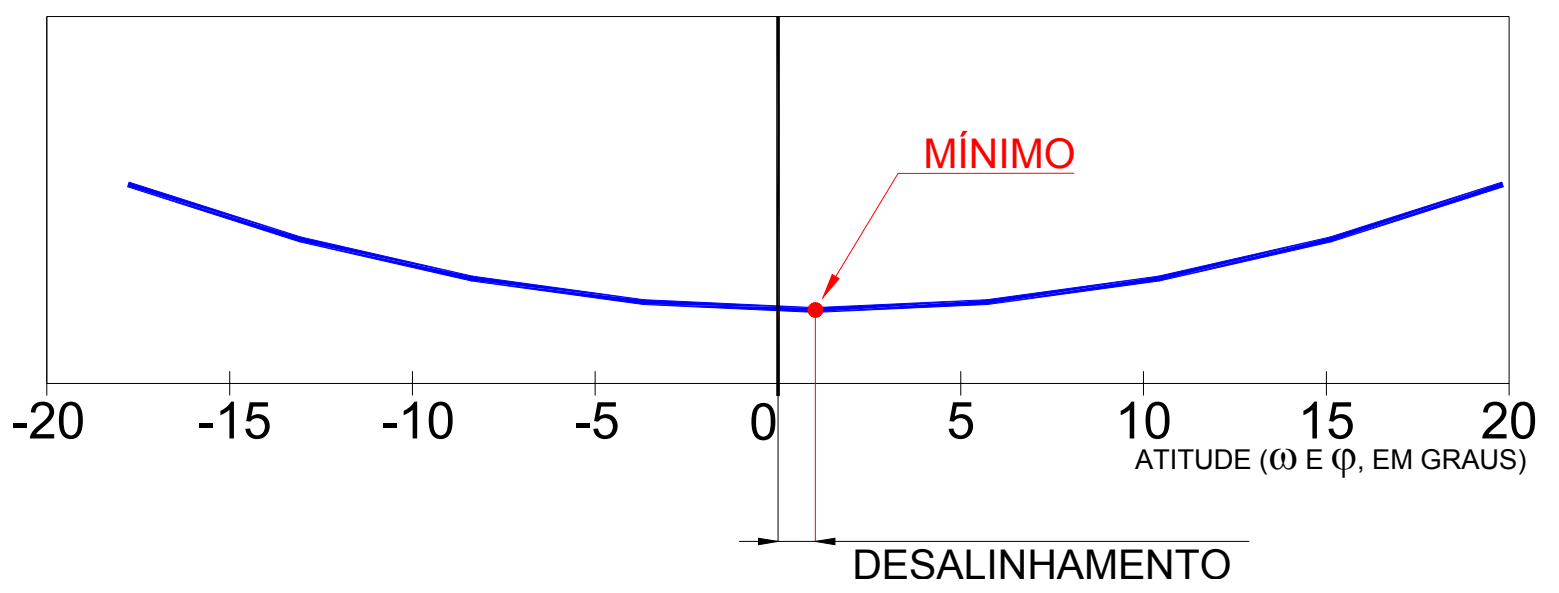

Figura 2.12 - Determinação de desalinhamentos em $\omega$ e $\varphi$

Adaptada de: Vaughn, 1996

Hofton (2000) fez tentativas para estender o método de Vaughn para os três parâmetros, porém a falta de gradientes sobre a superfície nivelada torna difícil a distinção entre erros em $\mathrm{k}$ e outras fontes de erro.

Kilian (1996) propõe a determinação de parâmetros de translação entre pontos correspondentes nas faixas sobrepostas, de modo a minimizar os resíduos em um ajustamento por faixas. Este método prevê a introdução de pontos de controle para garantir a orientação exterior. Primeiramente, pontos de enlace (tie points) e de controle (control points) são determinados (Figura 2.13). Os pontos de enlace são pontos identificáveis, situados na área de sobreposição de duas faixas distintas. Estes são identificados a partir de um algoritmo de correlação de imagens. Pontos de controle horizontal podem ser identificados em cantos de edificações e, em áreas planas como campos de futebol, para o controle da elevação.

A proposta de Killian para determinação de pontos de controle, pode ser adotada também para avaliação de qualidade posicional (como faremos no presente trabalho), comparando esses pontos com algum produto cartográfico de referência. 


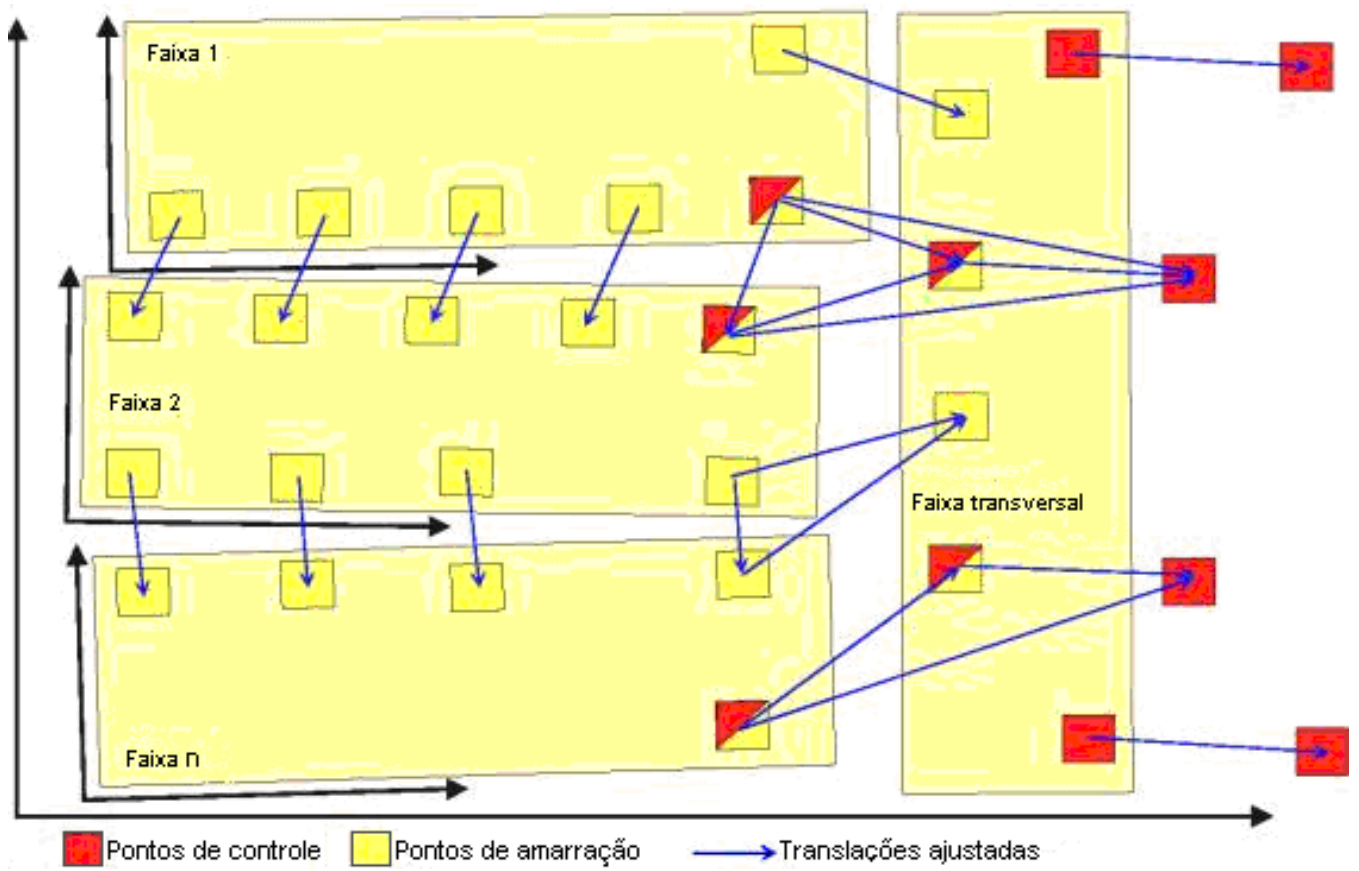

Figura 2.13 - Pontos de amarração e controle para ajustamento por faixas. Adaptado de: Kilian, 1996.

Determinados esses pontos, para cada par de janelas de pontos correspondentes determinam-se três parâmetros de translação ( $d X, d Y, d Z$ ). Este procedimento é feito, primeiramente, aproximando-se o valor das incógnitas. Em seguida são calculadas as translações $d X$ e dY e, a seguir, a translação dZ.

Os pontos de controle são utilizados com injunções no ajustamento. Ao final do processo, obtém-se para cada faixa parâmetros de transformação, garantindo a homogeneidade do bloco e coerência com o sistema exterior de coordenadas (Kilian, 1996).

Há certa dificuldade na definição de pontos de controle. Os dados da varredura a LASER têm natureza descontínua, ou seja, diferente de uma imagem em que cada pixel se conecta a outro. Pontos de controle pequenos e precisos, muitas vezes, não são detectados no levantamento. Mesmo se detectados, a identificação dos mesmos é bastante difícil. Na prática, opta-se por cantos de edificação com topo plano.

Morin (2002) expandiu as equações de observação para incluir o ângulo de varredura e outras fontes de erro, como a refração atmosférica e erros dos mecanismos de varredura e ópticos: 
$\left|\begin{array}{l}X \\ Y \\ Z\end{array}\right|_{T}=\left|\begin{array}{l}X_{0} \\ Y_{0} \\ Z_{0}\end{array}\right|+\left(R_{I N S} \cdot R_{\text {INS }}^{\text {Laser }} \cdot R_{\text {laser }}^{\text {med }}\right) \cdot\left|\begin{array}{l}l_{X} \\ l_{Y} \\ l_{Z}\end{array}\right|_{\text {Laser }}+R_{I N S} \cdot\left|\begin{array}{c}X \\ y \\ Z\end{array}\right| \quad$ Eq. 2.10

Onde: $X_{T}, Y_{T}, Z_{T}$ são as coordenadas no terreno, $X_{0}, Y_{0}, Z_{0}$ são as coordenadas no centro ótico do sistema de varredura, $R_{I N S} e R_{\text {laser }}^{\text {med }}$, são as matrizes de rotação: uma função da atitude da aeronave (lidas pelo INS) e outra função da orientação instantânea do medidor LASER com relação ao corpo do sensor.

A principal diferença com relação à equação original (equação 2.9) é a inclusão de um termo $R_{I N S}^{\text {Laser }}$, que é a matriz de rotação entre a atitude do INS e a realmente experimentada pelo sensor. Este parâmetro é função dos ângulos de varredura instantâneos $\left(\theta_{\text {inst }}\right)$, correções atmosféricas e dos mecanismos de varredura e ópticos. A refração atmosférica é modelada, em função do comprimento de onda, ângulo de varredura e condições atmosféricas. Erros mecânicos e ópticos são a soma de diversos erros relativos ao sensor como erros na leitura de $\theta_{\text {inst. }}$ Estes erros são, normalmente, constantes e característicos do equipamento (Morin, 2002).

Os parâmetros desconhecidos, no caso o desalinhamento e as correções referentes à orientação instantânea do medidor de distância, podem ser determinados com a observação de pontos de controle, em uma solução por mínimos quadrados. É atingida uma solução única para todo o conjunto de dados. Não havendo tendências na aquisição dos pontos de amarração supõe-se que a média das posições pode ser considerada uma boa aproximação da posição verdadeira. A discrepância entre as posições observadas e a média das posições, gera um resíduo que deve ser minimizado em um processo iterativo (Morin, 2002).

O ajustamento por mínimos quadrados com a observação de pontos de controle e amarração permite, além de corrigir os parâmetros de calibração citados, garantir uma maior homogeneidade entre faixas e maior coerência com o referencial local. Processos similares à aerotriangulação vêm se tornando menos usuais com o georeferenciamento direto dos sensores embarcados. É necessário não desprezar metodologias eficientes, com a melhora dos equipamentos de posicionamento e navegação. A integração de posições e atitude mais acuradas e as técnicas de ajustamento por bloco garantem uma qualidade geométrica ainda maior aos produtos a serem gerados. 


\subsubsection{Filtragem de pontos não-pertencentes ao terreno}

Objetos sobre o terreno são problemáticos para geração de um MDT. Os pulsos LASER podem refletir em vários objetos acima do terreno como árvores, edificações, linhas de transmissão etc. Tal informação pode ser utilizada na geração de outros produtos que serão apresentados em seções posteriores. No entanto, na construção dos MDT, estes pontos poluem o conjunto dos dados e devem ser eliminados (Figura 2.14). Para tal, métodos de filtragem devem ser empregados para distinguir pontos válidos de ruído e suprimir estes últimos.
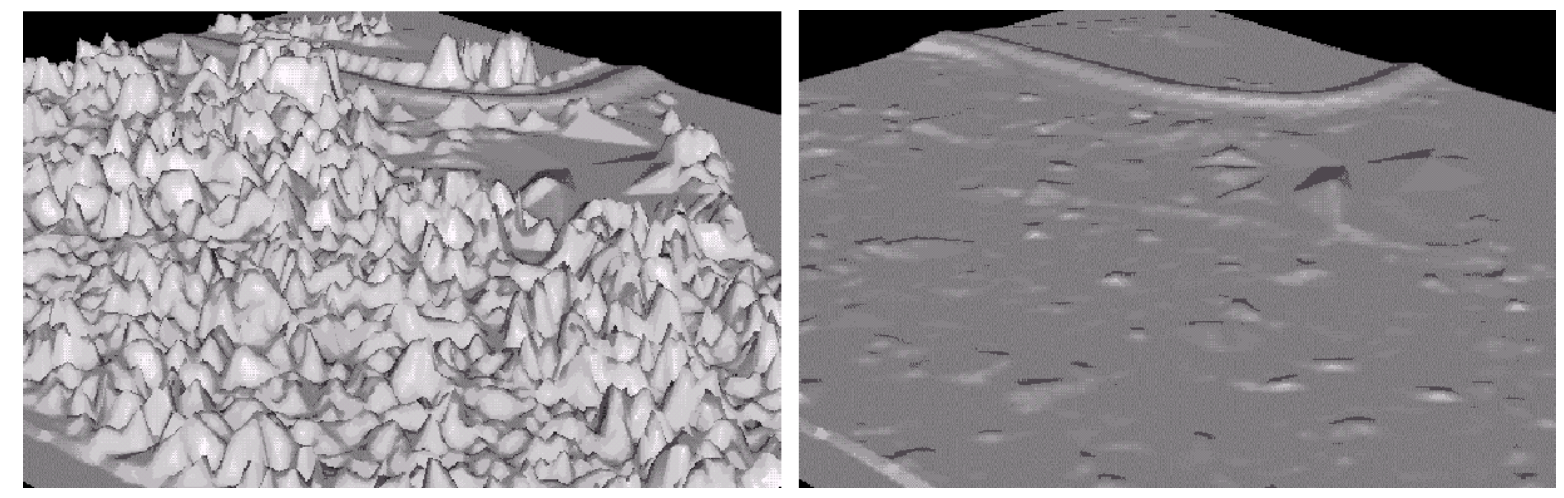

Figura 2.14 - MDT: a) Gerados com dados brutos e b) Após filtragem. Fonte: Vosselman, 2000.

A utilização do último eco do pulso LASER para a determinação da distância entre sensor e alvo, resolve vários problemas com relação à captura de pontos indesejáveis. Vários sensores, atualmente, conseguem gravar separadamente, 0 primeiro, o último e os demais ecos do LASER.

Porém, dependendo da micro-estrutura, cor e textura, um objeto pode ser opaco ao LASER, não produzir retroespalhamento ou gerar vários ecos sem ser transposto. Certas construções, por exemplo, são opacas ao comprimento de onda de operação do LASER (normalmente no infravermelho próximo, 800-1500 nm). Em florestas com diversos níveis de copas, podem-se coletar vários ecos sem que se atinja o terreno (Fig 2.16). Corpos d'água tranqüilos ou superfícies polidas têm reflexão especular e, dependendo do ângulo de incidência, não geram resposta para os sensores, causando buracos nos dados (gaps). Por tais características dos alvos, métodos de filtragem são necessários, para melhorar a modelagem do terreno. 


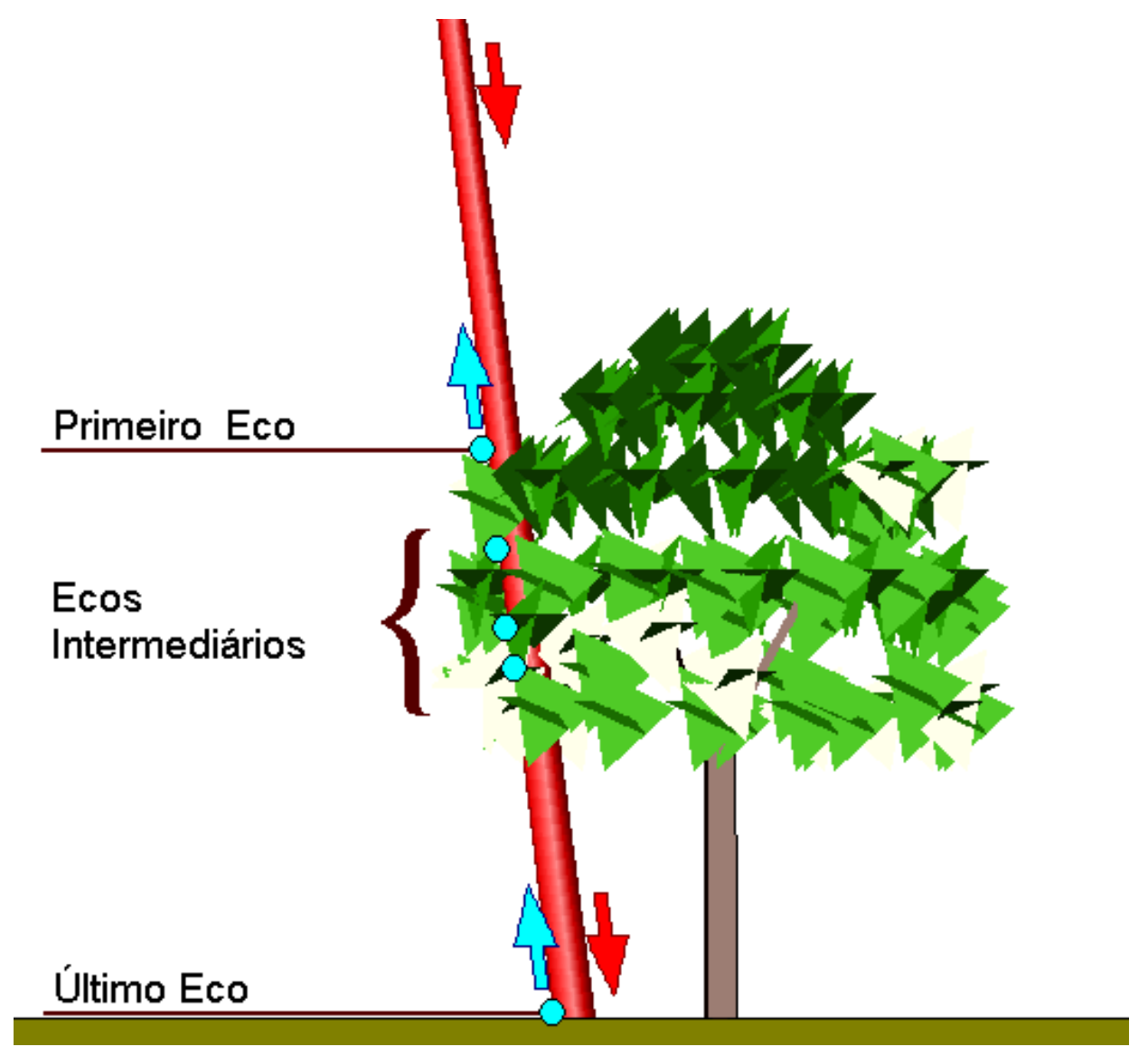

Figura 2.15 - Interação do pulso LASER com a vegetação, gerando múltiplos ecos.

O registro dos diferentes ecos permite penetrar em certos tipos de cobertura, como por exemplo, bosques, onde uma primeira camada de objetos (o topo das árvores) produz um primeiro eco, galhos e folhas produzem ecos intermediários e as ultimas parcelas do feixe são refletidas pelo solo. Esta característica permite a utilização da tecnologia em diversas aplicações com determinação de volumes de florestas ou detecção automática de feições (Morsdorf, 2005). Porém, os alvos não se comportam de maneira uniforme aos pulsos do LASER, fazendo com que a correta extração de modelos de terreno (solo) ou de superfícies careça de uma metodologia única de interpretação ou utilização de filtros.

Não é difícil para um intérprete identificar se um ponto pertence ou não ao terreno. Porém é praticamente impossível editar manualmente o volume de dados gerados por um levantamento do sistema de varredura a LASER. Existem diversos métodos automáticos de filtragem, entre eles: filtros morfológicos, filtros baseados em gradiente e estimadores de superfície. 
Filtros morfológicos começam por dividir a região em pequenas áreas e, através de operadores locais, identificam pontos de terreno. Operadores locais efetuam operações de vizinhança que consideram os valores de pontos próximos a cada área de entrada para determinação do valor de saída (Morin, 2002).

Filtros baseados em gradiente identificam pontos como sendo terreno, se estes respeitarem um gradiente máximo com relação aos vizinhos, numa abordagem ponto a ponto. O conceito de gradiente pode ser utilizado, também, para detecção dos contornos das edificações e outros objetos não pertencentes ao terreno e extração dessas feições (Morin, 2002).

Estimadores de superfícies ajustam um modelo de superfície através de uma solução por mínimos quadrados ponderada pela distância de uma observação em relação a uma superfície aproximada determinada a priori (Morin, 2002).

Segundo Vosselman (2000), uma diferença de altura muito grande entre dois pontos vizinhos e próximos dificilmente representa um declive no terreno. Normalmente, o ponto mais alto não pertence ao terreno. Entre dois pontos com grande diferença de altura, a probabilidade do mais alto não pertencer ao terreno aumenta com a diminuição da distância entre os mesmos. Pode-se definir uma diferença de altura máxima aceitável em função da distância entre dois pontos. Estes podem ser classificados de acordo com a seguinte condição:

Se: $h_{i}-h_{j} \leq \Delta h_{\max }\left(d\left(P_{i}, P_{j}\right)\right)$, o ponto pertence ao terreno.

Onde: $h_{\mathrm{i}}$ é a altitude do ponto analisado, $h_{\mathrm{j}}$ é a altitude do vizinho e $\Delta \mathrm{h}_{\max }$ é a diferença de altura máxima aceitável, função da distância entre os pontos i e j.

De acordo com a definição do filtro, a altura do ponto deve ser comparada com a altura de todos os outros pontos da amostra. Para minimizar o esforço computacional, é utilizada uma heurística para verificação das diferenças de alturas aos vizinhos de uma triangulação, e aos vizinhos dos vizinhos, até uma distância máxima de busca a ser considerada. Esta heurística não satisfaz totalmente a definição do filtro, porém os erros gerados são muito pequenos comparados com a economia de esforço computacional. A função-filtro deve incorporar uma aproximação do gradiente. Pode ser utilizada uma função aproximada de $\Delta \mathrm{h}_{\max }$ a 
partir do conhecimento a priori das características do terreno ou de estatísticas de amostras, como médias e desvios-padrão.

Roggero (2001) propõe um algoritmo que elimina pontos não pertencentes ao terreno, através de um operador local em todos os elementos do conjunto de dados. O objetivo inicial é obter uma aproximação do MDT excluindo pontos fora dos limiares definidos. O algoritmo calcula uma altura mínima do operador local, depois classifica os pontos como sendo terreno se a diferença de altura entre esses pontos e o mínimo forem compatíveis com a declividade local. Este processo é refinado com um critério de regressão local que considera a variância do conjunto local de dados. Posteriormente, o algoritmo usa um limiar de classificação, cujos resultados são armazenados para futuros ajustamentos. Estas etapas são repetidas, porém a partir da segunda iteração os parâmetros (tamanho do operador local, declividade local, coeficiente de propagação da variância e limiar de classificação) são mais restritivos. Após o cálculo da primeira aproximação de um MDT, com base no critério da regressão local, são estabelecidos dois limiares $K_{1}$ e $K_{2}$ para refinar a classificação. Nesse processo os dados brutos são classificados conforme sua diferença de altura em relação ao MDT aproximado.

Elmqvist (2001) utiliza como estimador uma curva de minimização de energia guiada por forças de inércia, que tendem a suavizar a superfície, e forças de atração, que tendem a aproximar a superfície aos dados brutos. Estas forças são aplicadas às observações, para extrair a superfície do terreno em dado sistema de varredura a LASER. No método proposto por esse autor, os dados são reamostrados para uma grade regular ou imagem, onde o valor da célula/pixel é dado pelo menor valor entre os pontos brutos contidos nessa célula/pixel. Células sem dados não são interpoladas, permanecendo sem valor. Processam-se duas superfícies: uma relativa à inércia $\left(E_{\text {int }}\right)$ e outra à atração $\left(E_{\text {pot }}\right)$. Nesta implementação, $E_{\text {int }}$ é uma função da primeira derivada do modelo. Essa função é

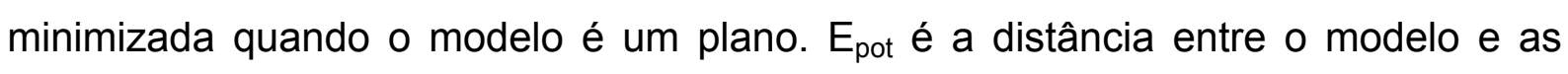
observações. Essa função é minimizada quando o modelo é igual aos dados amostrados. Pontos que estão próximos da aproximação inicial do modelo são incorporados ao mesmo. Pontos que estão distantes, e possivelmente não pertencem ao terreno, não conseguem vencer a inércia imposta por $E_{i n t}$ e não entram no modelo. 
Este método pode gerar resultados diferentes dependendo da aproximação inicial do processo iterativo. É necessário certo conhecimento a priori para encontrar um resultado razoável. Dependendo dos parâmetros utilizados, o método pode ser muito rigoroso, eliminando pontos pertencentes ao terreno.

No algoritmo proposto por Brovelli (2002), os dados do sistema de varredura a LASER são interpolados através de splines bicúbicas, utilizando-se mínimos quadrados. Após a remoção de erros grosseiros, faz-se a detecção de bordas entre as superfícies: terreno e objetos. Isto é possível, analisando variações significativas na altura, em um pequeno deslocamento horizontal. Não se faz a imposição de um limiar para o gradiente, pois isto poderia gerar erros de classificação. Em vez disso, estabelecem-se dois limiares de gradiente: um alto e outro baixo. Um ponto que exceda o limiar alto é uma possível borda. Para pontos entre os dois limiares, é feita uma análise da vizinhança para verificar se há a possibilidade destes serem bordas. Uma vez detectadas as bordas, classificam-se os pontos em seu interior como objetos e eliminam-se os mesmos do conjunto de dados. Este método tende a suavizar certas feições, principalmente, em áreas com falta de dados.

Wack e Wimmer (2002) propõem uma abordagem de filtragem baseada em grade regular. Cada célula desta grade pode conter diversos pontos, porém será representada por um único valor. Este valor é definido em função de informações de gradiente. $\mathrm{O}$ autor sugere um processo iterativo. No primeiro passo, gera-se uma grade com resolução de $9 \times 9 \mathrm{~m}$. Esta grade utiliza como valor da célula a menor diferença de altura entre todos os pontos contidos na célula a uma significância de 99\% da amostra. Esta grade serve para o cálculo do gradiente a ser usado em etapas posteriores. No segundo passo, pontos não pertencentes ao terreno devem ser detectados e eliminados. O modelo resultante serve como base para cálculos na geração de uma grade de $3 \times 3 \mathrm{~m}$. Utiliza-se a informação do gradiente determinado anteriormente para realizar a adaptação da menor diferença de altura entre os pontos contidos na célula de $3 \mathrm{~m}$ de resolução, com relação ao centro da mesma. Gera-se novamente o gradiente do modelo resultante, que será utilizado em futuras iterações. O terceiro passo é realizado sobre uma grade de $1 \times 1 \mathrm{~m}$ e assim por diante. O limite do processo é atingido quando a resolução de grade for inferior ao espaçamento entre pontos levantados. A definição da resolução da grade inicial e do 
passo de redução das resoluções é função da densidade de pontos do levantamento.

Sithole (2004) realizou testes com diversos filtros para a detecção e remoção de pontos não pertencentes ao terreno. Através dos resultados, observou que a complexidade do terreno é um fator decisivo no desempenho do mesmo. Nota-se também que filtros que consideram o contexto ou vizinhança dos pontos têm vantagens sobre os que não fazem tais considerações. Os resultados dos estudos apontam para a utilização de informações adicionais no processo de filtragem como a informação de intensidade do pulso (gravada pela maioria dos sensores atuais) ou análise da onda completa do pulso refletido e escolha de parâmetros mais adequados de acordo com o terreno a ser levantado. Deve-se ponderar que certos métodos se adeqüam melhor a determinados terrenos, densidade de pontos e padrão de varredura. Um método baseado em grade regular, por exemplo, não será o mais indicado para o processamento de um conjunto de dados com distribuição muito irregular. Uma total automação ainda está longe de ser alcançada. Porém os métodos descritos acima, podem melhorar a qualidade dos dados e reduzir em muito a edição manual.

\subsection{Modelos digitais de terreno e dados de varreduras a LASER}

O conhecimento do terreno é indispensável para diversas atividades humanas como o projeto e execução de obras de engenharia, planejamento do uso do solo, análises geomorfológicas e geofísicas, entre outras aplicações. Porém, a superfície do terreno, como quase qualquer característica no mundo real, é impossível de se representar matematicamente em todos os seus detalhes. Para Cintra (1985) só é possível realizar uma boa representação se for feita uma criteriosa seleção de dados, cujos valores discretos sejam representativos e, por isso, permitam a representação do terreno com a precisão desejada. 
É possível representar, praticamente qualquer característica do terreno. Felgueiras (2001) define tais modelos com uma representação matemática da distribuição espacial de um fenômeno que ocorre em uma região. Tais fenômenos ou características podem ser: informações meteorológicas, dados geofísicos e geoquímicos, profundidades etc.

No processo de geração de um MDT destacam-se duas etapas: amostragem e modelagem.

\subsubsection{Amostragem e redução de pontos redundantes}

A amostragem compreende a aquisição do conjunto de amostras representativas do fenômeno em estudo (Felgueiras, 2001).

Para Cintra (1985), quanto à posição relativa das amostras pode-se classificar a amostragem em: regular, semi-regular e irregular. A amostragem regular é aquela cuja posição espacial $(x, y)$ das amostras mantém uma regularidade de distribuição nas direções $x$ e y. As amostragens semi-regulares são aquelas que preservam a regularidade de distribuição espacial na direção x ou y mas nunca nas duas ao mesmo tempo. Na amostragem irregular não existe regularidade na distribuição das amostras. Na quase totalidade dos casos as amostras mais representativas de um fenômeno não estão regularmente distribuídas. Para os dados do sistema de varredura a LASER, com mecanismo de varredura de espelhos oscilantes verifica-se que nenhuma destas definições se adequa perfeitamente.

Nos dados gerados por varredura a LASER, muitos dos pontos são redundantes por se encontrarem em regiões de gradiente uniforme (superamostragem). A abundância de pontos requer grande espaço para armazenamento dos dados e exige maior esforço computacional para o seu processamento. Atualmente, a capacidade de armazenamento e poder de processamento dos microcomputadores não são os maiores obstáculos à utilização 
desta fonte de dados. Essa abundância, porém, pode causar erros nos processos automáticos de modelagem de superfícies, exigindo a intervenção do usuário.

Rivas (2002) descreve uma metodologia de redução de pontos através da seleção de pontos segundo certo espaçamento. Primeiro são determinadas as distâncias entre todos os pontos e um ponto de referência. A partir desse ponto define-se um critério de seleção, por exemplo, pontos que estejam dentro de um círculo de determinado raio, função da quantidade de pontos desejada. Esse raio pode ser variável em função do número de pontos que se deseja. A metodologia de Rivas não respeita as feições do terreno e não pode ser aproveitada para a geração de MDT em escalas maiores, como é o caso do presente trabalho.

Kersting (2004) utiliza um processo de simplificação de uma triangulação inicial com todos os pontos, preservando, na medida do possível, feições do terreno, até que se atinja o limite de uma dada precisão com o mínimo de pontos. Primeiramente constrói-se a triangulação de Delaunay para os pontos fornecidos. Esta triangulação é simplificada, iterativamente, reduzindo seus vértices redundantes, como ilustra a figura 2.16.

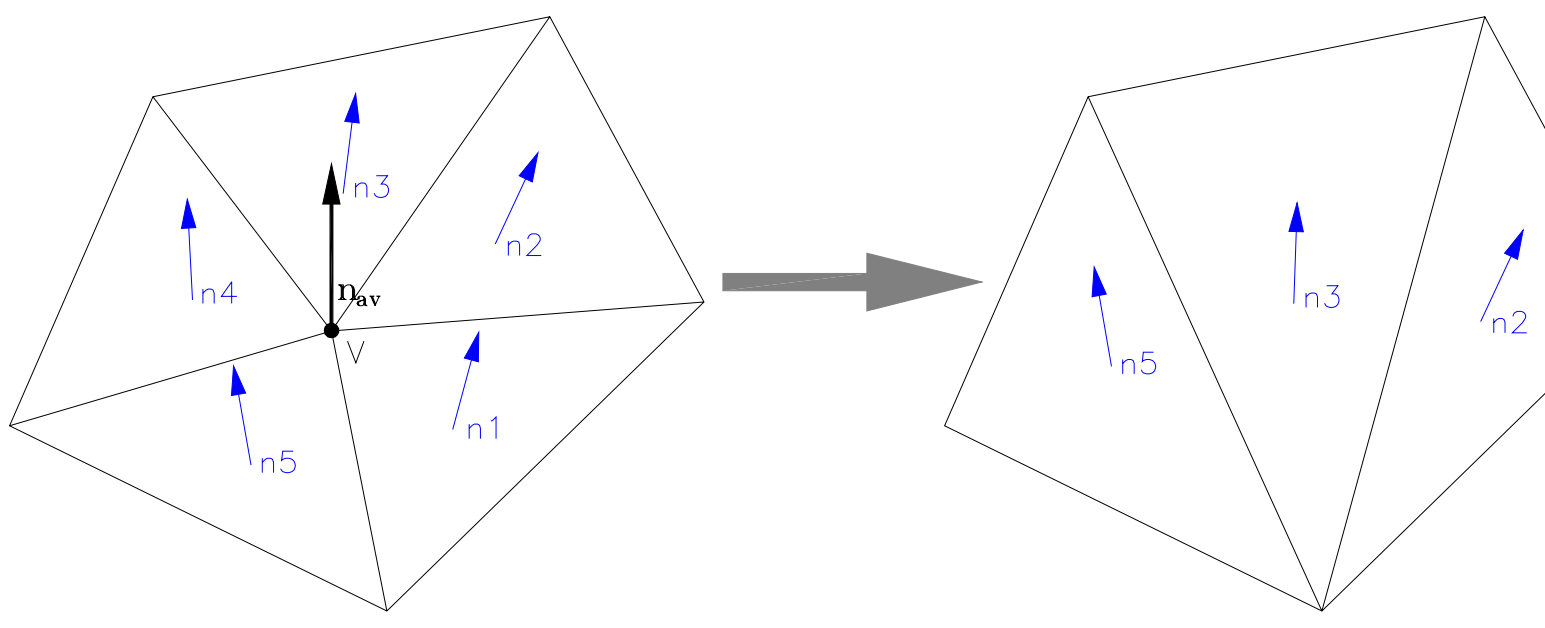

Figura 2.16 - Remoção de um vértice redundante

A cada iteração a relevância do vértice é analisada pela variação local da superfície, dada pelo gradiente dos triângulos adjacentes que possuem esse vértice em comum. Caso a diferença angular entre o gradiente médio $\left(n_{a v}\right)$, calculado pela equação a seguir (Eq. 2.11), e os gradientes dos triângulos $\left(n_{i}\right)$ adjacentes a $V$ seja 
maior que uma tolerância definida a priori $\left(10^{\circ}\right.$, por exemplo), a região é considerada heterogênea e o vértice relevante.

$$
\vec{n}_{a v}=\sum \frac{\vec{n}_{i} \cdot A_{i}}{\sum A_{i}} \text { para } 0 \leq \vec{n}_{i} \leq \pi \quad \text { Eq. } 2.11 \text { (Kersting, 2004) }
$$

Caso contrário o ponto é considerado redundante e eliminado. A metodologia de Kersting mostra-se bastante eficiente na preservação das feições do terreno, dependendo dos limiares utilizados (Kersting, 2004).

\subsubsection{Modelagem de dados}

A modelagem envolve a definição de superfícies que permitam a representação contínua do fenômeno, a partir das amostras discretas no espaço. Os modelos para construção dessas superfícies contínuas podem ser globais ou locais (Cintra, 1985). Modelos globais são representados por uma única função definida utilizando-se todos os elementos do conjunto de amostras. Modelos locais utilizam funções cujos coeficientes são definidos por elementos amostrais escolhidos dentro de uma vizinhança. Este será o tipo de modelo utilizado no presente trabalho. Dentre modelos locais destacam-se: as grades regulares retangulares ou quadradas e a grade triangular irregular, TIN (do inglês triangular irregular network).

As grades regulares são definidas pelo seu espaçamento em $\mathrm{x}$ e $\mathrm{y}$ (resolução espacial) e o método de interpolação a ser utilizado para estimativa dos pontos da grade (nós). Os métodos de interpolação são normalmente aplicados sobre as amostras vizinhas ao nó da grade e utilizam funções como média simples, média ponderada por uma potência da distância, splines ou polinômios.

A grade irregular triangular é um modelo em que os pontos amostrais são conectados por linhas e definem triângulos. Neste modelo, as amostras não precisam ser estimadas por interpolação, sendo fiéis os valores levantados. Os pontos contidos no interior de cada triângulo da grade podem ser interpolados por 
ajuste linear, ou seja, pela equação do plano (Eq. 2.12), de modelagem simples e pequeno esforço computacional para cálculo.

$Z=\frac{a \cdot X+b \cdot Y+d}{c}$

Onde os coeficientes a, b, c e d são ajustados pelo método dos mínimos quadrados.

A grande vantagem da TIN sobre outros tipos de MDT é a preservação dos valores das amostras. Como desvantagem, tem-se a não continuidade da superfície quando se utiliza ajuste linear (equação do plano). Porém, pode-se obter ajuste por polinômios que garantam a continuidade como, por exemplo, um polinomio de quinto grau (Hermite), que mantém a continuidade da segunda derivada. Maiores detalhes sobre ajuste de grades irregulares, consultar Cintra (1985). Em casos em que os pontos amostrais são estrategicamente coletados ou a densidade de pontos é grande, a não continuidade entre triângulos é desprezível.

Pela característica do levantamento realizado pelo sistema de varredura a LASER, devem-se tecer algumas considerações sobre a geração de MDT a partir desses dados. Os dados amostrados geram uma distribuição de pontos pseudoregular e com alta densidade. Estas características elegem a TIN, com ajuste linear, como excelente modelo de interpolação para dados oriundos de sistemas de varredura a LASER.

A questão do referencial altimétrico também deve ser considerada. As elevações obtidas através do levantamento com o sistema de varredura a LASER estão referenciadas ao elipsóide. Para a maioria das aplicações, tem-se interesse em elevações referenciadas ao geóide. Para tal, devem ser utilizados modelos geoidais que garantam uma boa conversão entre referenciais altimétricos. Para muitas aplicações, o modelo MAPGEO2004 (disponível em: http://www.ibge.gov.br/home/geociencias/ geodesia/modelo geoidal.shtm) e de validade nacional), ou EGM96 (disponível em: http://cddis.nasa.gov/926/egm96/) e de validade global), satisfazem as exigências do projeto. O modelo MAPGEO considera observações sobre a rede altimétrica brasileira, sendo mais coerente com o sistema geodésico brasileiro.

Além disso, para uma correta modelagem da elevação é recomendável a inserção de restrições no modelo, sob a forma de linhas de quebra. Tais linhas 
devem corresponder a descontinuidades, isolando vertentes com mudanças bruscas de declividade. Estas linhas podem ser coletadas no campo, o que é mais aconselhável, porém mais oneroso e demorado. Linhas de quebra podem ser extraídas da própria imagem de intensidade dos dados do sistema de varredura a LASER, de câmaras fotográficas embarcadas na aeronave ou da detecção de bordas sobre a própria triangulação (método proposto no presente trabalho). A figura 2.17 mostra um exemplo de como introdução dessas linhas podem melhorar a representação do terreno. Sem estas restrições, podem ser gerados triângulos que desrespeitam a morfologia do terreno, falseando o modelo construído.

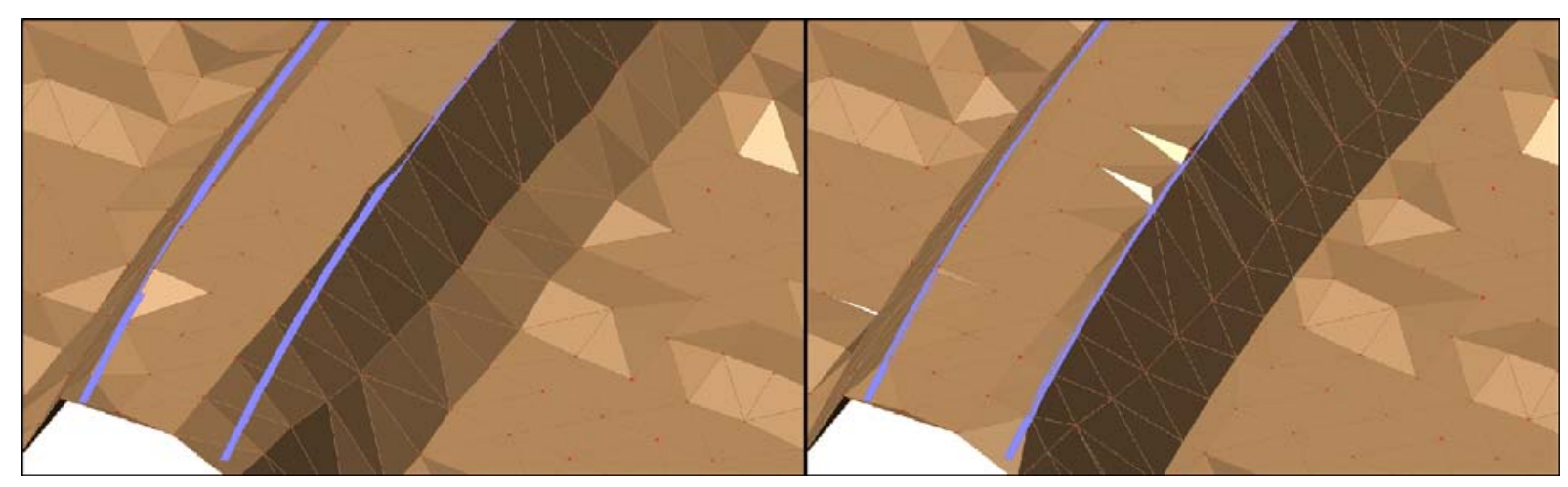

Figura 2.17 - Triangulação: sem linhas de quebra à esquerda e com linhas de quebra, à direita. Utilizando o bordo de uma estrada, como linha de quebra percebe-se melhor definição da estrada e dos taludes.

\subsubsection{Avaliação da Qualidade Cartográfica de um MDT ou MDS}

A qualidade de um MDT é resultante da acurácia dos pontos amostrados, da densidade dos mesmos e do método de interpolação. MDTs são ferramentas de suporte a projetos de engenharia e como tal devem ter sua qualidade posicional tridimensional garantida. O controle de qualidade desse produto cartográfico é extremamente importante. 
Com a demanda por informações cartográficas cada vez mais acuradas, várias organizações desenvolveram padrões de qualidade específicos para avaliação. No Brasil, as normas que regulamentam e classificam documentos cartográficos, quanto à qualidade geométrica, são descritas no Decreto-Lei $\mathrm{n}^{\circ}$ 89.817/84. O artigo $8^{\circ}$ deste Decreto-Lei determina que as cartas quanto à sua exatidão devem obedecer ao Padrão de Exatidão Cartográfica (PEC). Uma descrição de como se faz esse controle pode ser encontrada em Nero (2000).

Nos próximos capítulos, as análises de qualidade serão comentadas e utilizadas para a avaliação da qualidade cartográfica de levantamentos obtidos com sistema de varredura a LASER aerotransportado.

\subsection{Detecção de bordas e dados de varredura a LASER.}

Para extrair uma região em um conjunto de dados é necessário localizar sua borda ou contorno: o limite entre esta região e regiões vizinhas. No caso de uma imagem esta borda é o conjunto de pixels (do inglês picture elements, ou elementos de imagem), que separam duas regiões distintas. Ziou e Tabbone (1998), definem bordas como descontinuidades físicas relativas a variações significativas na refletância, iluminação, orientação e profundidade dos objetos de uma imagem.

Em processamento de imagens e visão computacional, o processo de detecção de bordas é composto por três etapas: suavização, diferenciação e classificação (Ziou; Tabbone, 1998). Na suavização, são aplicados filtros para regularizar as imagens evitando falsas bordas nas etapas posteriores. $\mathrm{Na}$ diferenciação, são calculadas as derivadas parciais $\partial / \partial \mathrm{X}$ e $\partial / \partial \mathrm{Y}$ necessárias na classificação, normalmente utilizando funções gradiente. Na classificação, são estabelecidos os limiares dos módulos do gradiente, relativos a bordas ou outras regiões de interesse. 
O mesmo conceito pode ser extrapolado para uma nuvem de pontos tridimensionais, que representa melhor o universo real que a representação matricial. Nesta nuvem de pontos pode ser construída uma TIN e realizada operações para detecção deste limites físicos. A vantagem de se realizar as operações de detecção de bordas sobre a TIN é a preservação de valores dos dados originais. Em grades regulares os valores são interpolados, oferecem mais uma fonte de erro. A TIN possui outra vantagem especifica sobre imagens de tons de cinza, pois trabalha sempre sobre um universo real $\left(R^{3}\right)$, enquanto a imagens em tons de cinza discretiza os valores da variável de interesse.

A etapa de suavização não deve ser aplicada ao processo de detecção de bordas em TINs de altimetria, pois pode gerar perda ou degradação de informação. Esta etapa é importante e indicada para avaliações qualitativas, em imagens com ruídos.

A diferenciação sobre uma TIN, consiste em calcular o vetor gradiente ( $\partial / \partial X, \partial / \partial Y, \partial / \partial Z)$ e seu módulo para cada triângulo da rede. O módulo do gradiente ou declividade, necessário a classificação é obtido por:

$$
|\vec{\nabla}|=\sqrt{\left(\frac{\partial}{\partial X}\right)^{2}+\left(\frac{\partial}{\partial Y}\right)^{2}+\left(\frac{\partial}{\partial Z}\right)^{2}}
$$

Aplicando o operador à equação do plano (Eq. 2.12), tem-se:

$|\vec{\nabla}|_{i}=\sqrt{a^{2}+b^{2}+c^{2}}$

Onde $a, b$ e c são os coeficientes do plano ajustado sobre os vértices de cada triângulo da grade.

A classificação é uma etapa dependente das características do dado como: densidade e distribuição de pontos, tamanho e forma dos triângulos; dos objetos a serem identificados e da sensibilidade do técnico/classificador.

$\mathrm{Na}$ identificação de edificações, a altura e forma do telhado são fundamentais para a definição do limiar de declividade. Em um perfil com um metro de espaçamento entre pontos coletados, podem ocorrer casos, como apresentados na figura 2.18. 


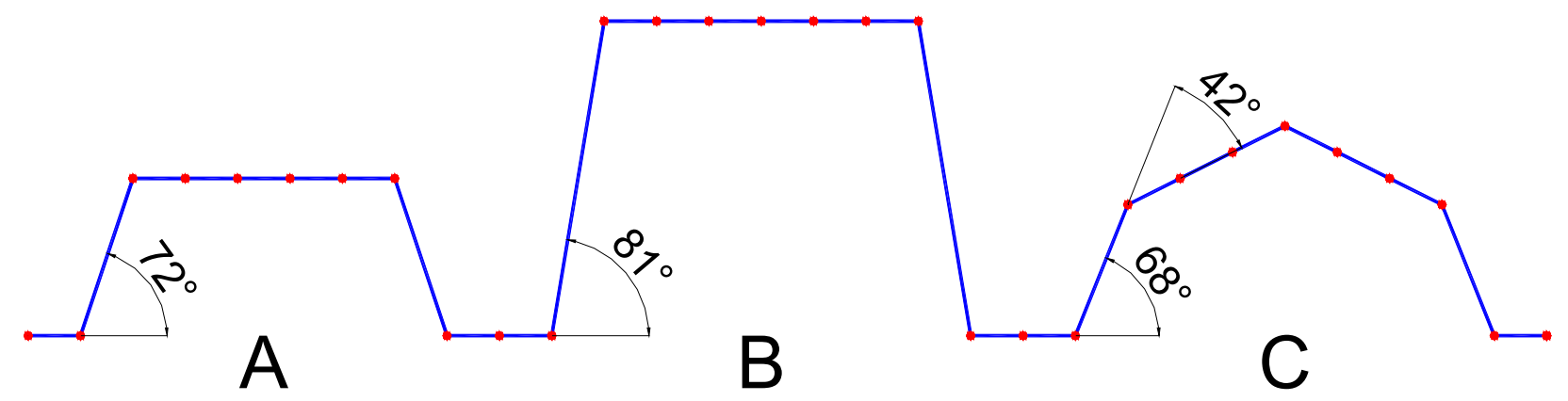

Figura 2.18 - Perfil esquemático representando diferentes tipos de edificações e declividades.

Uma edificação baixa com topo plano, representada pelo caso $A$, apresenta um valor de declividade, em sua borda, inferior a uma edificação alta (caso B). A definição de um limiar ótimo para o caso $B$, pode suprimir edificações pequenas na deteç̧ão de bordas. Por outro lado, a definição de um limiar baseado no caso A, pode gerar falsas bordas em edificações mais altas ou em árvores. Outra situação de difícil análise são edificações com topo não-plano (caso $C$ ), onde um limiar muito baixo pode detectar bordas falsas ao longo do telhado.

$\mathrm{Na}$ identificação das bordas de edificações deve-se atentar para a qualidade posicional. Na nuvem de pontos gerada pelo sistema de varredura a LASER, os alvos são coletados indiscriminadamente. A distância entre o primeiro ponto coletado no topo de edificação e seu vértice real depende da posição e orientação da construção com relação ao sensor. Segundo Volsseman e Maas (2001), as maiores diferenças posicionais ocorrem em bordas perpendiculares ou paralelas à orientação de varredura.

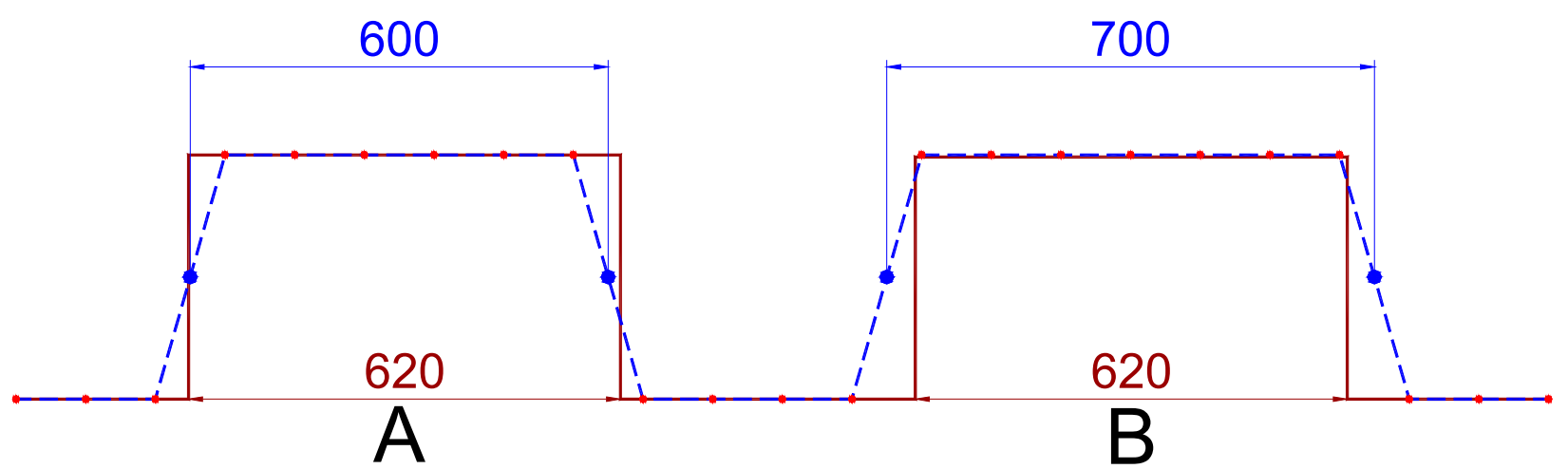

Figura 2.19 - Perfil esquemático representando diferenças entre pontos coletados (em vermelho) e vértices reais de edificações (em marrom) 
Na figura 2.19, observam-se duas edificações de mesma dimensão real porém em função de suas diferentes posições com relação ao perfil de aquisição (direção dos pulsos no espaço). A edificação A teve pontos coletados afastados de seus vértices reais (em marrom). A edificação $B$ teve pontos coletados próximos a seus vértices reais (em marrom). Utilizando o ponto médio da aresta com alta declividade como borda do objeto (baricentro do triângulo, representado em azul), percebe-se que a edificação do caso A é detectada com dimensão menor que a real e deslocada para esquerda. A edificação do caso B é detectada com dimensão maior que a real.

Segundo Steinle (2000), esta diferença depende, também, do eco do pulso LASER analisado. Dados de último pulso apresentam melhor coincidência com o formato das edificações e são menos sensíveis a vegetação e a detalhes irrelevantes do telhado de edificações, como antenas e chaminés. Porém objetos detectados pelo último eco do pulso são, geralmente, menores que o real. Isso ocorre, pois, somente, as projeções de feixe de LASER (footprints) que estão inteiramente compreendidas no topo da edificação fornecem a elevação do topo. Projeções de LASER que atingem, parcialmente, o topo das edificações, fornecem a elevação do terreno.

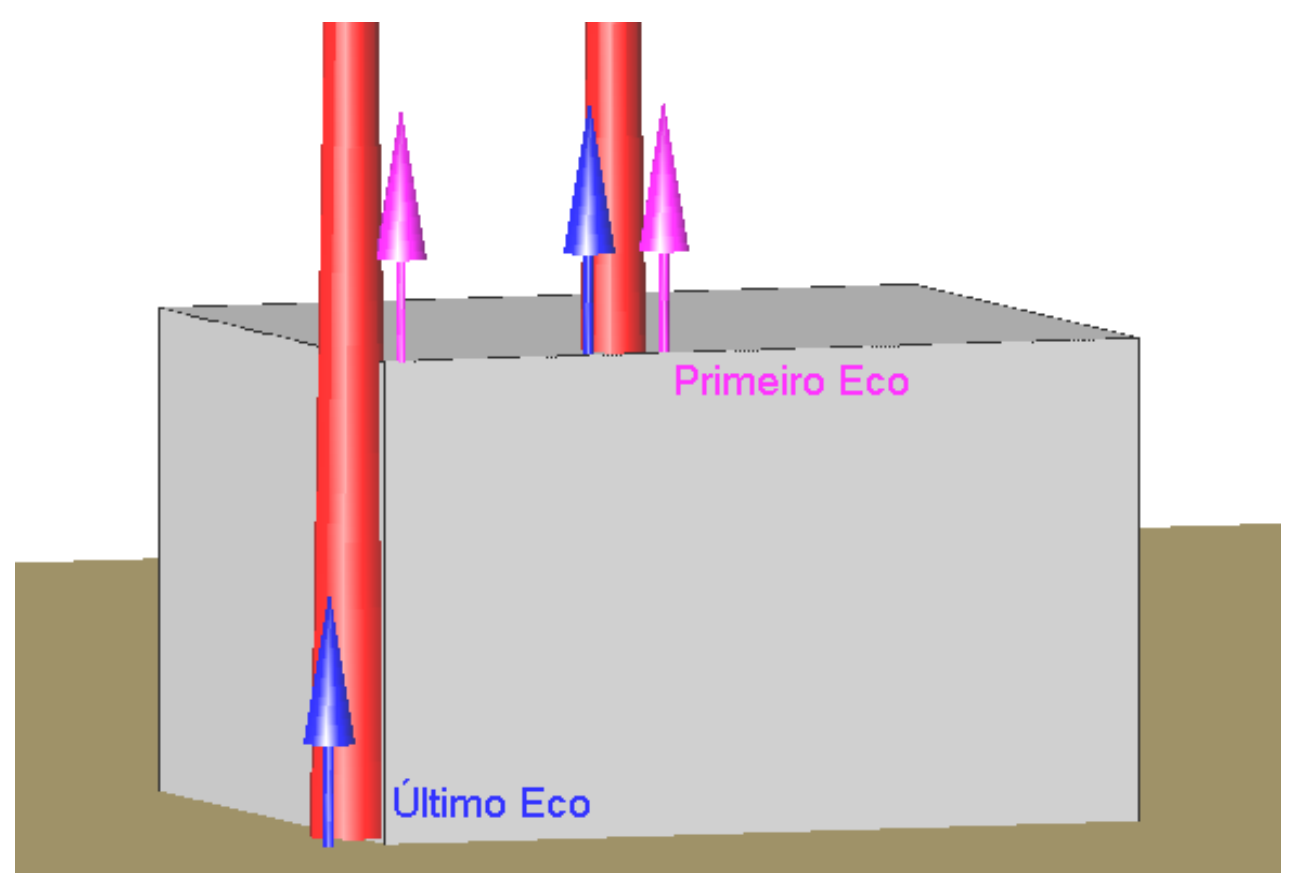

Figura 2.20 - Representação dos retornos do LASER ao atingir edificação. Quando a projeção do LASER atinge parcialmente um topo de edificação (à esquerda) o primeiro eco (magenta) fornece a elevação do topo e o último eco (azul) fornece a elevação do terreno 


\section{Proposta de metodologia para a avaliação da qualidade cartográfica de produtos gerados a partir de levantamentos a LASER}

Avaliar a qualidade posicional de um produto cartográfico significa submeter esse produto a normas e padrões, utilizando ferramentas estatísticas. Para se avaliar a qualidade de um produto cartográfico qualquer, necessita-se de outro com qualidade superior, que servirá como referência ou base de comparação. Este pode ser uma base cartográfica da mesma região de melhor qualidade (escala maior) ou pontos coletados no campo, por topografia convencional ou GPS. É importante identificar bem e coletar os mesmos pontos na base a ser avaliada e na base de referência, para que haja uma exata correspondência.

Os MDT e MDS, como qualquer outro produto cartográfico, estão sujeitos a erros sistemáticos, aleatórios e grosseiros. Os erros sistemáticos são quantificados segundo a acurácia, que é a proximidade do valor encontrado (MDT a ser avaliado) em relação ao valor verdadeiro (MDT de referência). Os erros aleatórios possuem natureza desconhecida. A precisão, a dispersão das observações em torno do valor médio é utilizada para avaliação destes erros. Os erros grosseiros podem ser detectados em função de seu grande afastamento da média, em geral superior a 3 vezes o desvio padrão.

Para avaliação dos produtos gerados, através dos levantamentos oriundos de sistema de varredura a LASER aerotransportado, foi elaborada uma metodologia de processamento de dados, modelagem e ajustamentos. 
Esta metodologia é composta das seguintes etapas:

- Processamento preliminar dos dados;

- Delimitação da área de estudo;

- Geração do MDS;

- Testes e controles planimétricos

- Detecção de bordas de edificações;

o Cálculo dos gradientes (declividade);

o Definição de limiar de declividade e classificação;

o Vetorização das bordas detectadas.

- Coleta de pontos de controle planimétrico;

- Cálculo de estatísticas;

- Detecção e eliminação de erros grosseiros;

- Testes de tendência;

- Minimização de erros sistemáticos;

- Teste de precisão (padrão americano);

- Satisfação ao PEC (padrão brasileiro);

- Testes e controles altimétricos

- Coleta de pontos de controle altimétrico;

- Detecção e eliminação de erros grosseiros;

- Testes de tendência;

- Minimização de erros sistemáticos;

- Teste de precisão (padrão americano);

- Satisfação ao PEC (padrão brasileiro);

\section{Avaliação final}

Além disso podem se realizar ajustamentos para eliminação de erros grosseiros, minimização de erros sistemáticos e tentativas de melhora da qualidade. 


\subsection{Processamento dos dados e delimitação da área de estudo}

Para a avaliação da qualidade devem ser utilizados os dados do último pulso de levantamentos e algum outro produto cartográfico de referência com melhor qualidade cartográfica. Serão utilizados dados do último pulso, contrariando recomendação de Steinle (2000), para avaliar se a metodologia proposta consegue minimizar os erros de dimensão de objetos, detectados pelo autor citado.

Caso o sistema de coordenada do levantamento a LASER e o do produto cartográfico de referência sejam diferentes, deve-se buscar a compatibilidade, em geral reprojetando os do sistema LASER para o de referência (imutável). Existem vários programas computacionais no mercado capazes de realizar tal transformação.

A delimitação da área de estudo visa minimizar o esforço computacional e de coleta de pontos de controle, ajustamento e modelagem das superfícies. Segundo a metodologia proposta, os dados devem ser importados, como tabelas, para um programa gerenciador de banco de dados. A delimitação espacial pode ser realizada através de uma consulta com restrições nos campos Este e Norte, utilizando os limites inferiores e superiores da área de estudo. As seleções devem ser exportadas em formato ASCll, visando facilitar a importação por outros programas.

Os arquivos ASCII, com os dados de cada faixa devem ser importados em um programa de computação gráfica. A visualização desses pontos em plataforma gráfica possibilita a escolha de pontos de controle, como se mostrará.

\subsection{Geração do MDS e deteç̧ão de bordas de edificações}

Após a importação, devem ser gerados modelos digitais de superfície (MDS) para cada faixa em estudo. Pode-se utilizar diversos programas de modelagem das superfícies. Recomenda-se que os MDS sejam construídos pelo método da 
triangulação de Delaunay, indicado para dados com distribuição irregular. Devido a grande densidade de pontos, recomenda-se a utilização de ajuste linear (equação do plano) na modelagem.

Deverão ser calculadas as declividades (módulos dos gradientes de elevação) para todos os triângulos dos MDS, através da equação 2.14.

Para detecção de bordas deverá ser estabelecido um limiar de classificação, acima do qual, os triângulos serão classificados como borda. A utilização desse limiar são determinadas empiricamente, de acordo com as características do levantamento.

O conhecimento da região em estudo e do levantamento são importantes para a boa definição do limiar. Um levantamento em escala pequena da região, como uma imagem CBERS pancromática, pode auxiliar nos testes de definição de limiar, evitando com que se omitam as feições comuns. Sabendo-se a resolução média $(\mathrm{dx})$ do levantamento a LASER, pode-se determinar diferença de altura limite, para classificação como borda $(\mathrm{H})$, em função da declividade, através da equação 3.1.
$H=d x \cdot \tan ($ declividade $)$
Eq. 3.1

Outra ferramenta que pode auxiliar na definição do limiar e posterior vetorização das bordas são os mapas de elevação ou hipsométricos. Com pouco conhecimento dos dados, podem-se estabelecer várias classes de elevação com intervalos de três metros (altura média de um andar de edificações), a partir da cota mais baixa do levantamento. Regiões com grande quantidade de triângulos contínuos representam terrenos planos ou topos planos de edificações. Operações de adição entre dados de elevação e declividade, como álgebra de mapas, também auxiliam a definição de limiar no caso de pouca informação da região e do levantamento.

Definido o limiar, devem ser classificados triângulos com declividade superior a ele. Esses triângulos identificam variações abruptas de elevação e delimitam elementos não-pertencentes ao terreno, como edificações ou árvores. Através desta segmentação pretende-se identificar edificações no MDS (e em seus produtos, gerados pela nuvem de pontos). 


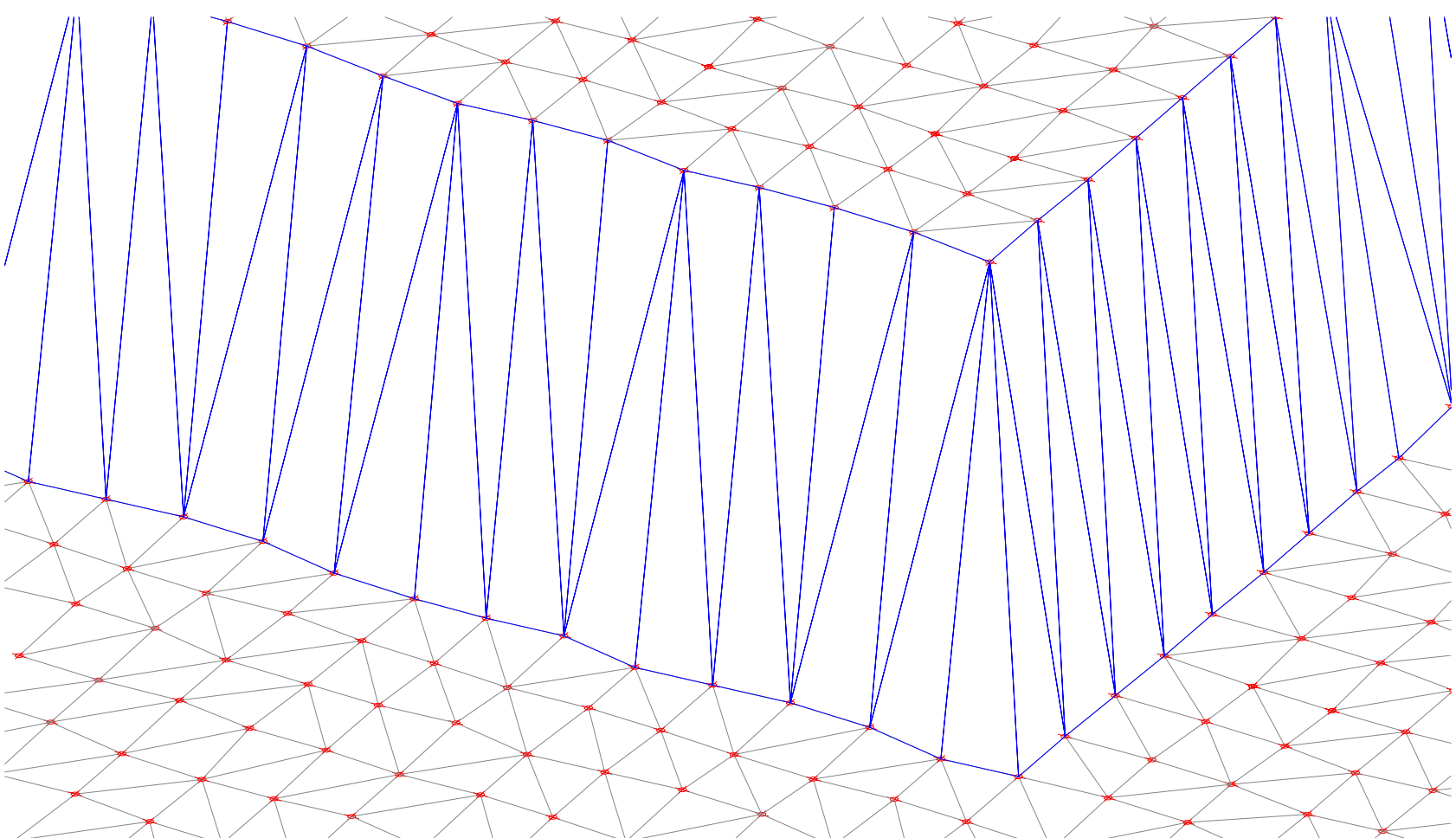

Figura 3.1 - Perspectiva de uma TIN sobre uma nuvem de pontos oriundos de levantamento LASER.

Triângulos azuis correspondem a declividades superiores ao limiar estabelecido.

Após a classificação devem-se vetorizar as bordas, transformando os triângulos classificados em linhas. Este processo pode ser realizado manualmente, destacando os triângulos de borda com cor diferente permitindo com que o técnico trace retas sobre arestas das edificações. Este processo requer experiência do profissional e é subjetivo e demorado. Pode-se adotar uma metodologia semiautomática, eliminando tendências do operador e agilizando o processo.

Este trabalho propõe um método semi-automático em duas etapas. $\mathrm{Na}$ primeira etapa o operador indica a diretriz de uma aresta entre os triângulos classificados e o algoritmo ajusta uma reta em função dos baricentros destes triângulos (fluxogramas indicado na figura 3.2 e e código comentado, na figura 3.3). Foi adotado o baricentro para ajuste de arestas por facilidade de cálculo, sem prejuízos perante outras opções. Na segunda etapa, um algoritmo de pósprocessamento conecta as arestas perante teste de proximidade de seus vértices (fluxograma da figura 3.4). Atualmente, estas rotinas funcionam dentro do programa computacional AutoCad. 


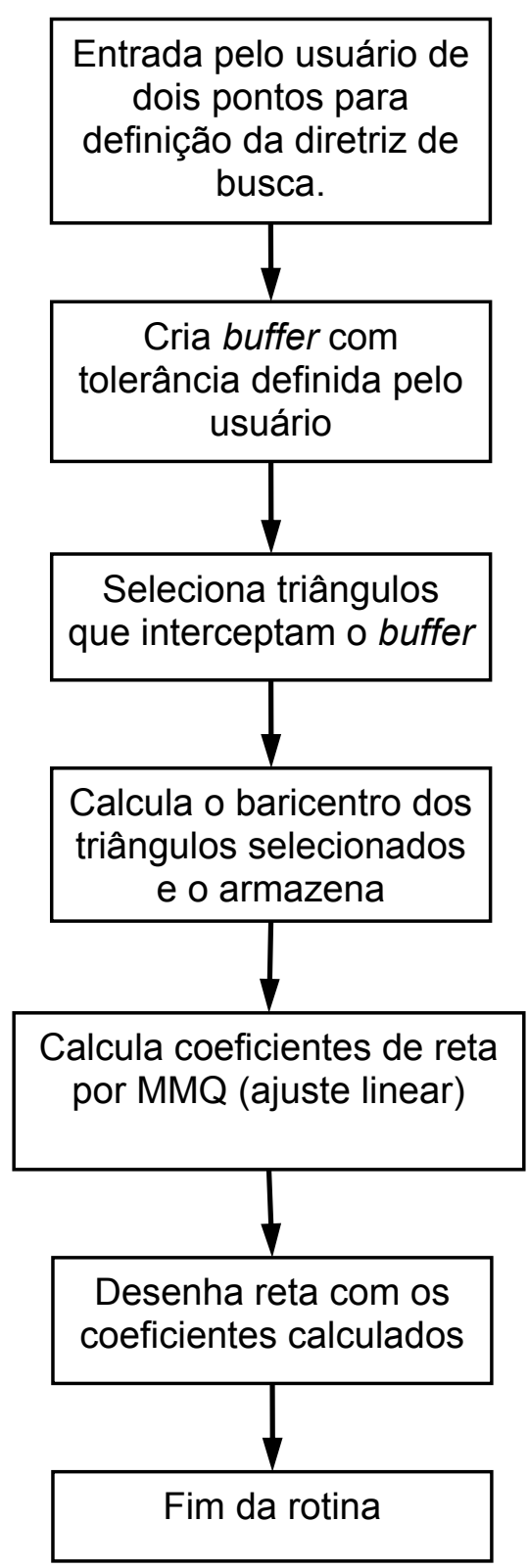

Figura 3.2 - Algoritmo da rotina de geração de arestas por regressão linear de baricentros de triângulos de borda. 
Tisual LISP for AutoCAD <Drawing1.dwg $>$ - [Triangulo_r3.Isp]

$\checkmark$ File Edit Search View Project Debug Iools Window Help

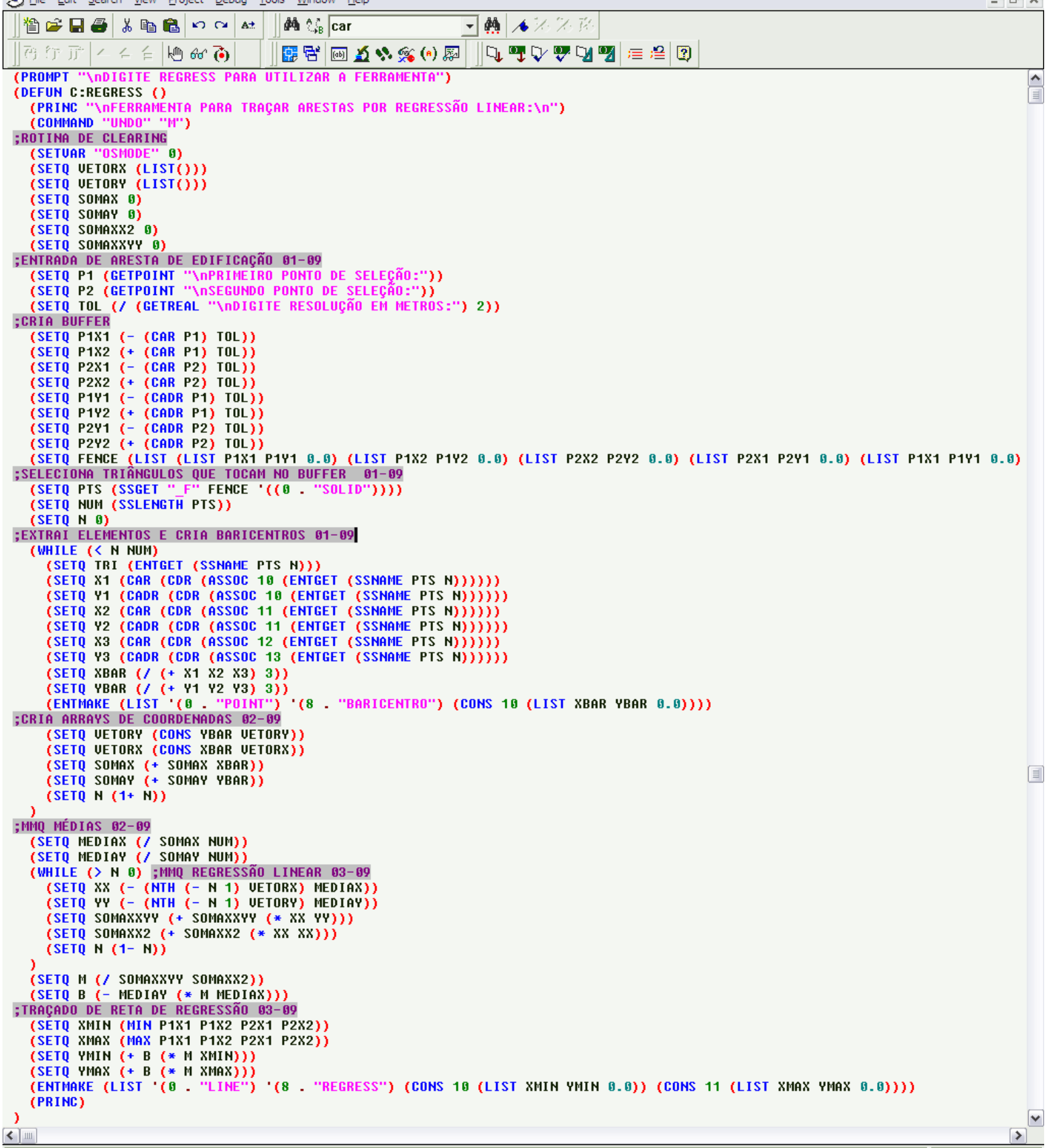

Edit: H:/Mestrado/BORDAS/Triangulo_r3.Isp ${ }^{\times}$[Visual LISP]

Figura 3.3 - Código comentado em AutoLISP da rotina de geração de arestas por regressão linear de baricentros de triângulos de borda. 


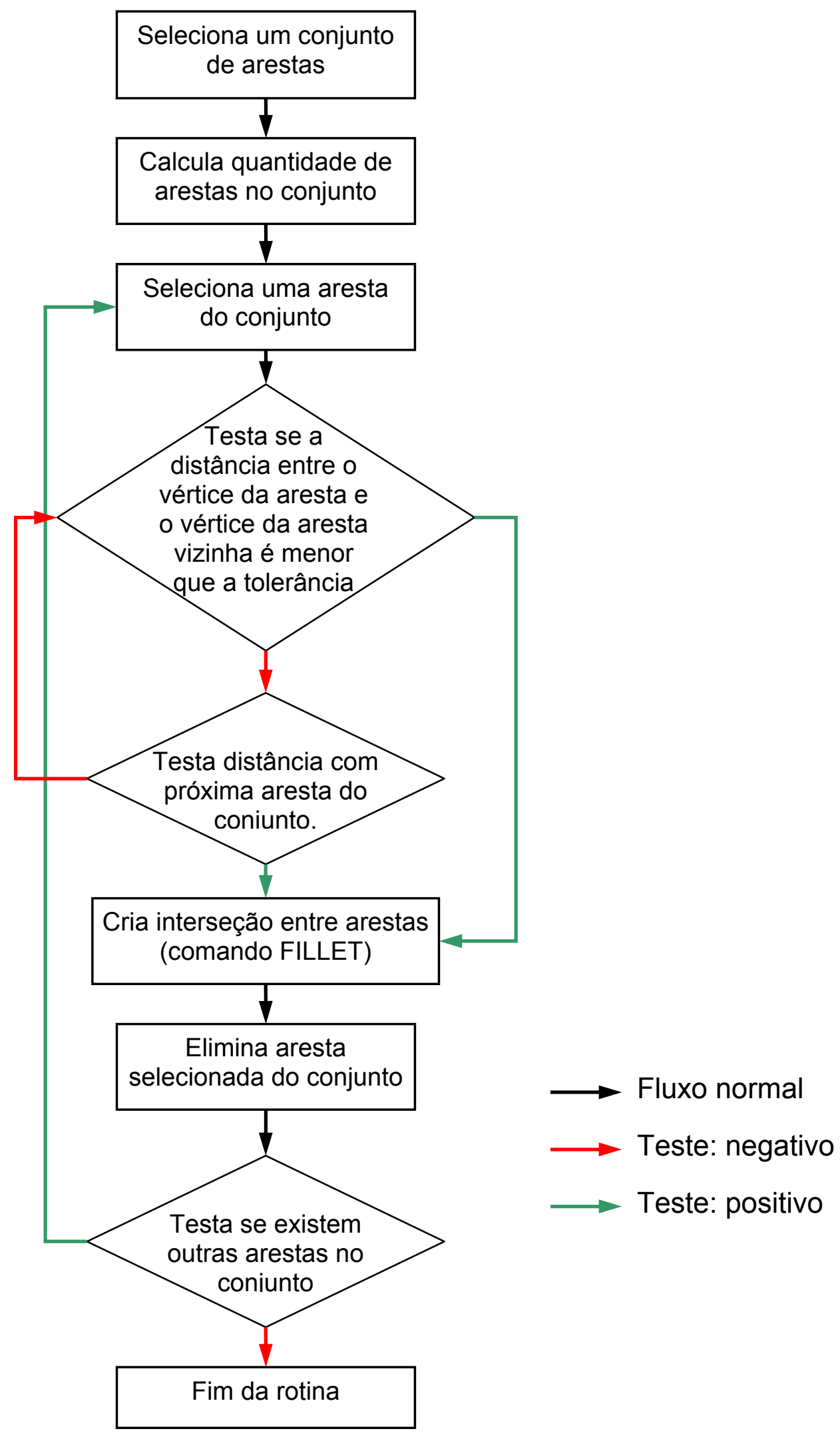

Figura 3.4 - Algoritmo da rotina de conexão de arestas.

Os vértices resultantes dessas operações serão utilizados como pontos de controle planimétrico. 
O cálculo da declividade também permite segmentação de regiões planas. Triângulos com baixa declividade (menor que $5^{\circ}$ ) delimitam áreas quase planas, onde podem ser coletados pontos de controle para análise altimétrica.

\subsection{Coleta de pontos de controle planimétricos e altimétricos}

Deverão ser coletados pontos de controle planimétrico, em quantidade suficiente e em regiões de fácil identificação tanto no MDS segmentado como no produto cartográfico de referência. Recomenda-se que estes pontos sejam coletados no MDS sem a exibição do produto de referência, evitando assim a indução do intérprete.

Segundo norma, no caso de cartas e mapas, recomenda-se coleta de 20 ou mais pontos de controle por folha. No caso de levantamentos a LASER, adotou-se quantidade de pontos maior que 20, por faixa de levantamento. Nos estudos de caso serão utilizadas quantidades superiores a 20 (mais de 50 pontos por faixa), aumentando a qualidade estatística dos experimentos, por tratar-se de processo de validação e avaliação de um produto novo.

Devido à facilidade de detecção de vértices de edificações no MDS e sua presença nos produtos cartográficos de referência, recomenda-se estas feições como pontos de controle.

Os pontos de controle planimétrico podem ser utilizados como controle altimétrico, caso o produto cartográfico de referência possua as elevações de pontos facilmente identificáveis, como vértices de edificações. No caso de coleta de pontos utilizando GPS, estes pontos devem ser escolhidos estrategicamente para que possam ser usados como controle tanto planimétrico, quanto altimétrico, reduzindo assim a quantidade total de pontos a serem levantados. 
Caso o produto de referência não contenha pontos com elevação de fácil identificação no MDS, devem-se coletar pontos de controle em regiões planas, minimizando assim erros de coleta, advindos entre outras coisas do não ajuste planimétrico entre os documentos.

O conceito do que seja uma região relativamente plana varia com o espaçamento/resolução média entre pontos do levantamento a LASER e a qualidade cartográfica que se pretende obter nos testes e tratamentos. Para um espaçamento médio, entre pontos de um levantamento a LASER, de um metro (em centro de faixa) a uma declividade de $5^{\circ}$, representa uma diferença de nível de cerca de nove centímetros no terreno. Este erro altimétrico, oriundo da coleta equivocada (por erro planimétrico) é bem inferior ao admissível na norma brasileira para levantamentos na escala $1 / 500$ e na classe $A(0,25 \mathrm{~cm})$, ou seja, levantamentos cadastrais em escalas muito grandes e excelente qualidade.

\subsection{Cálculo de estatísticas, detecção e eliminação de erros grosseiros}

Após a coleta de pontos no MDS ou até paralelamente, esses pontos devem ser identificados e coletados em campo ou em produto cartográfico com qualidade superior.

Denomina-se, no presente trabalho, discrepância a diferença entre o valor da observação no produto a ser avaliado e o valor de referência. Sugere-se montar planilhas com as discrepâncias nas coordenadas Este $(\Delta \mathrm{E})$, Norte $(\Delta \mathrm{N})$ e elevação $(\Delta \mathrm{H})$

$$
\begin{array}{lr}
\Delta \mathrm{E}=\mathrm{E}_{\text {carta }}-\mathrm{E}_{\text {LASER }} & \text { Eq. } 3.1 \\
\Delta \mathrm{N}=\mathrm{N}_{\text {carta }}-\mathrm{N}_{\text {LASER }} & \text { Eq. } 3.2 \\
\Delta \mathrm{H}=\mathrm{H}_{\text {carta }}-\mathrm{H}_{\text {LASER }} & \text { Eq. } 3.3
\end{array}
$$


A partir dessas discrepâncias podem ser calculadas diversas grandezas estatísticas, entre elas a média $(\overline{\Delta X})$ e o desvio-padrão $\left(S_{X}\right)$. A análise das discrepâncias permite a detecção e correção, de alguns tipos de erros aos quais os levantamentos estão sujeitos: erros grosseiros e sistemáticos.

A seguir devem ser eliminados pontos com erros grosseiros, mediante uma análise dos pontos que estão fora do intervalo definido pela média e três vezes o desvio padrão (nos casos normais). O processo de eliminação de pontos grosseiros deve ser realizado iterativamente, recalculando-se a média e o desvio-padrão dos pontos restantes a cada iteração.

No caso de pontos de controle planimétricos e altimétricos distintos, a detecção e eliminação se dão primeiramente sobre as observações planimétricas, uma vez que estas interferem na correta coleta dos pontos de controle altimétrico. De fato, a coleta dos pontos de controle altimétrico só ocorre após completo tratamento estatístico ou ajustamento pelo método dos mínimos quadrados da parte planimétrica. Os pontos discrepantes serão eliminados caso alguma das ordenadas, $\mathrm{E}$ ou $\mathrm{N}$, contenha erro grosseiro. No caso de pontos de controle plani-altimétricos, ocorre eliminação de pontos discrepantes se qualquer uma de suas ordenadas: $\mathrm{E}, \mathrm{N}$ ou $\mathrm{H}$, contiver erro grosseiro.

Amostras eivadas de erros grosseiros têm suas estatísticas contaminadas, o que pode ocasionar mascaramento de erros sistemáticos ou a detecção errônea dos mesmos, degradação da qualidade em testes de precisão e, principalmente, falseamento do MDT construído. Após a eliminação dos pontos discrepantes, notase diminuição do desvio-padrão e melhoras em outros parâmetros estatísticos, como assimetria (desvio do pico da curva de distribuição de uma curva normal) e curtose (grau de achatamento da curva de distribuição) aproximando os histogramas de distribuições normais. 


\subsection{Testes de tendência e eliminação de erros sistemáticos}

Após a eliminação de erros grosseiros, a partir das estatísticas e do tamanho da amostra resultante(n) pode-se determinar a existência ou não de tendências, que neste caso, significam erros sistemáticos inerentes ao levantamento e/ou ao processo de coleta de pontos de controle. Para tal, realiza-se o teste de tendência (Merchant, 1982), para o nível de confiança de 90\% (valor padrão). Embora este teste não seja preconizado no padrão brasileiro e sim no padrão americano, é um procedimento bastante conhecido e utilizado em trabalhos. O teste de tendência é baseado na distribuição de Student, com a seguinte definição:

H0: $\overline{\Delta X}=0$, hipótese nula

Que será verdadeira se: $\left|t_{X}\right|<t_{n-1, \alpha / 2}$, e então o produto está livre de tendências no eixo X examinado (N, E ou $\mathrm{H})$;

Onde $t_{n-1, \alpha / 2}$ representa o valor crítico, que vem tabelado para $\mathrm{n}$ e $\alpha$ ou pode ser calculado.

$\mathrm{H} 1: \quad \overline{\Delta X} \neq 0$, hipótese alternativa

Que será verdadeira, rejeitando $\mathrm{H} 0$, se: $\left|t_{X}\right| \geq t_{n-1, \alpha / 2}$, e então o produto apresenta de tendência no eixo $X$ examinado.

Na definição, para o cálculo, $t_{X}$ se escreve:

$t_{E}=\frac{\overline{\Delta E} \cdot \sqrt{n}}{S_{E}} \quad$ (coordenada Este) $\quad$ Eq. 3.4

$t_{N}=\frac{\overline{\Delta N} \cdot \sqrt{n}}{S_{N}} \quad$ (coordenada Norte) $\quad$ Eq. 3.5

$t_{H}=\frac{\overline{\Delta H} \cdot \sqrt{n}}{S_{H}} \quad$ (coordenada $\mathrm{H}$ ou elevação) $\quad$ Eq. 3.6 
Onde, $\overline{\Delta E}, \overline{\Delta N}$ e $\overline{\Delta H}$ são, respectivamente, as médias das discrepâncias em Este, Norte e elevação e $S_{E}, S_{N}$ e $S_{H}$ são os desvios-padrão em Este, Norte e elevação. Os valores de $t_{\text {crítico }}$ são tabelados em função de número de amostras (n) e do grau de significância $(\alpha)$, considerado 90\%. Segundo Nero (2000) admite-se que constatado o erro sistemático, através do teste, o mesmo pode ser minimizado, subtraindo-se o seu valor de cada ordenada. Sobre a amostra resultante são realizados os testes de precisão e de satisfação ao padrão brasileiro.

\subsection{Teste de precisão (padrão americano)}

Uma análise de satisfação a um dado padrão é o teste de precisão (Nero, 2000). Este teste é utilizado na norma americana, como a NMAS, do inglês National Map Accuracy Standards (USBB, 1947) e o padrão da ASPRS (ASPRS, 1989), ambos baseados na distribuição $\chi^{2}$, segundo as seguintes hipóteses:

Ho: $S_{x}^{2}=\sigma_{x}^{2}$, hipótese nula

$\mathrm{H} 1: \mathrm{S}_{\mathrm{x}}^{2}<\sigma_{\mathrm{x}}{ }^{2}$, hipótese alternativa

Para realizar o teste, deve-se comparar o valor de $\chi^{2}$ da amostra com um valor limite da estatística, para aquele tamanho da amostra (n) e um determinado nível de confiança, que se adota normalmente $\alpha=0,10$. A fórmula para o cálculo é:

$$
\chi_{x, n-1}^{2}=(n-1) \cdot \frac{S_{x}^{2}}{\sigma_{x}^{2}}
$$

Onde, $S_{x}^{2}$ corresponde à variância ou desvio padrão da amostra ao quadrado e $\sigma_{x}^{2}$ representa o desvio padrão ao quadrado da classe cartográfica que se quer verificar e que no caso da norma brasileira, corresponde ao Erro planimétrico padrão (EPP), gerando a equação 3.8, conforme Nero (2005)

$$
\chi_{x, n-1}^{2}=\frac{(n-1) \cdot S_{P}^{2}}{E P P^{2}}
$$


Esse valor calculado deve ser comparado com o valor crítico $\left(\chi_{\text {crit }}^{2}\right)$ extraído da tabela da distribuição $\chi^{2}$ para um grau de significância $\alpha$, normalmente, igual a 90\% (Cintra; Nero, 2009). O teste de hipóteses fica sendo:

H0: $\chi_{c r i t}^{2} \leq \chi_{n-1, \alpha}^{2}$, a precisão da amostra atende a precisão especificada.

H1: $\chi_{c r i t}^{2}>\chi_{n-1, \alpha}^{2}$, a precisão da amostra não atende a precisão especificada.

\subsection{Satisfação ao PEC (padrão brasileiro)}

No Brasil, análises de satisfação de produtos cartográficos estão amparadas pelo Decreto-Lei 89.187/84. Este decreto define o Padrão de Exatidão Cartográfica (PEC) e apresenta três classes de produto e estabelece valores numéricos para cada uma. Em seu artigo oitavo esse Decreto prevê que:

"Noventa por cento dos pontos bem definidos numa carta, quando testados no terreno, não deverão apresentar erro superior ao Padrão de Exatidão Cartográfica Planimétrico estabelecido".

"Noventa por cento dos pontos isolados de altitude, obtidos por interpolação de curvasde-nível, quando testados no terreno, não deverão apresentar erro superior ao Padrão de Exatidão Cartográfica - Altimétrico - estabelecido".

Em seu artigo nono, o Decreto estabelece as classificações quanto a exatidão, resumidas nas tabelas 3.1 e 3.2

Tabela 3.1 - Valores do PEC e do EPP (planimétrico) relativos à escala do produto cartográfico

\begin{tabular}{|c|c|c|}
\hline \multirow{2}{*}{ Classe } & \multicolumn{2}{|c|}{ Planimetria } \\
\cline { 2 - 3 } & PEC & EPP \\
\hline A & $0,5 \mathrm{~mm}$ & $0,3 \mathrm{~mm}$ \\
\hline B & $0,8 \mathrm{~mm}$ & $0,5 \mathrm{~mm}$ \\
\hline C & $1,0 \mathrm{~mm}$ & $0,6 \mathrm{~mm}$ \\
\hline
\end{tabular}


Tabela 3.2 - Valores do PEC altimétrico relativos à escala do produto cartográfico

\begin{tabular}{|c|c|c|c|c|}
\hline \multirow{2}{*}{ Classe } & \multicolumn{4}{|c|}{ Altimetria } \\
\cline { 2 - 5 } & PEC & $\begin{array}{c}\text { Escala } \\
1 / 1.000\end{array}$ & $\begin{array}{c}\text { Escala } \\
1 / 2.000\end{array}$ & $\begin{array}{c}\text { Escala } \\
1 / 5.000\end{array}$ \\
\hline A & $1 / 2$ da eqüidistância & $0,50 \mathrm{~m}$ & $1,00 \mathrm{~m}$ & $2,5 \mathrm{~m}$ \\
\hline B & $3 / 5$ da eqüidistância & $0,60 \mathrm{~m}$ & $1,20 \mathrm{~m}$ & $3,0 \mathrm{~m}$ \\
\hline C & $3 / 4$ da eqüidistância & $0,75 \mathrm{~m}$ & $1,50 \mathrm{~m}$ & $3,75 \mathrm{~m}$ \\
\hline
\end{tabular}

Embora o conceito de curvas de nível adotado pela norma brasileira não reflita a natureza dos MDT e MDS, uma atualização da norma brasileira ainda não foi homologada.

Para aplicação do padrão brasileiro devem ser criadas colunas para verificar se o erro em cada ponto (nas duas coordenadas) ultrapassa ou não o valor do PEC especificado no padrão (tabela 3.1). Ou seja, busca-se a verificação da satisfação ao PEC, ponto a ponto, para cada escala. Para tal, foram calculados os valores do PEC no campo para as diferentes escalas e classes de qualidade e comparados com as discrepâncias das componentes planimétricas de cada observação.

Para cada conjunto de amostra verificam-se quantos pontos foram reprovados para cada classe. Segundo o padrão, se a porcentagem de pontos reprovados na amostra, for igual ou superior a 10\%, esta não atinge a classificação de qualidade preconizada.

\subsection{Ajustamento com transformação afim}

Outra abordagem para minimizar erros sistemáticos e melhorar a qualidade posicional é a utilização de uma transformação afim. O tratamento estatístico, abordado nas etapas anteriores, promove translações em $\mathrm{E}, \mathrm{N}$ e H , baseado nos erros sistemáticos detectados. A transformação afim foi considerada para minimização de erros planimétricos, pois promove além das translações, rotações, 
escala de eixos e não-ortogonalidade entre eixos. Esta transformação, em tese, permite a resolução de problemas como, algumas diferenças entre o tamanho real do objeto e o detectado palas bordas extraídas pelo último pulso, erros de pontaria e de identificação de vértices de controle.

No caso de pontos de controle plani-altimétricos pode-se utilizar uma transformação afim no espaço (equações 3.8, 3.9 e 3.10). No caso de pontos de controle planimétricos e altimétricos distintos, deve-se utilizar uma transformação afim no plano, apenas para a parte planimétrica (equações 3.11 e 3.12) e uma outra transformação para a parte altimétrica.

$$
\begin{array}{ll}
X_{a}=A 0+A 1 \cdot X+A 2 \cdot Y+A 3 \cdot H & \text { Eq. } 3.8 \\
Y_{a}=B 0+B 1 \cdot X+B 2 \cdot Y+B 3 \cdot H & \text { E9. } 3.9 \\
Z_{a}=C 0+C 1 \cdot X+C 2 \cdot Y+C 3 \cdot H & \text { Eq. } 3.10 \\
X_{a}=A 0+A 1 \cdot X+A 2 \cdot Y & \text { Eq. } 3.11 \\
Y_{a}=B 0+B 1 \cdot X+B 2 \cdot Y & \text { E9. } 3.12
\end{array}
$$

Nas equações anteriores, os termos independentes (A0, B0, C0) correspondem às translações e composições dos demais termos ( $A 1, A 2, A 3, B 1$, B2, B3, C1, C2, C3) correspondem a, rotações, escala de eixos e nãoortogonalidade entre eixos.

Os coeficientes da transformação são determinados através de ajustamento, utilizando o método dos mínimos quadrados para modelo paramétrico linear. A formulação matemática adotada foi extraída de Gemael (1994):

$$
\begin{array}{ll}
X_{a}=\left(A^{T} \cdot P \cdot A\right)^{-1} \cdot\left(A^{T} \cdot P \cdot L_{b}\right) & \text { Eq. } 3.13 \\
V=A \cdot X_{a}-L_{b} & \text { Eq. } 3.14 \\
L_{a}=L_{b}+V=A \cdot X_{a} & \text { Eq. } 3.15 \\
\sigma_{0}=\frac{V^{T} \cdot V}{G L} & \text { Eq. } 3.16
\end{array}
$$


Onde $X_{a}$ é o vetor dos parâmetros ajustados; A é a matriz das derivadas parciais em função dos coeficientes; $L_{b}$ é o vetor das observações; $P$ é a matriz-peso (no ajustamento, adotou-se a matriz-identidade), $V$ é a vetor dos resíduos, $L_{a}$ é o vetor das observações ajustadas, $\sigma_{0}$ é a variância a posteriori e GL são os graus de liberdade do ajustamento (diferença entre o número de equações e o número de incógnitas).

Podem-se calcular estatísticas adicionais como a matriz variânciacovariância (MVC) dos parâmetros, das observações ajustadas e dos resíduos. Para análise da qualidade do ajustamento, na parte prática, foi utilizada a MVC dos parâmetros ajustados (equação 3.17).

$\Sigma X_{a}=\sigma_{0}^{2} \cdot\left(A^{T} \cdot P \cdot A\right)^{-1}$

Para o ajustamento recomenda-se a utilização de $40 \%$ dos pontos coletados (antes do tratamento estatístico), cuja discrepância mais se aproxima da média das discrepâncias. Os demais pontos são utilizados para verificação da qualidade do ajustamento.

Os coeficientes determinados devem ser aplicados, então, nas equações 3.8, 3.9 e 3.10 (no caso de transformação afim no espaço) ou nas equações 3.11 e 3.12 (no caso de transformação afim plana) para se calcularem as coordenadas corrigidas. Sobre estas coordenadas calculam-se as discrepâncias e se realizam testes de satisfação (precisão e PEC).

A transformação afim será utilizada nos estudos de caso para verificar se este procedimento gera resultados significativamente melhores que o tratamento estatístico simples de tendência (duas translações). Caso não, recomendar-se-á a utilização desse tratamento estatístico, dada sua maior facilidade de cálculo.

Ao final deve-se verificar o atendimento conjunto das exigências planimétricas e altimétricas para enquadrar o produto numa determinada classe / escala especificadas no padrão brasileiro. 


\section{Avaliação da qualidade do levantamento a LASER realizado no Campus da UFPR}

\subsection{Local de testes, equipamentos e programas computacionais utilizados}

Seguindo a metodologia proposta foram realizados os experimentos práticos, descritos no capítulo anterior.

A avaliação da qualidade cartográfica foi realizada para o levantamento por sistema de varredura a LASER aerotransportado, sobre o campus do Instituto Politécnico da Universidade Federal do Paraná. Para o experimento foram utilizados os dados do último retorno do pulso de duas faixas desse levantamento e, como referência, mapeamento realizado por restituição aerofotogramétrica, na escala 1/2.000. O levantamento LASER e a restituição encontram-se no sistema de projeção cartográfica UTM, fuso 22 e Referencial SAD-69.

O levantamento foi realizado pelo LACTEC, com o sistema de varredura Optech ALTM 2050, em maio de 2003. Este utiliza mecanismo de varredura de espelho oscilante, produzindo um padrão de zigue-zague sobre a área levantada.

Tabela 4.1 - Características do sistema de varredura a LASER (Fonte: Optech, 2008).

\begin{tabular}{|l|l|}
\hline Sistema & ALTM 2050 \\
\hline Fabricante & Optech \\
\hline Dados Fornecidos pelo sistema & Coordenadas 3D / Dados de Intensidade \\
\hline Método de Varredura & Espelhos Oscilantes \\
\hline Pulsos por segundo & 50.000 \\
\hline Ângulo de Varredura & Variável entre $0^{\circ}$ e 40 \\
\hline Registro do pulso & Primeiro e último retorno do pulso \\
\hline Padrão de Varredura & Dente de Serra (Zig-Zag) \\
\hline Comprimento de onda do LASER & 1064 nm \\
\hline Altitude de operação & 210 - 2.000 mts \\
\hline Classificação do LASER & Classe IV (ANSI) \\
\hline Potência Requerida & 28 VDC/ 26-35 A \\
\hline
\end{tabular}


Um exemplo dos dados brutos está mostrado na figura 4.1. A primeira coluna corresponde à coordenada Este, a segunda à coordenada Norte (ambas em UTM), a terceira à altitude e a quarta à refletância.

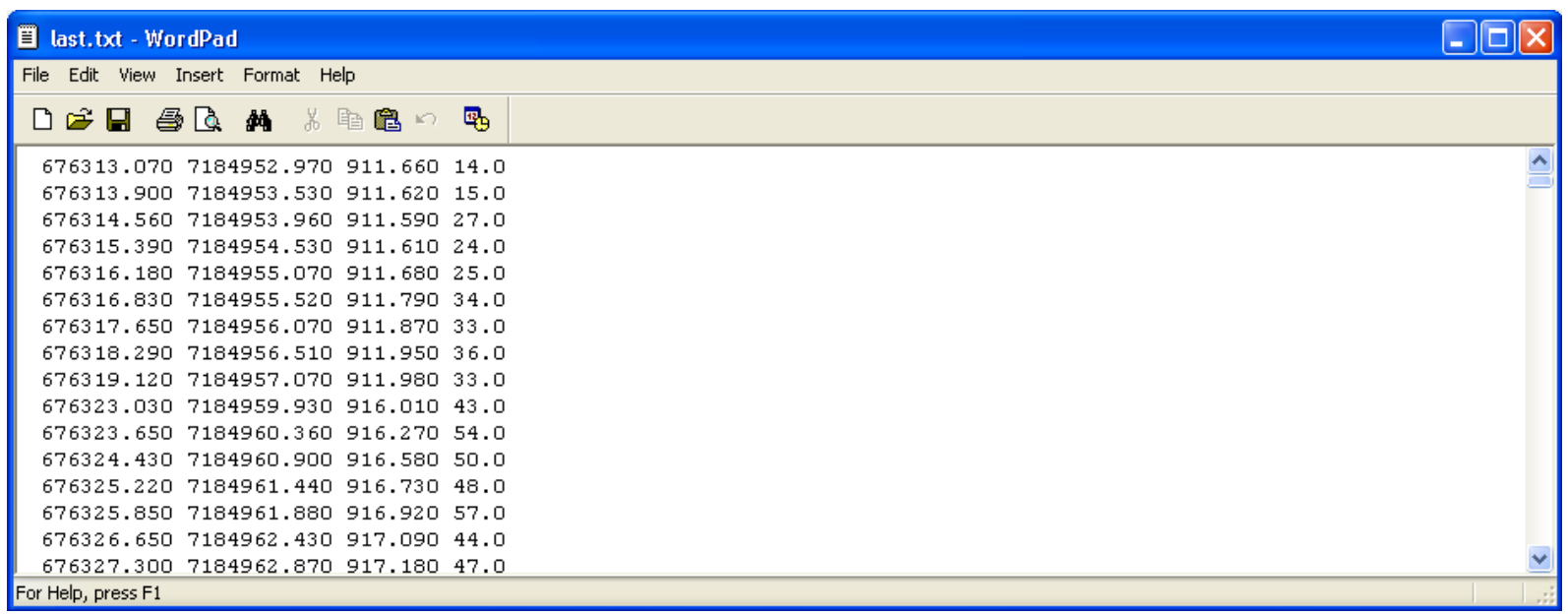

Figura 4.1 - Trecho dos dados brutos da faixa 3, último pulso.

Foram utilizados os programas computacionais:

a) Microsoft Excel: construção de planilhas e análises estatísticas.

b) Microsoft Word: construção de rotina de importação de pontos.

c) Microsoft Access: armazenamento, consultas e operações algébricas sobre os dados.

d) Autodesk Land Desktop 2000i: visualização, construção de MDS, cálculo de declividades, vetorização e desenvolvimento de rotinas.

e) Mathcad: desenvolvimento de rotinas.

\subsection{Processamento dos dados e coletas de pontos de controle}

Primeiramente, foi delimitada uma área de estudo (figura 4.2). Para tal, foi considerada uma região crítica do campus, com grande variação de relevo, edificações e bosques. Esta restrição mostrou-se bastante interessante dado o 
volume total dos dados brutos: seis faixas de levantamento com aproximadamente 1.200.000 pontos, cada.

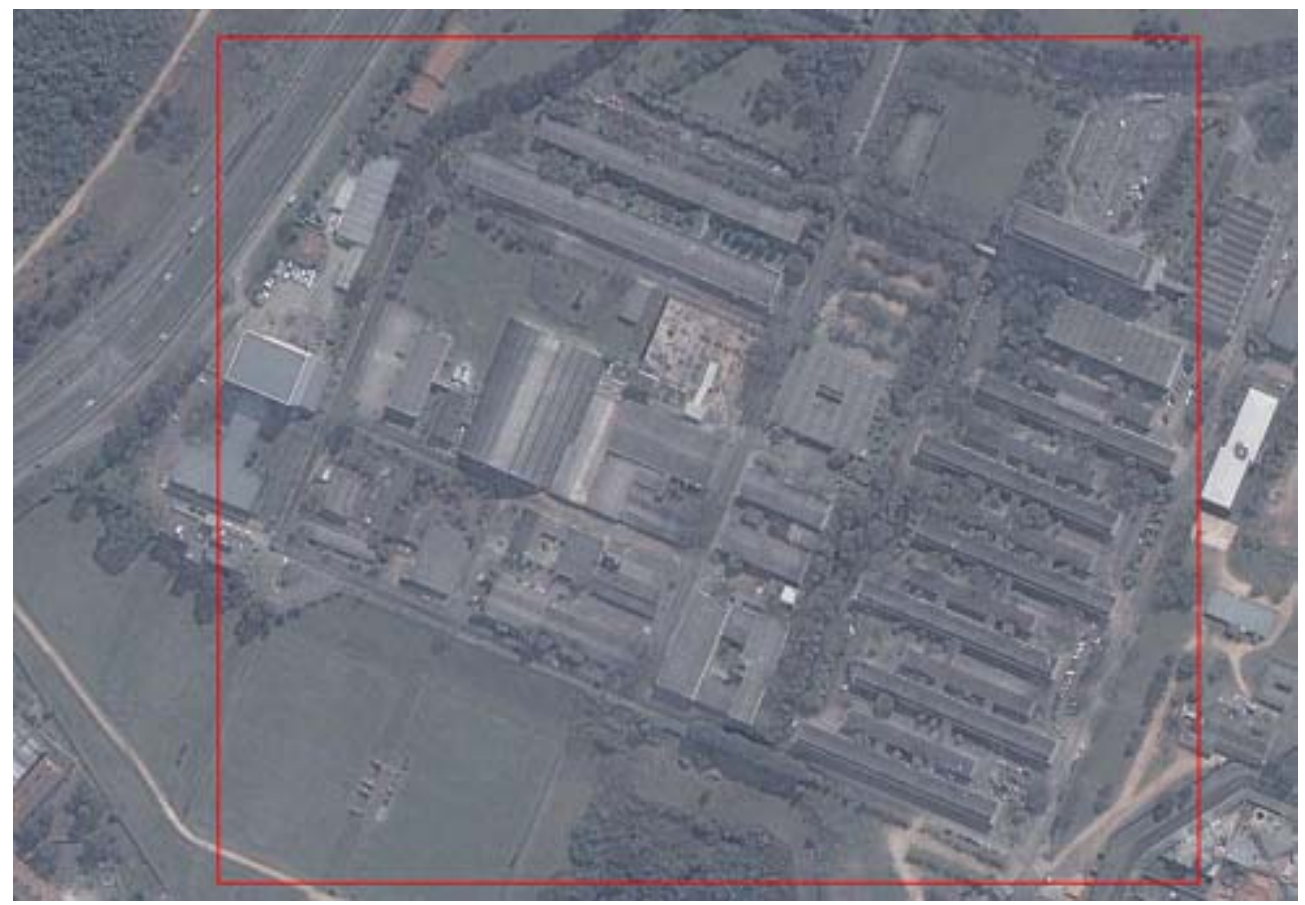

Figura 4.2 - Imagem de satélite da área em estudo (recorte em vermelho). Fonte: Google Maps, 2009

As faixas de interesse foram importadas, como tabelas, para um banco de dados através no programa computacional MS Access. Foi realizada uma consulta com restrições nos campos Este e Norte, utilizando os limites inferiores e superiores da área de interesse (Tabela 4.2). Dessa consulta resultaram novas tabelas, exportadas em formato ASCII com os campos separados por vírgula. Nesta exportação, desprezou-se o campo refletância, presente nos dados brutos.

Tabela 4.2 - Limites da área de estudo em coordenadas UTM, fuso 22, SAD-69.

\begin{tabular}{|c|c|c|}
\hline Limites & Este $(\mathrm{m})$ & Norte $(\mathrm{m})$ \\
\hline Inferior & 677.290 & 7.183 .710 \\
\hline Superior & 677.870 & 7.184 .260 \\
\hline
\end{tabular}




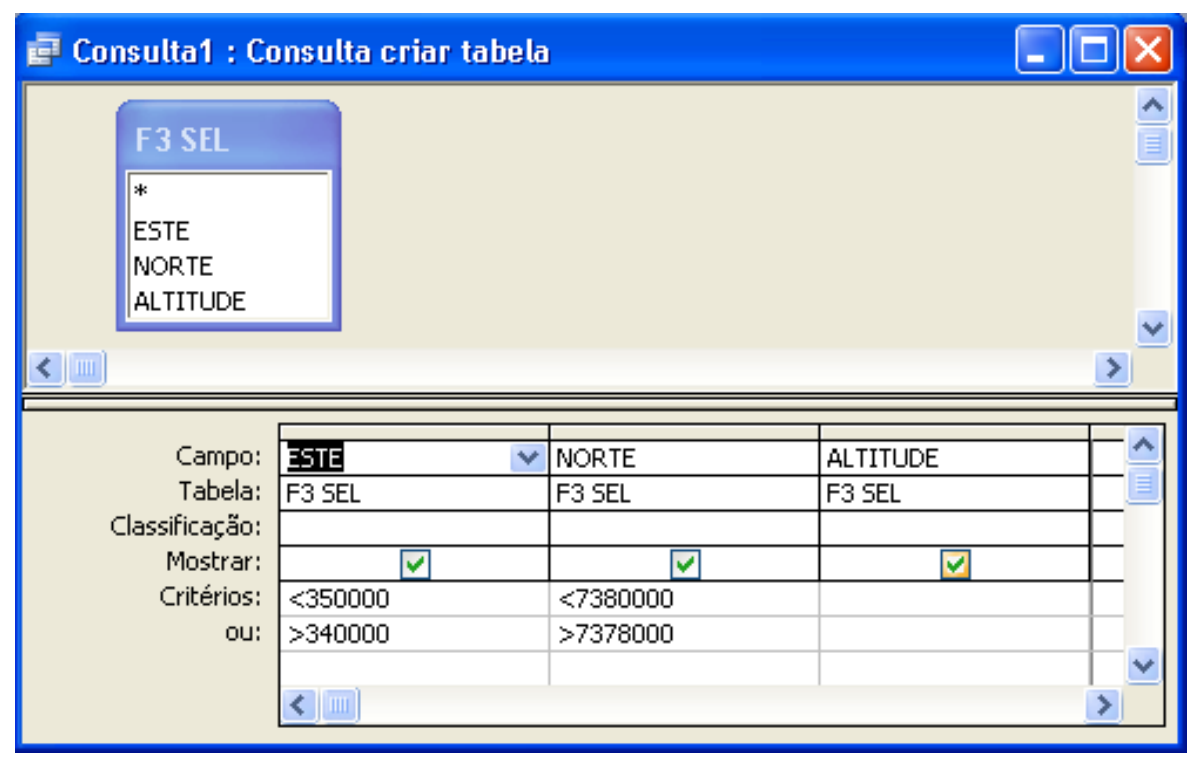

Figura 4.3 - Exemplo de consulta com as restrições utilizadas na delimitação de áreas.

Os arquivos em formato ASCII, com os dados de cada faixa foram processados a fim de gerar uma rotina de importação para o programa de computação gráfica Autocad. Este processamento pode ser executado em processadores de textos com recursos de procura e substituição, como o MS Word, utilizado nessa tarefa. Trata-se de incluir entre as coordenadas os comandos, necessários ao desenho (Figura 4.4). A exibição em plataforma gráfica facilita a análise dos dados e geração dos MDS.

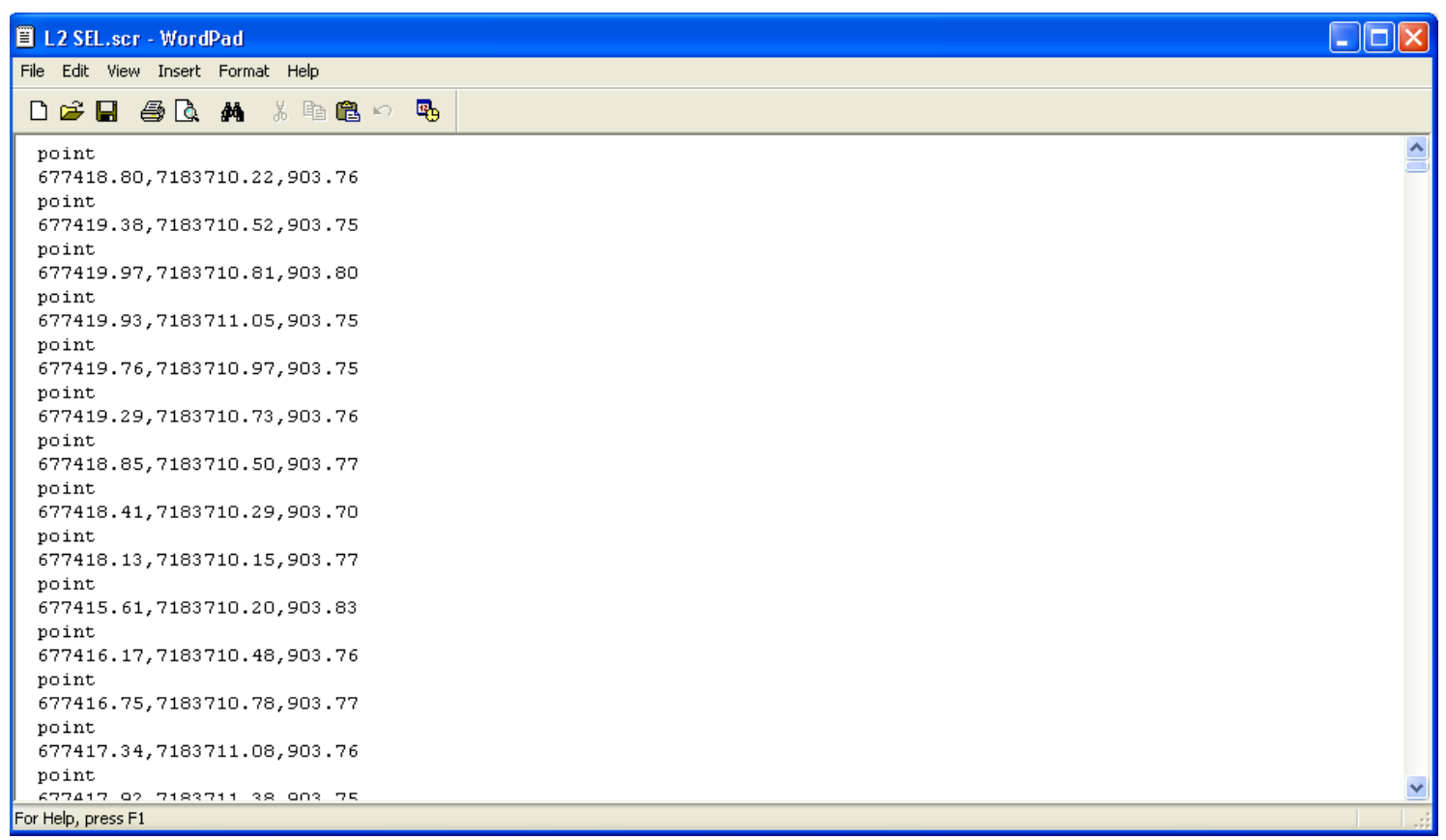

Figura 4.4 - Exemplo de criação de arquivo Script para importação no Autocad. 


\subsection{Geração do MDS e coleta de pontos de controle planimétrico}

Após a importação, foram gerados modelos digitais de superfície (MDS) para cada faixa em estudo. Utilizou-se a versão educacional do módulo Land Desktop 2000i que trabalha sobre o Autocad, para modelagem de superfícies. Os MDS foram construídos pelo método da triangulação de Delaunay, dada a distribuição dos pontos levantados. Na figura 4.5 apresenta-se uma tela desse programa com a triangulação gerada aparecendo ao fundo e parâmetros estatísticos na tela superposta.

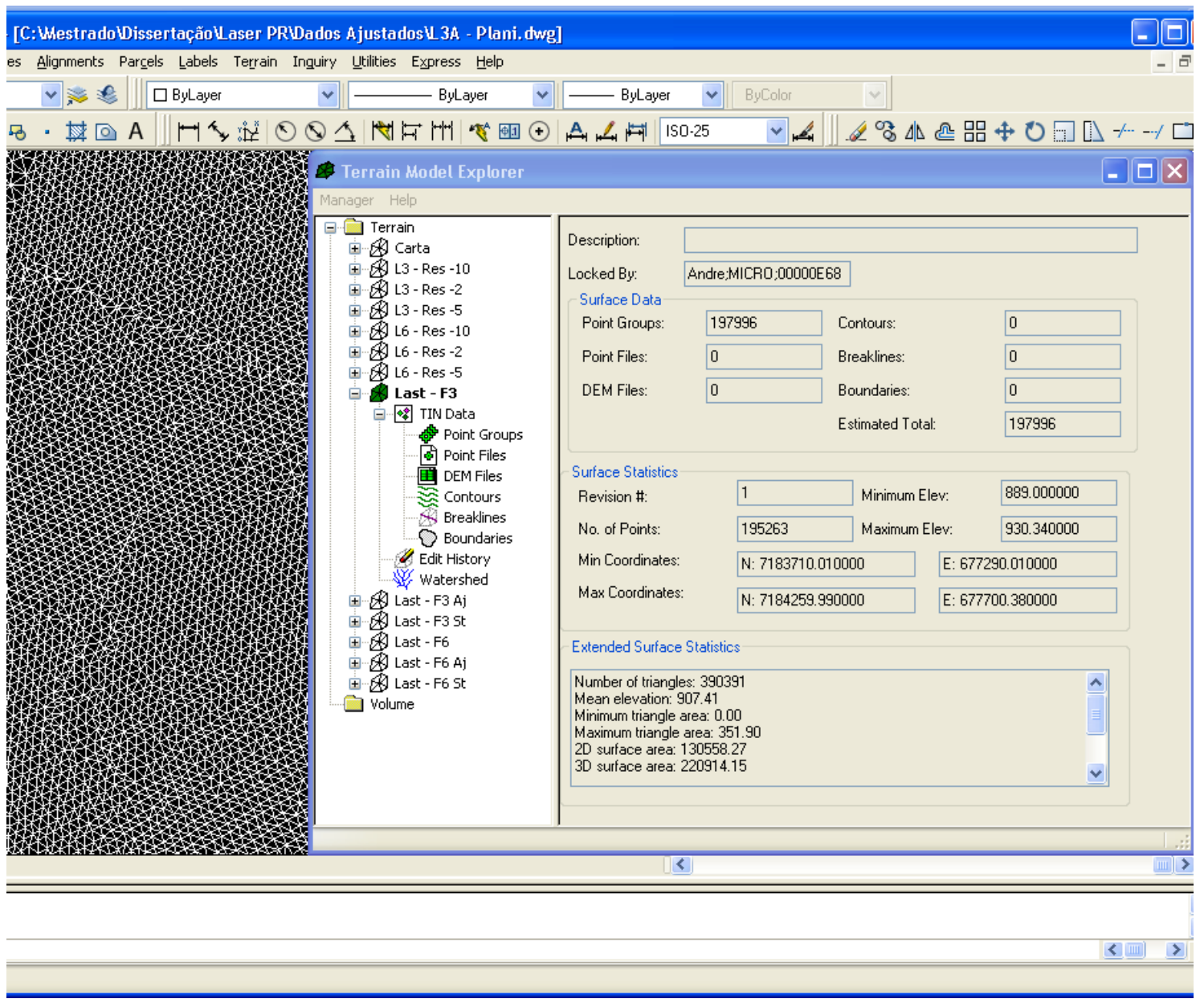

Figura 4.5 - Tela do módulo Land Desktop, utilizado para modelagem de superfícies.

Através desse mesmo programa, foram calculadas as declividades de todos os triângulos de cada MDS (faixa 3 e faixa 6 do levantamento). Dentre os resultados, foram selecionados todos os triângulos com declividade superior a $80^{\circ}$. Estes 
triângulos identificam variações abruptas de declividade e delimitam elementos nãopertencentes ao terreno em sentido estrito, como edificações e árvores.

Como a planta proveniente da restituição não continha a elevação das edificações, esses pontos não puderam servir como controle altimétrico. Uma opção seria a ida a campo com GPS para levantamento desses pontos em vértices de coberturas planas, quando possível. Mas preferiu-se verificar outras possibilidades que evitassem trabalhos adicionais de campo e assim, os pontos de controle altimétrico foram definidos de outra maneira, como será relatado mais adiante.

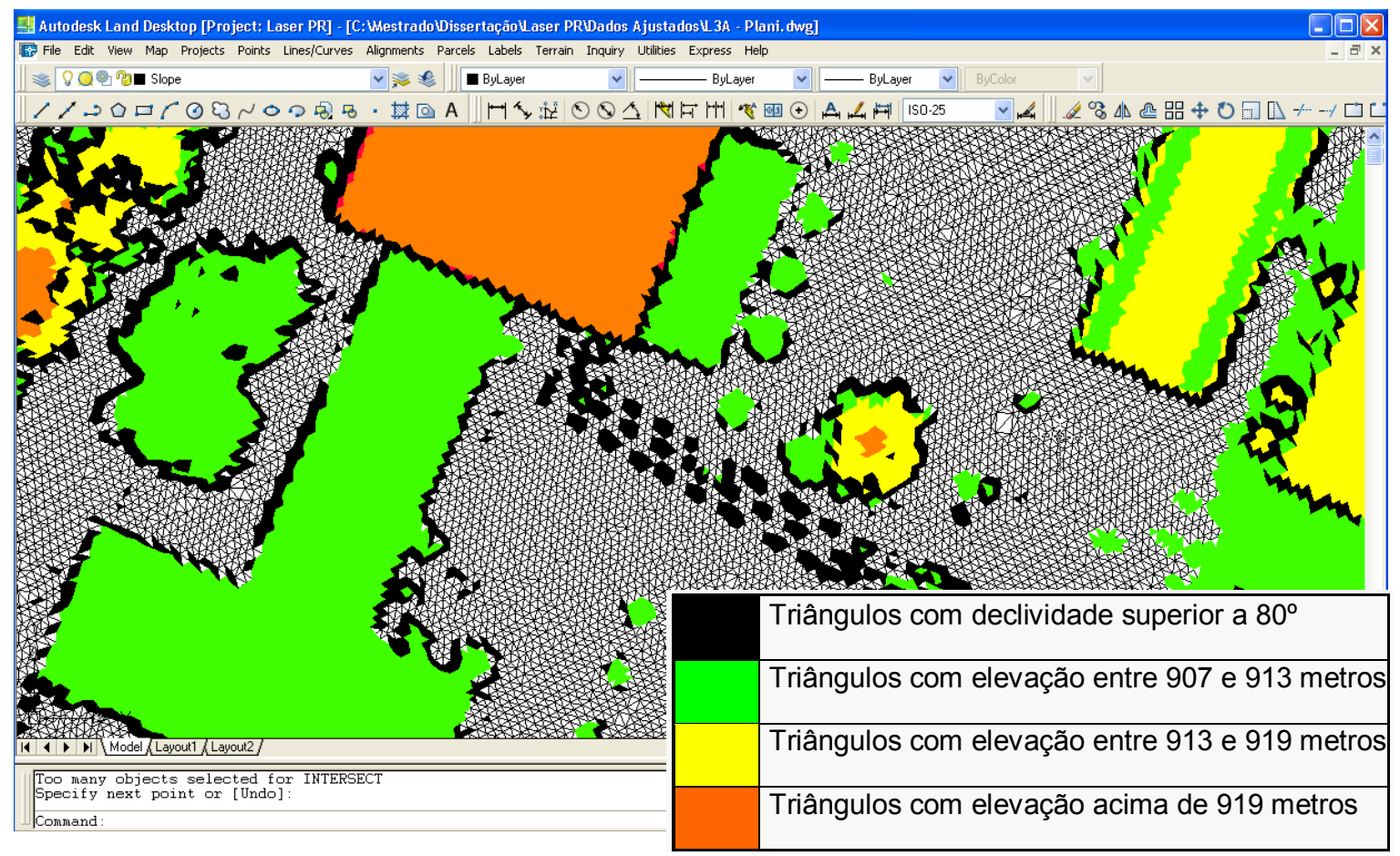

Figura 4.6 - Representação de declividades superiores a $80^{\circ}$ e classes hipsométricas.

Os vértices de edificações, utilizados como pontos de controle planimétrico, foram determinados vetorizando-se as arestas identificadas através de segmentação de declividades altas, superiores a $80^{\circ}$. Para facilitar a identificação dos vértices de edificações, além da delimitação das declividades superiores à $80^{\circ}$ (os triângulos foram pintados de preto), foi elaborado um mapa hipsométrico com classes estratégicas (figura 4.6). Podem se identificar diversos telhados planos, identificados por zonas retangulares de uma única cor e em alturas crescentes, além de árvores isoladas.

As arestas das edificações foram vetorizadas manualmente e através do algoritmo de ajuste linear, desenvolvido para o trabalho. Foram coletados dois conjuntos distintos de pontos de controle, um através da vetorização manual e outro 
através da vetorização semi-automática, no intuito de avaliar a eficácia desses dois processos, comparados como o documento cartográfico de referência. Para facilitar a análise só foram considerados vértices que puderam ser obtidos pelos dois métodos de vetorização e se utilizou a mesma nomenclatura para os dois conjuntos de dados.

Foram coletados 145 pontos de controle planimétrico, sobre a área de interesse (Figura 4.7). Destes, 56 pertencem à faixa 3 e 108 à faixa 6 . Alguns pontos coletados nas duas faixas. Para evitar indução do operador na coleta dos pontos, os mesmos foram coletados sem a exibição da restituição fotogramétrica, usada como documento de referência.

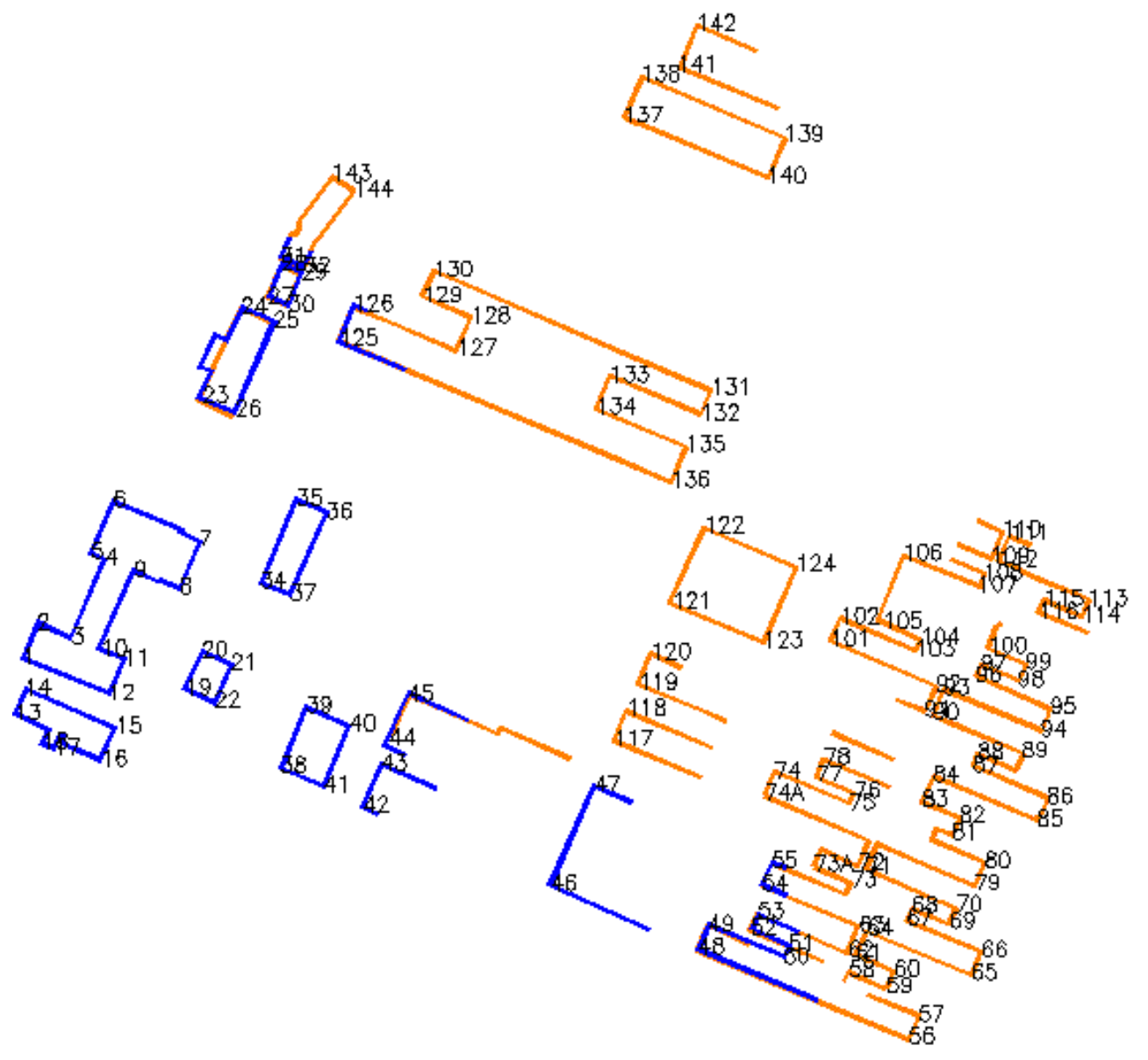

Figura 4.7 - Pontos de controle planimétrico. Vetores em azul pertencem a edificações levantadas na faixa 3. Em laranja pertencem a edificações levantadas na faixa 6 . Ambas foram coletados manualmente. 


\subsection{Detecção e eliminação de erros grosseiros na planimetria, sobre o conjunto de dados vetorizados manualmente}

Para definir os pontos testados em campo preconizados pela norma (mínimo de 20), utilizou-se como referência os pontos da restituição aerofotogramétrica (na escala 1:2.000, cuja região de interesse é apresentada na figura 4.8) que, presumese possuir qualidade cartográfica superior ao levantamento a LASER. Como não foi realizado o controle de qualidade da restituição, para efeito de avaliação da metodologia, esta foi considerada isenta de erros. Os pontos correspondentes aos de controle coletados no levantamento LASER foram identificados, então, na restituição.

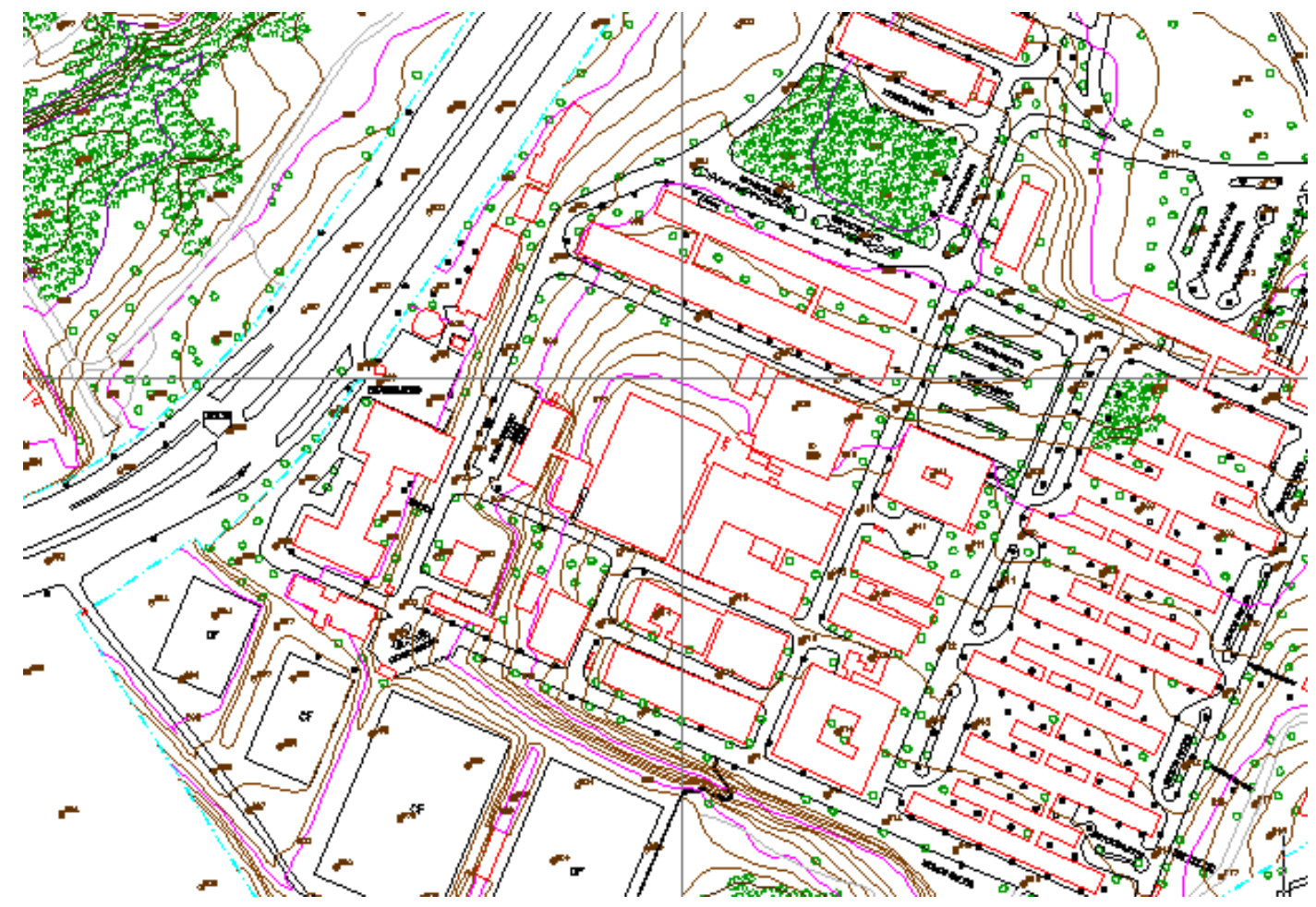

Figura 4.8 - Restituição aerofotogramétrica, utilizada como produto cartográfico de referência.

Foi montada então uma planilha (em Excel) com as discrepâncias nas coordenadas Este $(\Delta \mathrm{E})$ e Norte $(\Delta \mathrm{N})$. Conforme formulário apresentado na metodologia (equações 3.1 e 3.2). 
A partir das estatísticas calculadas sobre as discrepâncias, foram realizados testes para detecção de erros grosseiros. Foram eliminados criteriosamente pontos com erros grosseiros, mediante uma análise prévia dos pontos que estão fora do intervalo definido pela média e três vezes o desvio padrão. Por exemplo, para a faixa 3 , sem eliminar esses pontos os dados apresentam valores de curtose $(7,236)$ e assimetria $(-2,232)$ bastante fora da normalidade estatística. Após eliminá-los, os valores desses parâmetros passaram a ser menores que 0,5 em módulo e, portanto, aceitáveis $(-0,037$ e $-0,146)$. Na coordenada $\mathrm{N}$ da mesma faixa, ocorre algo semelhante, com o descarte dos pontos discrepantes, chega-se a valores aceitáveis de curtose e assimetria (próximos à zero). O mesmo comportamento aparece em outras estatísticas. As figuras a seguir, apresentam as tabelas com estatística descritiva e histograma das discrepâncias (coordenadas E e N), para a faixa 3, antes e após a eliminação dos erros grosseiros, obtidas através da aplicação do programa Excel.

\begin{tabular}{|l|r|}
\hline \multicolumn{2}{|c|}{ Estatística descritiva E } \\
\hline Média & 0.147 \\
\hline Erro padrẫo & 0.073 \\
\hline Mediana & 0.280 \\
\hline Modo & 0.352 \\
\hline Desvio padrão & 0.549 \\
\hline Variância da amostra & 0.301 \\
\hline Curtose & 7.236 \\
\hline Assimetria & -2.232 \\
\hline Intervalo & 3.248 \\
\hline Mínimo & -2.166 \\
\hline Máximo & 1.082 \\
\hline Soma & 8.225 \\
\hline Contagem & 56.000 \\
\hline
\end{tabular}

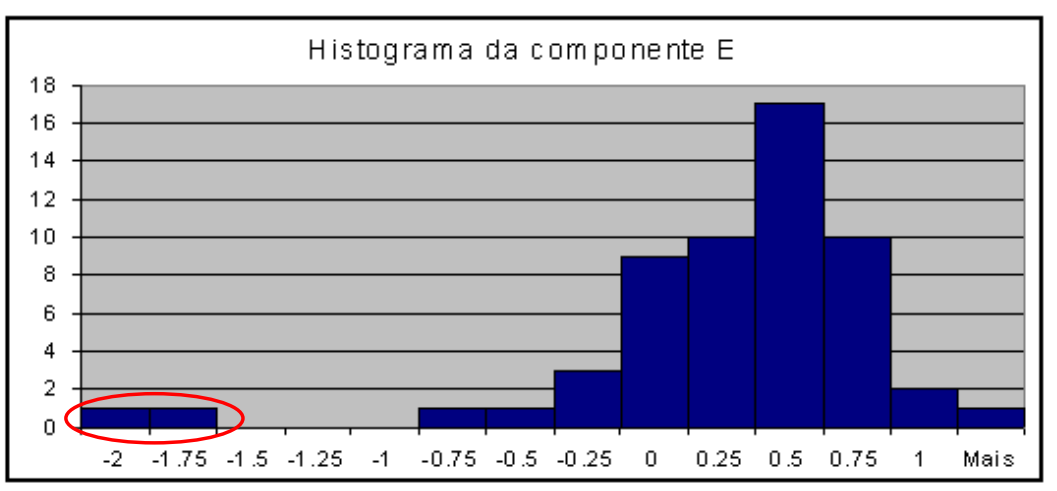

\begin{tabular}{|l|r|}
\hline \multicolumn{2}{|c|}{ Estatística descritiva N } \\
\hline Média & 2.606 \\
\hline Erro padrẫo & 0.077 \\
\hline Mediana & 2.734 \\
\hline Modo & \#N/D \\
\hline Desvio padrẫo & 0.577 \\
\hline Variância da amostra & 0.333 \\
\hline Curtose & 10.445 \\
\hline Assimetria & -2.481 \\
\hline Intervalo & 3.651 \\
\hline Mínimo & -0.267 \\
\hline Máximo & 3.384 \\
\hline Soma & 145.941 \\
\hline Contagem & 56.000 \\
\hline
\end{tabular}

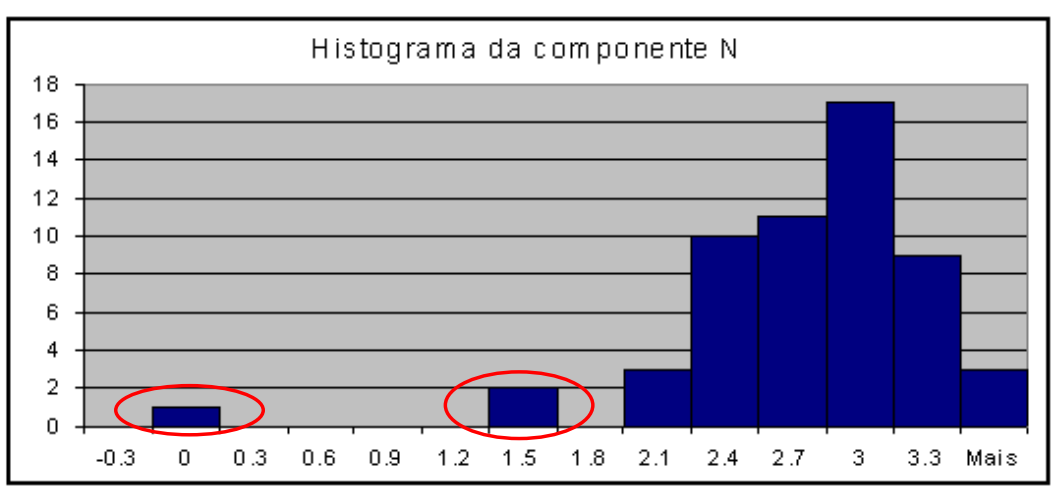

Figura 4.9 - Estatísticas descritivas e histogramas das componentes E e N, da faixa 3, antes da eliminação de erros grosseiros (destacados em vermelho), valores em metros. 


\begin{tabular}{|l|r|}
\hline \multicolumn{2}{|c|}{ Estatística descritiva E } \\
\hline Média & 0.250 \\
\hline Erro padrão & 0.047 \\
\hline Mediana & 0.291 \\
\hline Modo & 0.352 \\
\hline Desvio padrẫo & 0.336 \\
\hline Variância da amostra & 0.113 \\
\hline Curtose & -0.037 \\
\hline Assimetria & -0.146 \\
\hline Intervalo & 1.627 \\
\hline Mínimo & -0.545 \\
\hline Máximo & 1.082 \\
\hline Soma & 12.755 \\
\hline Contagem & 51.000 \\
\hline
\end{tabular}

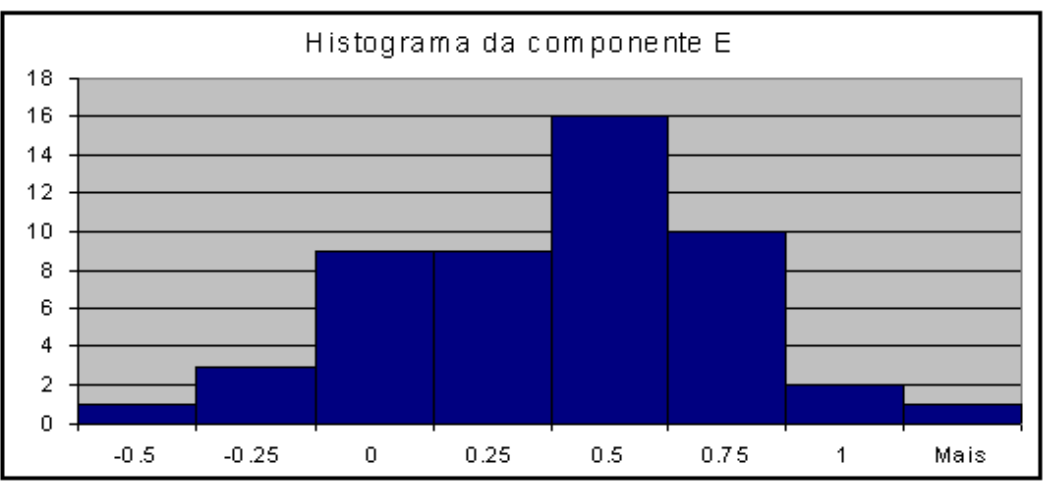

\begin{tabular}{|l|r|}
\hline \multicolumn{2}{|c|}{ Estatística descritiva N } \\
\hline Média & 2.701 \\
\hline Erro padrã̃o & 0.049 \\
\hline Mediana & \multicolumn{1}{c|}{2.740} \\
\hline Modo & \#N/ D \\
\hline Desvio padrẫo & 0.347 \\
\hline Variância da amostra & 0.120 \\
\hline Curtose & -0.672 \\
\hline Assimetria & -0.155 \\
\hline Intervalo & 1.352 \\
\hline Mínimo & 1.999 \\
\hline Máximo & 3.351 \\
\hline Soma & 137.738 \\
\hline Contagem & 51.000 \\
\hline
\end{tabular}

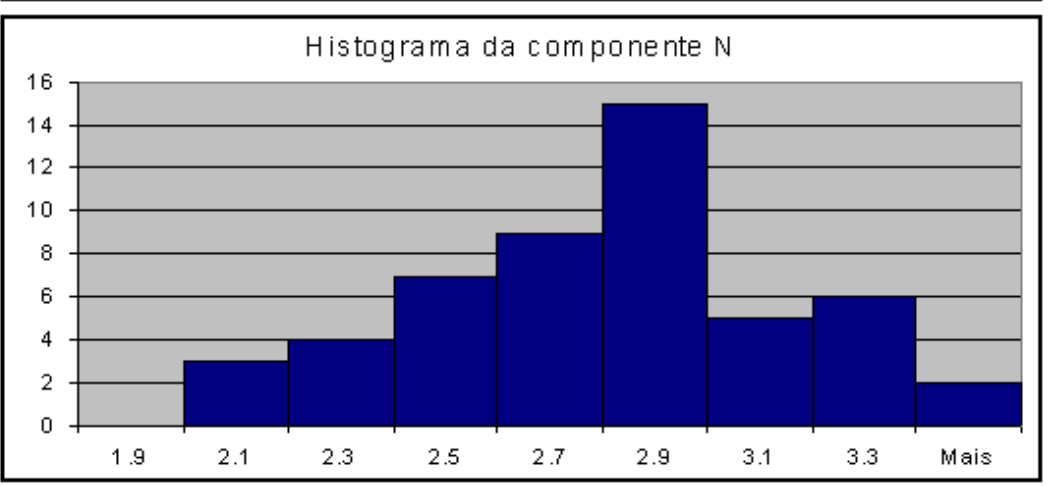

Figura 4.10 - Estatísticas descritivas e histogramas das componentes E e N, da faixa 3, após a eliminação de erros grosseiros, valores em metros.

Percebe-se ainda, uma relativa melhora (cerca de $23 \mathrm{~cm}$ ) OK no desvio padrão com a eliminação dos pontos discrepantes em ambos os eixos. O mesmo acontece com as amostras da faixa 6 . Isso influi diretamente nas avaliações de qualidade cartográfica que serão apresentados a seguir.

\subsection{Testes de tendência e minimização de erros sistemáticos na planimetria, sobre o conjunto de dados vetorizados manualmente}

Foram realizados testes de tendências com os conjuntos de amostras, através das equações apresentadas na metodologia (3.4 e 3.5), gerando os seguintes resultados: 
Para a faixa $3, t_{n-1, \alpha}=1,676$ (tabelado) e:

$t_{E}=\frac{\overline{\Delta E} \cdot \sqrt{n}}{S_{E}}=\frac{0,250 \cdot \sqrt{51}}{0,336}=5,318$

$t_{E}=5,318>1,676$, rejeita-se $\mathrm{HO}$ e a amostra apresenta tendências na coordenada Este.

$t_{N}=\frac{\overline{\Delta N} \cdot \sqrt{n}}{S_{N}}=\frac{2,701 \cdot \sqrt{51}}{0,347}=55,572$

$t_{N}=55,572>1,676$, rejeita-se $\mathrm{H} 0$ e a amostra apresenta tendências também na coordenada Norte.

Para faixa $6, t_{n-1, \alpha}=1,659$ (tabelado) e:

$t_{E}=\frac{\overline{\Delta E} \cdot \sqrt{n}}{S_{E}}=\frac{0,149 \cdot \sqrt{104}}{0,427}=3,558$

Como $t_{E}=3,558>1,659$, a amostra apresenta tendência na coordenada Este.

$t_{N}=\frac{\overline{\Delta N} \cdot \sqrt{n}}{S_{N}}=\frac{2,231 \cdot \sqrt{104}}{0,385}=59,090$

Como $t_{N}=59,090>1,659$, a amostra apresenta tendência na coordenada Norte.

Comprovada a existência de tendência em ambos os eixos, foi possível a minimização desses erros sistemáticos, subtraindo a média das discrepâncias das observações. As figuras 4.10 e 4.11 apresentam tabelas com a estatística descritiva e histograma após esta operação, para as faixas 3 e 6 , respectivamente. 


\begin{tabular}{|l|r|}
\hline \multicolumn{2}{|c|}{ Estatística descritiva E } \\
\hline Média & 0.000 \\
\hline Erro padrão & 0.047 \\
\hline Mediana & 0.041 \\
\hline Modo & 0.102 \\
\hline Desvio padrão & 0.336 \\
\hline Variância da amostra & 0.113 \\
\hline Curtose & -0.037 \\
\hline Assimetria & -0.146 \\
\hline Intervalo & 1.627 \\
\hline Mínimo & -0.795 \\
\hline Máximo & 0.832 \\
\hline Soma & 0.000 \\
\hline Contagem & 51.000 \\
\hline \hline
\end{tabular}

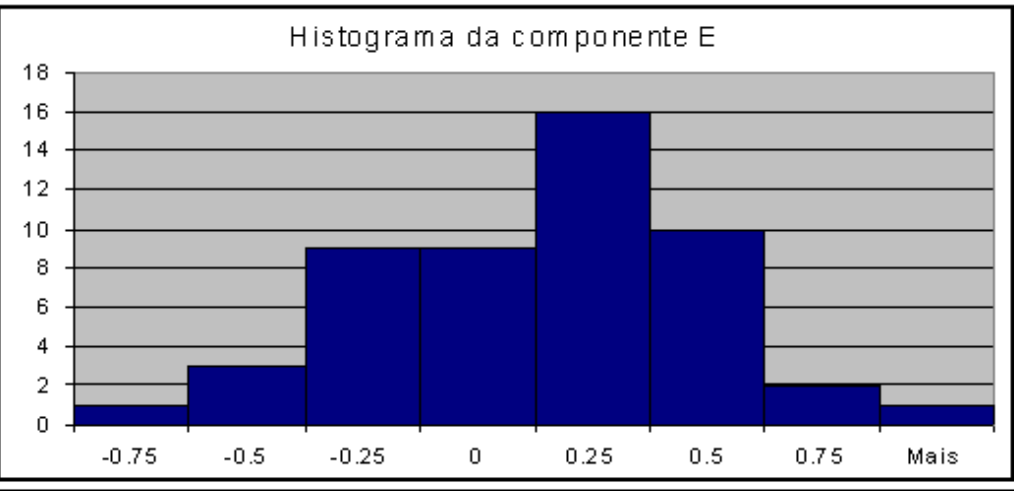

\begin{tabular}{|l|r|}
\hline \multicolumn{2}{|c|}{ Estatística descritiva N } \\
\hline Média & 0.000 \\
\hline Erro padrẫo & 0.049 \\
\hline Mediana & 0.039 \\
\hline Modo & \#N/D \\
\hline Desvio padrẫo & 0.347 \\
\hline Variância da amostra & 0.120 \\
\hline Curtose & -0.672 \\
\hline Assimetria & -0.155 \\
\hline Intervalo & 1.352 \\
\hline Mínimo & -0.702 \\
\hline Máximo & 0.650 \\
\hline Soma & 0.000 \\
\hline Contagem & 51.000 \\
\hline
\end{tabular}

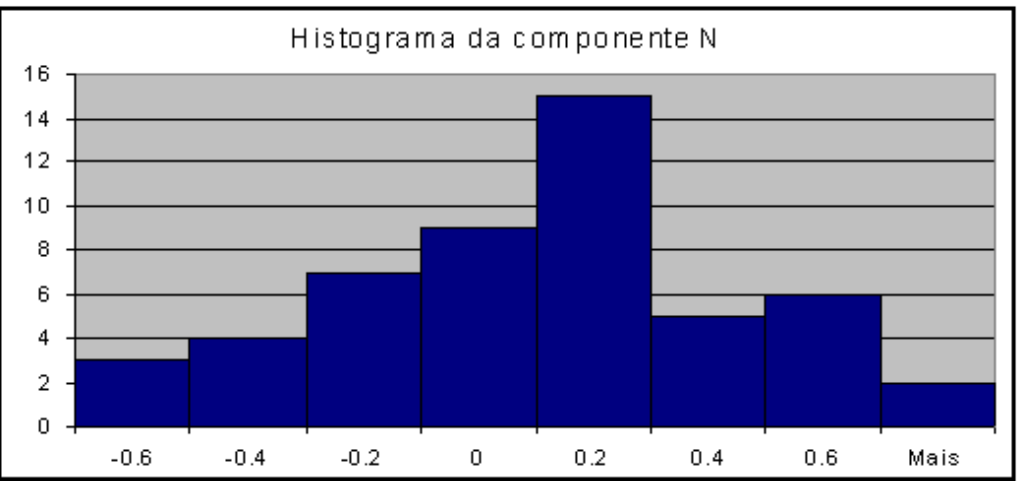

Figura 4.10 - Estatísticas descritivas e histogramas, da faixa 3, após a eliminação de erros grosseiros e sistemáticos, valores em metros.

\begin{tabular}{|l|r|}
\hline \multicolumn{2}{|c|}{ Estatística descritiva E } \\
\hline Média & 0.000 \\
\hline Erro padrã̃o & 0.040 \\
\hline Mediana & -0.048 \\
\hline Modo & -0.065 \\
\hline Desvio padrẫo & 0.408 \\
\hline Variância da amostra & 0.166 \\
\hline Curtose & -0.054 \\
\hline Assimetria & 0.388 \\
\hline Intervalo & 2.041 \\
\hline Mínimo & -0.863 \\
\hline Máximo & 1.178 \\
\hline Soma & 0.000 \\
\hline Contagem & 103.000 \\
\hline \hline
\end{tabular}

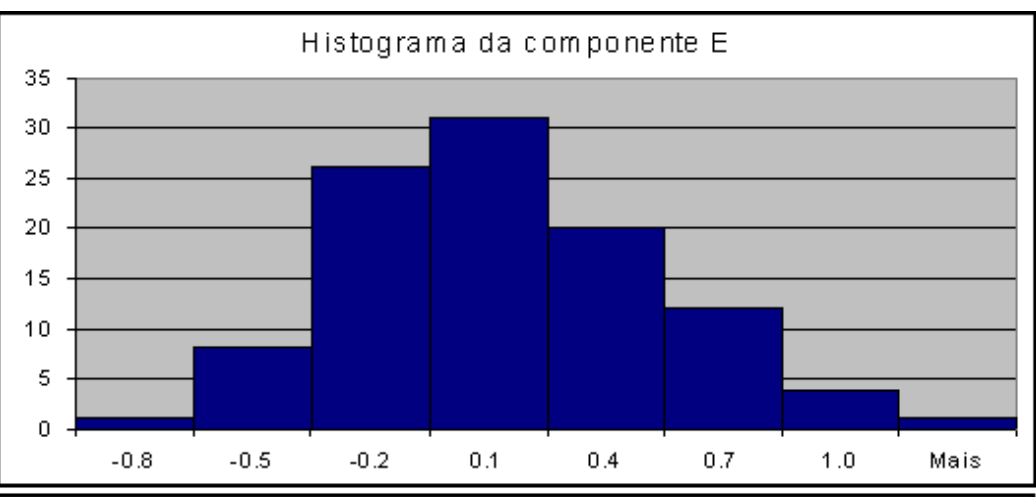

\begin{tabular}{|l|r|}
\hline \multicolumn{2}{|c|}{ Estatística descritiva $\mathbf{N}$} \\
\hline Média & 0.000 \\
\hline Erro padrã̃o & 0.038 \\
\hline Mediana & 0.001 \\
\hline Modo & -0.425 \\
\hline Desvio padrẫo & 0.386 \\
\hline Variância da amostra & 0.149 \\
\hline Curtose & -0.058 \\
\hline Assimetria & -0.241 \\
\hline Intervalo & 2.006 \\
\hline Mínimo & -1.152 \\
\hline Máximo & 0.854 \\
\hline Soma & 0.000 \\
\hline Contagem & 103.000 \\
\hline
\end{tabular}

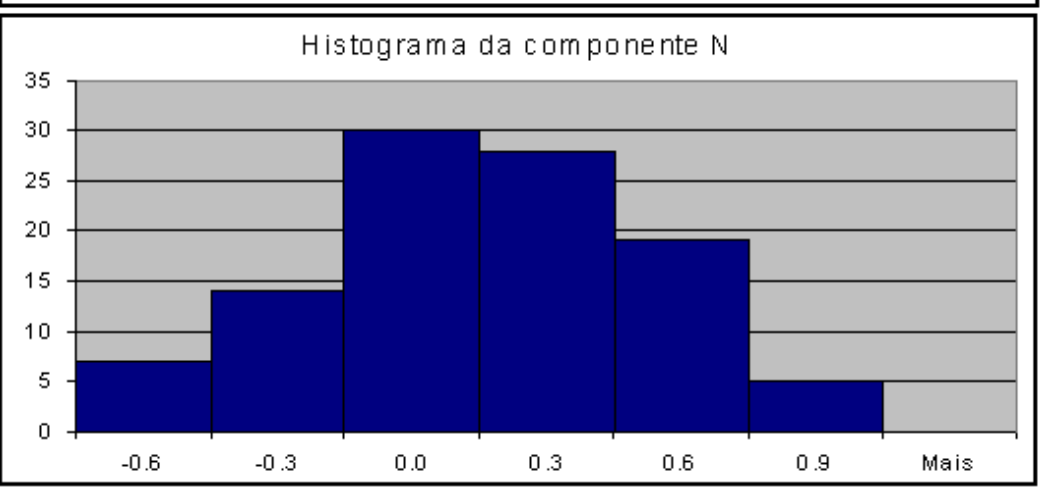

Figura 4.10 - Estatísticas descritivas e histogramas, da faixa 6, após a eliminação de erros grosseiros e sistemáticos, valores em metros.

Após eliminar os erros sistemáticos, observa-se que a média das discrepâncias torna-se zero (pela própria definição da operação realizada). 
4.6. Teste de precisão (padrão americano) e satisfação ao PEC (padrão brasileiro) sobre o conjunto de dados vetorizados manualmente

A partir das amostras tratadas estatisticamente, foram realizados os testes de qualidade cartográfica, segundo os padrões americano e brasileiro, conforme metodologia apresentada no capítulo anterior.

Para ilustrar a melhora na qualidade após tratamento estatístico, são apresentados resultados da satisfação à norma cartográfica, antes e após eliminação de erros grosseiros e sistemáticos.

Primeiramente, foi realizado o teste de precisão, cujos resultados são apresentados nas tabelas 4.3 e 4.4 .

Tabela 4.3 - Teste de precisão, baseado no EPP, para a faixa 3

\begin{tabular}{|c|c|c|c|c|c|c|c|c|c|c|c|c|}
\hline \multirow[t]{2}{*}{ Classe } & \multirow[t]{2}{*}{$\begin{array}{l}\text { EP } \\
(\mathrm{mm})\end{array}$} & \multirow[t]{2}{*}{$\begin{array}{c}\text { Escala } \\
1 /\end{array}$} & \multicolumn{5}{|c|}{ Dados brutos $-\chi_{\mathrm{tab}}^{2}=69,898$} & \multicolumn{5}{|c|}{$\begin{array}{l}\text { Livre de erros grosseiros e } \\
\text { sistemáticos }-\chi_{\text {tab }}=63,168\end{array}$} \\
\hline & & & $\chi^{2}$ & $\chi^{2}>\chi_{\mathrm{ta}}^{2}$ & $\chi_{N}^{2}$ & $\chi^{2}>\chi_{\text {ta }}^{2}$ & Final & $\chi^{2}$ & $\chi^{2}>\chi_{t}^{2}$ & $\chi_{N}^{2}$ & $\chi^{2}>\chi^{2}$ & Final \\
\hline \multirow{3}{*}{ A } & \multirow{3}{*}{0,3} & 1.000 & 183,9 & $\mathrm{~N}$ & 203,6 & $\mathrm{~N}$ & não & 62,66 & $S$ & 66,92 & $\mathrm{~N}$ & não \\
\hline & & 2.000 & 45,99 & $S$ & 50,90 & $S$ & sim & 15,66 & $S$ & 16,73 & $S$ & sim \\
\hline & & 5.000 & 7,36 & $S$ & 8,14 & $S$ & sim & 2,51 & $S$ & 2,68 & $S$ & sim \\
\hline \multirow{3}{*}{ B } & \multirow{3}{*}{0,5} & \begin{tabular}{|l|l}
1.000 \\
\end{tabular} & 66,22 & S & 73,30 & $\mathrm{~N}$ & não & 22,56 & $S$ & 24,09 & $S$ & sim \\
\hline & & 2.000 & 16,56 & $S$ & 18,32 & $S$ & sim & 5,64 & $S$ & 6,02 & $S$ & sim \\
\hline & & 5.000 & 2,65 & $\mathrm{~S}$ & 2,93 & $S$ & sim & 0,90 & $S$ & 0,96 & $S$ & sim \\
\hline \multirow{3}{*}{ C } & \multirow{3}{*}{0,8} & 1.000 & 25,87 & $S$ & 28,63 & $S$ & $\operatorname{sim}$ & 8,81 & $S$ & 9,41 & $\mathrm{~S}$ & $\operatorname{sim}$ \\
\hline & & 2.000 & 6,47 & $S$ & 7,16 & $S$ & $\operatorname{sim}$ & 2,20 & $S$ & 2,35 & $S$ & $\operatorname{sim}$ \\
\hline & & 5.000 & 1,03 & $S$ & 1,15 & $S$ & $\operatorname{sim}$ & 0,35 & $S$ & 0,38 & $S$ & $\operatorname{sim}$ \\
\hline
\end{tabular}


Tabela 4.4 - Teste de precisão, baseado no EPP, para a faixa 6

\begin{tabular}{|c|c|c|c|c|c|c|c|c|c|c|c|c|}
\hline \multirow[t]{2}{*}{ Classe } & \multirow[t]{2}{*}{$\begin{array}{l}\mathrm{EP} \\
(\mathrm{mm})\end{array}$} & \multirow[t]{2}{*}{$\begin{array}{c}\text { Escala } \\
1 /\end{array}$} & \multicolumn{5}{|c|}{ Dados brutos $-\chi_{\mathrm{tab}}^{2}=126,127$} & \multicolumn{5}{|c|}{$\begin{array}{l}\text { Livre de erros grosseiros e } \\
\text { sistemáticos }-\chi_{\text {tab }}=120,681\end{array}$} \\
\hline & & & $\chi^{2}$ & $\chi^{2}>\chi_{t}^{2}$ & $\chi^{2} \mathrm{~N}$ & $\chi^{2}>\chi_{t}^{2}$ & Final & $\chi^{2}$ & $\chi^{2}>\chi^{2}$ & $\chi_{N}^{2}$ & $\chi^{2}>\chi_{t}^{2}$ & Final \\
\hline \multirow{3}{*}{ A } & \multirow{3}{*}{0,3} & 1.000 & 408,0 & $\mathrm{~N}$ & 285,4 & $\mathrm{~N}$ & não & 188,4 & $\mathrm{~N}$ & 169,0 & $\mathrm{~N}$ & não \\
\hline & & 2.000 & 102,0 & $S$ & 71,36 & $S$ & $\operatorname{sim}$ & 47,10 & $S$ & 42,26 & $S$ & sim \\
\hline & & 5.000 & 16,32 & $S$ & 11,42 & $S$ & $\operatorname{sim}$ & 7,54 & $S$ & 6,76 & $S$ & sim \\
\hline \multirow{3}{*}{ B } & \multirow{3}{*}{0,5} & 1.000 & 146,9 & $\mathrm{~N}$ & 102,8 & $S$ & não & 67,82 & $S$ & 60,85 & $S$ & $\operatorname{sim}$ \\
\hline & & 2.000 & 36,72 & $S$ & 25,69 & $S$ & $\operatorname{sim}$ & 16,95 & $S$ & 15,21 & $S$ & sim \\
\hline & & 5.000 & 5,88 & $S$ & 4,11 & $S$ & $\operatorname{sim}$ & 2,71 & $S$ & 2,43 & $S$ & sim \\
\hline \multirow{3}{*}{ C } & \multirow{3}{*}{0,8} & 1.000 & 57,38 & $S$ & 40,14 & $S$ & $\operatorname{sim}$ & 26,49 & $S$ & 23,77 & $S$ & sim \\
\hline & & 2.000 & 14,34 & $S$ & 10,04 & S & $\operatorname{sim}$ & 6,62 & $S$ & 5,94 & $S$ & sim \\
\hline & & 5.000 & 2,30 & $S$ & 1,61 & S & $\operatorname{sim}$ & 1,06 & $\mathrm{~S}$ & 0,95 & $S$ & sim \\
\hline
\end{tabular}

Nessas duas tabelas calculam-se para diversas classes $(A, B, C)$ e escalas $\left(1: 1.000,1: 2.000\right.$ e 1:5.000) o valor de $\chi^{2}$ para as duas coordenadas e compara-se com o valor tabelado. Caso o valor da tabela seja excedido o produto não passa no teste e o resultado final (não) é expresso em cor vermelha; caso contrário (sim), em cor verde.

Os resultados mostram que os desvios-padrão das amostras atendem às especificações de EPP, compatíveis com a escala 1/2.000, classe A ou escala $1 / 1.000$, classe $\mathrm{C}$ nos dados brutos. Após tratamento estatístico, a qualidade das amostras é compatível com escala $1 / 1.000$, classe $B$, e escala $1 / 2.000$, classe $A$.

Segundo o padrão brasileiro (tabelas 4.5 e 4.6), o produto, antes da eliminação dos erros grosseiros, é reprovado em todas as escalas, menos na 1/5.000, classes B e C, em ambas as faixas. Após o tratamento estatístico, o produto é aprovado para todas as escalas e classes, a menos da classe $A$, na escala 1/1.000, em ambas as faixas. 
Tabela 4.5 - Satisfação ao PEC, faixa 3.

\begin{tabular}{|c|c|c|c|c|c|c|c|c|c|}
\hline \multicolumn{4}{|c|}{ Comparação com o PEC } & \multicolumn{4}{|c|}{ Dados brutos } & \multicolumn{2}{|c|}{$\begin{array}{c}\text { Após eliminação de erros } \\
\text { grosseiros e sistemáticos }\end{array}$} \\
\hline $\begin{array}{c}\text { Escala } \\
1 /\end{array}$ & Classe & \multicolumn{2}{|c|}{ PEC } & $\%$ reprovada & $>10 \% ?$ & $\%$ reprovada & $>10 \% ?$ \\
\cline { 2 - 9 } & & $(\mathrm{mm})$ & $(\mathrm{m})$ & $\mathrm{E}$ & $\mathrm{N}$ & $\mathrm{Ap} / \mathrm{Re}$ & $\mathrm{E}$ & $\mathrm{N}$ & $\mathrm{Ap} / \mathrm{Re}$ \\
\hline \multirow{3}{*}{1.000} & $\mathrm{~A}$ & 0,5 & 0,50 & $30,4 \%$ & $98,0 \%$ & Reprovado & $13,7 \%$ & $17,6 \%$ & Reprovado \\
\cline { 2 - 10 } & $\mathrm{B}$ & 0,8 & 0,80 & $8,9 \%$ & $98,0 \%$ & Reprovado & $2,0 \%$ & $0,0 \%$ & Aprovado \\
\cline { 2 - 10 } & $\mathrm{C}$ & 1,0 & 1,00 & $5,4 \%$ & $98,0 \%$ & Reprovado & $0,0 \%$ & $0,0 \%$ & Aprovado \\
\hline \multirow{3}{*}{2.000} & $\mathrm{~A}$ & 0,5 & 1,00 & $5,4 \%$ & $98,0 \%$ & Reprovado & $0,0 \%$ & $0,0 \%$ & Aprovado \\
\cline { 2 - 9 } & $\mathrm{B}$ & 0,8 & 1,60 & $3,6 \%$ & $98,0 \%$ & Reprovado & $0,0 \%$ & $0,0 \%$ & Aprovado \\
\cline { 2 - 9 } & $\mathrm{C}$ & 1,0 & 2,00 & $1,8 \%$ & $96,1 \%$ & Reprovado & $0,0 \%$ & $0,0 \%$ & Aprovado \\
\hline \multirow{3}{*}{5.000} & $\mathrm{~A}$ & 0,5 & 2,50 & $0,0 \%$ & $70,6 \%$ & Reprovado & $0,0 \%$ & $0,0 \%$ & Aprovado \\
\cline { 2 - 9 } & $\mathrm{B}$ & 0,8 & 4,00 & $0,0 \%$ & $0,0 \%$ & Aprovado & $0,0 \%$ & $0,0 \%$ & Aprovado \\
\cline { 2 - 9 } & $\mathrm{C}$ & 1,0 & 5,00 & $0,0 \%$ & $0,0 \%$ & Aprovado & $0,0 \%$ & $0,0 \%$ & Aprovado \\
\hline
\end{tabular}

Tabela 4.6 - Satisfação ao PEC, faixa 6.

\begin{tabular}{|c|c|c|c|c|c|c|c|c|c|}
\hline \multicolumn{3}{|c|}{ Comparação com o PEC } & \multicolumn{4}{|c|}{ Dados brutos } & \multicolumn{3}{c|}{$\begin{array}{c}\text { Após eliminação de erros } \\
\text { grosseiros e sistemáticos }\end{array}$} \\
\hline $\begin{array}{c}\text { Escala } \\
1 /\end{array}$ & \multirow{2}{*}{ Classe } & \multicolumn{2}{|c|}{ PEC } & \multicolumn{2}{c|}{$\%$ reprovada } & $>10 \% ?$ & $\%$ reprovada & $>10 \% ?$ \\
\cline { 2 - 9 } & & $(\mathrm{mm})$ & $(\mathrm{m})$ & $\mathrm{E}$ & $\mathrm{N}$ & $\mathrm{Ap} / \mathrm{Re}$ & $\mathrm{E}$ & $\mathrm{N}$ & $\mathrm{Ap} / \mathrm{Re}$ \\
\hline \multirow{3}{*}{1.000} & $\mathrm{~A}$ & 0,5 & 0,5 & $10,2 \%$ & $46,3 \%$ & Reprovado & $9,7 \%$ & $10,7 \%$ & Reprovado \\
\cline { 2 - 10 } & $\mathrm{B}$ & 0,8 & 0,8 & $4,6 \%$ & $46,3 \%$ & Reprovado & $1,9 \%$ & $1,0 \%$ & Aprovado \\
\cline { 2 - 10 } & $\mathrm{C}$ & 1,0 & 1,0 & $1,9 \%$ & $45,4 \%$ & Reprovado & $0,0 \%$ & $1,0 \%$ & Aprovado \\
\hline \multirow{3}{*}{2.000} & $\mathrm{~A}$ & 0,5 & 1,0 & $1,9 \%$ & $45,4 \%$ & Reprovado & $0,0 \%$ & $1,0 \%$ & Aprovado \\
\cline { 2 - 9 } & $\mathrm{B}$ & 0,8 & 1,6 & $1,9 \%$ & $42,6 \%$ & Reprovado & $0,0 \%$ & $0,0 \%$ & Aprovado \\
\cline { 2 - 9 } & $\mathrm{C}$ & 1,0 & 2,0 & $1,9 \%$ & $28,7 \%$ & Reprovado & $0,0 \%$ & $0,0 \%$ & Aprovado \\
\hline \multirow{3}{*}{5.000} & $\mathrm{~A}$ & 0,5 & 2,5 & $0,0 \%$ & $11,1 \%$ & Reprovado & $0,0 \%$ & $0,0 \%$ & Aprovado \\
\cline { 2 - 9 } & $\mathrm{B}$ & 0,8 & 4,0 & $0,0 \%$ & $0,0 \%$ & Aprovado & $0,0 \%$ & $0,0 \%$ & Aprovado \\
\cline { 2 - 9 } & $\mathrm{C}$ & 1,0 & 5,0 & $0,0 \%$ & $0,0 \%$ & Aprovado & $0,0 \%$ & $0,0 \%$ & Aprovado \\
\hline
\end{tabular}

Constatou-se que os dois levantamentos obtiveram qualidade compatível com produtos na escala $1 / 5.000$, classe $B$, quando analisados seus dados brutos, eivados de erros grosseiros e sistemáticos. Após a eliminação destes, ambos os levantamentos possuem qualidade cartográfica compatível com a escala 1/1.000, classe B, ou melhor. A expressão ou melhor, quer significar por exemplo 1/2.000, classe A etc. Como sempre é possível eliminar erros sistemáticos (a norma americana por exemplo, já pressupõe isso antes de qualquer análise), esta última posição constitui a avaliação final dos produtos. 
De acordo com os dois padrões, nota-se grande melhora de qualidade com a adoção desta metodologia e, mais ainda, uma coerência de qualidade entre as faixas 3 e 6 . Logicamente, mais testes devem ser conduzidos para a generalização das conclusões.

\subsection{Ajustamento com transformação afim e avaliação da qualidade planimétrica, sobre o conjunto de dados vetorizados manualmente}

Apesar dos bons resultados, foram realizados outros testes na tentativa de minimizar alguns erros, como definição dos vértices de edificações, não contemplados pela simples translação. Para isto utilizou-se uma transformação afim e não o tratamento estatístico para minimização do erro sistemático em $\mathrm{N}$ e E.

O objetivo inicial era realizar uma transformação afim no espaço, porém o produto cartográfico de referência não possuía pontos tridimensionais de fácil identificação no levantamento a LASER. A transformação afim foi considerada então para duas dimensões, visando minimizar os erros planimétricos, corrigindo translações, rotações, escala de eixos e não-ortogonalidade entre eixos. As equações utilizadas no ajustamento foram apresentadas no capítulo de metodologia (equações 3.11 a 3.17 )

Como mencionado na metodologia, foram escolhidos $40 \%$ dos pontos coletados (antes do tratamento estatístico), cuja discrepância mais se aproximava da média das discrepâncias. Assim, na faixa 3 foram utilizados 24 pontos para o modelo e 32 pontos para verificação da qualidade. Na faixa 6, foram utilizados 43 pontos para o modelo e 65 para verificação. O ajustamento foi realizado através de programação no MathCad, programa que provê diversas ferramentas para cálculo matricial e programação de alto nível.

Um desafio foi a construção da matriz das derivadas parciais em função dos coeficientes (A) para uma grande quantidade de equações. Para superá-lo, na aplicação prática, foi desenvolvida uma rotina de construção, para o presente 
trabalho, independente da quantidade de amostras, em ambiente MathCad (Figura 4.12).

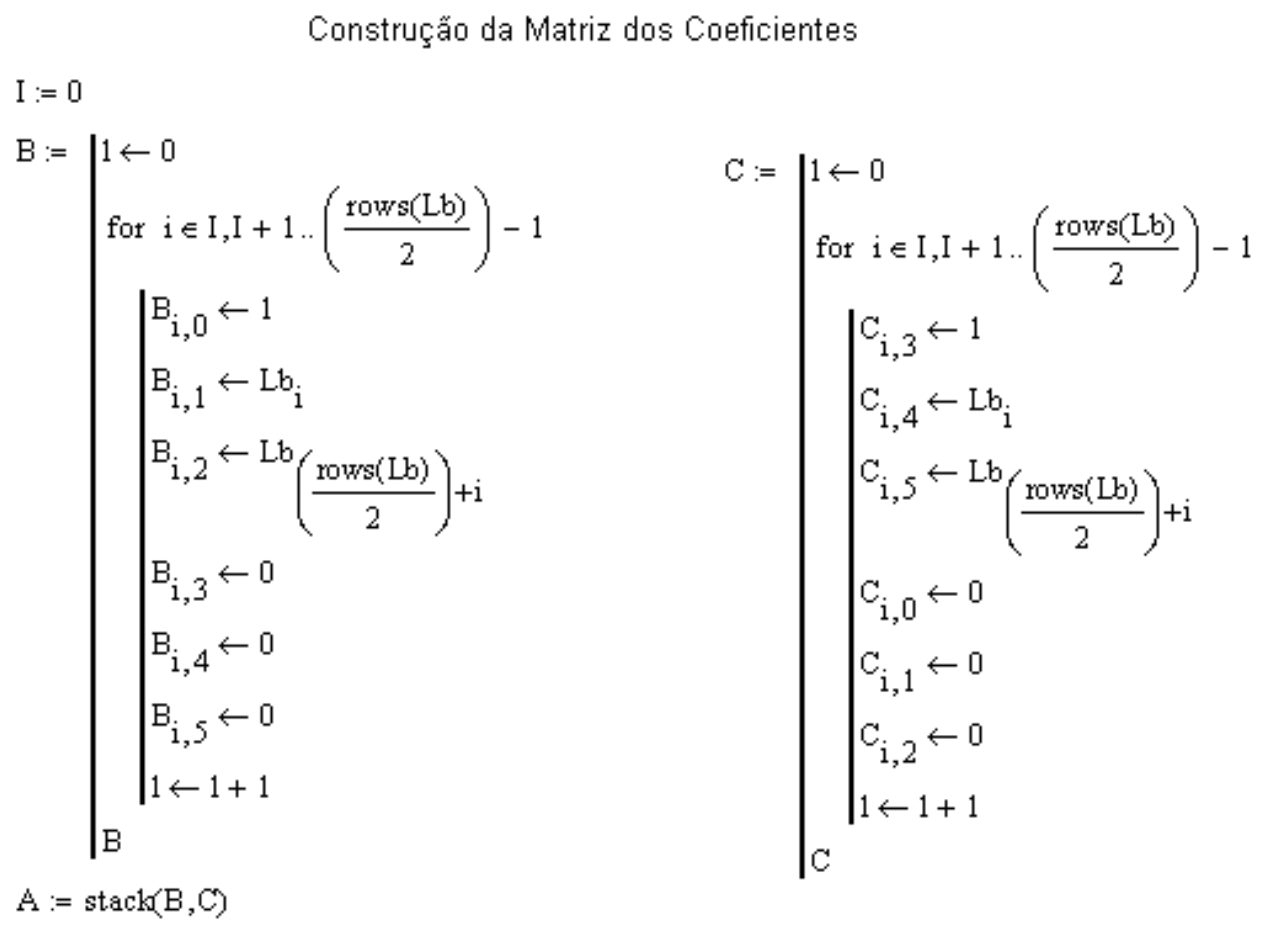

Figura 4.12 - Rotina para construção da matriz A.

O ajustamento das faixas, pela metodologia apresentada, gerou os seguintes resultados:

Tabela 4.7 - Parâmetros ajustados para as faixas 3 e 6, após a convergência dos resultados, em duas iterações.

\begin{tabular}{|c|c|c|}
\hline Coeficientes & Faixa 3 & Faixa 6 \\
\hline A0 & $-5442,03$ & 23138,90 \\
\hline A1 & 0,99982 & 0,996301 \\
\hline A2 & 0,00077 & $-0,002872$ \\
\hline B0 & $-2808,74$ & 4188,20 \\
\hline B1 & $-0,00002$ & $-0,000784$ \\
\hline B2 & 1,00039 & 0,999491 \\
\hline
\end{tabular}

Os parâmetros ajustados foram aplicados nas equações 3.11 e 3.12, para cada ponto de controle planimétrico. Estes resultados foram comparados com as coordenadas da restituição, calculando-se as discrepâncias como indicado nas equações 3.1 e 3.2. Foram calculadas as estatísticas descritivas (Figura 4.13): 
Faixa 3

\begin{tabular}{|c|c|c|c|}
\hline \multicolumn{2}{|c|}{ Estatistica Descritima - E Ajustado } & \multicolumn{2}{|c|}{ Estatistica Descritiva - E Ajustado } \\
\hline Média & -0.023 & Média & -0.018 \\
\hline Erro padrẫo & 0.074 & Erro padrẫo & 0.052 \\
\hline Mediana & 0.082 & Mediana & 0.033 \\
\hline Modo & 剒小 & Modo & 刑/ \\
\hline Desvio padrä́o & 0.553 & Desvio padrẫo & 0.541 \\
\hline Variância da amostra & $\overline{0.3 \square 6}$ & Variância da amostra & 0.293 \\
\hline Curtose & 6.926 & Curtose & 10.386 \\
\hline Assimetria & -2.129 & Assimetria & -0.443 \\
\hline Intervalo & 3.291 & Interwalo & 5.291 \\
\hline Minimo & -2.386 & Minimo & -2.724 \\
\hline Máximo & 0.905 & Máximo & 2.567 \\
\hline Soma & -1.310 & Soma & -1.896 \\
\hline Contagem & 56.0100 & Contagem & 108.0100 \\
\hline \multicolumn{2}{|c|}{ Estatistica Descritima - N Ajustado } & \multicolumn{2}{|c|}{ Estatistica Descritiva - N Ajustado } \\
\hline Média & -0.086 & Média & -0.037 \\
\hline Erro padräo & 0.078 & Erro padrẫo & 0.047 \\
\hline Mediana & 0.030 & Mediana & -0.013 \\
\hline Modo & 㛤/ & Mado & 刑/[C] \\
\hline Desvio padrẫo & 0.581 & Desvio padrẫo & 0.487 \\
\hline Variância da amostra & 0.337 & Variancia da amostra & 0.237 \\
\hline Curtose & 10.538 & Curtose & 4.174 \\
\hline Assimetria & -2.507 & Assimetria & -0.895 \\
\hline Intervalo & 3.671 & Interwalo & 3.794 \\
\hline Mínimo & -2.982 & Minimo & -2.262 \\
\hline Máxima & 0.690 & Máximo & 1.531 \\
\hline Soma & -4.821 & Soma & -4.014 \\
\hline 6 & 56.000 & $\mathrm{C}$ & 108.000 \\
\hline
\end{tabular}

Figura 4.13 - Estatísticas descritivas das componentes Este e Norte, após ajustamento.

Ao se compararem as estatísticas antes e após ajustamento, nota-se que este reduziu a média das discrepâncias, minimizando erros sistemáticos. Porém, não foi eficiente na eliminação de erros grosseiros. As amostras continuam apresentando valores anormais de curtose e assimetria e não houve redução do intervalo e do desvio padrão. Dada a ineficiência da transformação afim na detecção de erros grosseiros, os demais testes foram conduzidos após sua eliminação, utilizando processo descrito anteriormente.

A minimização dos erros sistemáticos pode ser verificada com a realização de testes de tendência. Estes foram executados nas duas faixas, gerando os seguintes resultados: 
Para faixa 3, dados ajustados, $t_{n-1, \alpha}=1,676$ e:

$t_{E}=\left|\frac{\overline{\Delta E} \cdot \sqrt{n}}{S_{E}}\right|=\left|\frac{-0,028 \cdot \sqrt{56}}{0,556}\right|=0,316$

$t_{E}=0,316<1,676$, logo a amostra não apresenta tendências em Este.

$t_{N}=\left|\frac{\overline{\Delta N} \cdot \sqrt{n}}{S_{N}}\right|=\left|\frac{-0,086 \cdot \sqrt{56}}{0,581}\right|=1,109$

$t_{N}=1.109<1,676$, logo a amostra não apresenta tendências em Norte.

Para faixa 6, dados ajustados, $t_{n-1, \alpha}=1,659 \mathrm{e}:$

$t_{E}=\left|\frac{\overline{\Delta E} \cdot \sqrt{n}}{S_{E}}\right|=\left|\frac{-0,018 \cdot \sqrt{108}}{0,541}\right|=0,337$

$t_{E}=0,337<1,659$, logo a amostra não apresenta tendências em Este.

$t_{N}=\left|\frac{\overline{\Delta N} \cdot \sqrt{n}}{S_{N}}\right|=\left|\frac{-0,037 \cdot \sqrt{108}}{0,487}\right|=0,793$

$t_{N}=0,793<1,659$, logo a amostra não apresenta tendências em Norte.

Os resultados do teste confirmam que o ajustamento minimizou os erros sistemáticos existentes nos levantamentos.

Foram realizados também testes de precisão sobre os dados ajustados, resultando nas tabelas 4.8 e 4.9 . 
Tabela 4.8 - Teste de precisão, baseado no EPP, para a faixa 3

\begin{tabular}{|c|c|c|c|c|c|c|c|c|c|c|c|c|}
\hline \multirow[t]{2}{*}{ Classe } & \multirow[t]{2}{*}{$\begin{array}{l}\mathrm{EP} \\
(\mathrm{mm})\end{array}$} & \multirow[t]{2}{*}{$\begin{array}{c}\text { Escala } \\
1 /\end{array}$} & \multicolumn{5}{|c|}{$\begin{array}{l}\text { Antes do ajustamento }-\chi_{\text {tab }}= \\
69,898\end{array}$} & \multicolumn{5}{|c|}{$\begin{array}{c}\text { Após ajustamento }-\chi_{\text {tab }}= \\
69,898\end{array}$} \\
\hline & & & $\chi^{2}$ & $\chi^{2}>\chi^{2}$ & $\chi_{N}^{2}$ & $\chi^{2}>\chi^{2}$ & Final & $\chi_{E}^{2}$ & $\chi^{2}>\chi^{2}$ & $\chi_{N}^{2}$ & $\chi^{2}>\chi^{2}$ & Final \\
\hline \multirow{3}{*}{ A } & \multirow{3}{*}{0,3} & \begin{tabular}{|l|l}
1.000 \\
\end{tabular} & 183,9 & $\mathrm{~N}$ & 203,6 & $\mathrm{~N}$ & não & 187,0 & $\mathrm{~N}$ & 206,0 & $\mathrm{~N}$ & não \\
\hline & & \begin{tabular}{|l|}
2.000 \\
\end{tabular} & 45,99 & $S$ & 50,90 & $S$ & sim & 46,76 & $S$ & 51,51 & $S$ & sim \\
\hline & & 5.000 & 7,36 & $S$ & 8,14 & $S$ & sim & 7,48 & $S$ & 8,24 & $S$ & sim \\
\hline \multirow{3}{*}{ B } & \multirow{3}{*}{0,5} & 1.000 & 66,22 & $S$ & 73,30 & $\mathrm{~N}$ & não & 67,33 & $S$ & 74,18 & $\mathrm{~N}$ & não \\
\hline & & 2.000 & 16,56 & $S$ & \begin{tabular}{|l}
18,32 \\
\end{tabular} & $S$ & sim & 16,83 & $S$ & 18,54 & $\mathrm{~S}$ & sim \\
\hline & & \begin{tabular}{|l|}
5.000 \\
\end{tabular} & 2,65 & $S$ & 2,93 & $S$ & sim & 2,69 & $S$ & 2,97 & $S$ & sim \\
\hline \multirow{3}{*}{ C } & \multirow{3}{*}{0,8} & 1.000 & 25,87 & $S$ & 28,63 & $S$ & sim & 26,30 & $\mathrm{~S}$ & 28,98 & $S$ & sim \\
\hline & & 2.000 & 6,47 & $S$ & 7,16 & $S$ & sim & 6,58 & $S$ & 7,24 & $S$ & sim \\
\hline & & 5.000 & 1,03 & S & 1,15 & S & sim & 1,05 & $S$ & 1,16 & $S$ & $\operatorname{sim}$ \\
\hline
\end{tabular}

Tabela 4.9 - Teste de precisão, baseado no EPP, para a faixa 6

\begin{tabular}{|c|c|c|c|c|c|c|c|c|c|c|c|c|}
\hline \multirow[t]{2}{*}{ Classe } & \multirow[t]{2}{*}{$\begin{array}{c}\mathrm{EP} \\
(\mathrm{mm})\end{array}$} & \multirow[t]{2}{*}{$\begin{array}{c}\text { Escala } \\
1 /\end{array}$} & \multicolumn{5}{|c|}{$\begin{array}{l}\text { Antes do ajustamento }-\chi_{\text {tab }}= \\
126,127\end{array}$} & \multicolumn{5}{|c|}{$\begin{array}{c}\text { Após ajustamento }-\chi_{\text {tab }}= \\
126,127\end{array}$} \\
\hline & & & $\chi_{E}^{2}$ & $\chi^{2}>\chi_{t}^{2}$ & $\chi^{2}{ }_{N}$ & $\chi^{2}>\chi_{t}^{2}$ & Final & $\chi^{2}$ & $\chi^{2}>\chi^{2}$ & $\chi^{2} N$ & $\chi^{2}>\chi^{2}$ & Final \\
\hline \multirow{3}{*}{ A } & \multirow{3}{*}{0,3} & 1.000 & 408,0 & $\mathrm{~N}$ & 285,4 & $\mathrm{~N}$ & não & 348,2 & $\mathrm{~N}$ & 281,8 & $\mathrm{~N}$ & não \\
\hline & & 2.000 & 102,0 & $S$ & 71,36 & $S$ & $\operatorname{sim}$ & 87,04 & $S$ & 70,45 & $S$ & sim \\
\hline & & 5.000 & 16,32 & S & 11,42 & S & $\operatorname{sim}$ & 13,93 & S & 11,27 & S & sim \\
\hline \multirow{3}{*}{ B } & \multirow{3}{*}{0,5} & \begin{tabular}{|l|l}
1.000 \\
\end{tabular} & 146,9 & $\mathrm{~N}$ & 102,8 & $S$ & não & 125,3 & $S$ & 101,4 & $S$ & sim \\
\hline & & 2.000 & 36,72 & $S$ & 25,69 & $S$ & $\operatorname{sim}$ & 31,33 & $S$ & 25,36 & $S$ & sim \\
\hline & & 5.000 & 5,88 & $S$ & 4,11 & $S$ & $\operatorname{sim}$ & 5,01 & $S$ & 4,06 & $S$ & sim \\
\hline \multirow{3}{*}{ C } & \multirow{3}{*}{0,8} & $\mid 1.000$ & 57,38 & $S$ & 40,14 & $S$ & $\operatorname{sim}$ & 48,96 & $S$ & 39,63 & $S$ & sim \\
\hline & & 2.000 & 14,34 & S & 10,04 & S & $\operatorname{sim}$ & 12,24 & $S$ & 9,91 & $S$ & sim \\
\hline & & 5.000 & 2,30 & $\mathrm{~S}$ & 1,61 & $S$ & $\operatorname{sim}$ & 1,96 & $S$ & 1,59 & $S$ & sim \\
\hline
\end{tabular}

Para a aplicação do padrão brasileiro, foi realizado teste de satisfação ao PEC, ponto-a-ponto, para diversas escalas e classes de qualidade, resultando em tabelas (4.10 e 4.11) semelhantes às apresentadas anteriormente. 
Tabela 4.10 - Satisfação ao PEC da faixa 3, antes e após ajustamento.

\begin{tabular}{|c|c|c|c|c|c|c|c|c|c|}
\hline \multicolumn{3}{|c|}{ Comparação com o PEC } & \multicolumn{3}{c|}{ Antes do Ajustamento } & \multicolumn{3}{c|}{ Após Ajustamento } \\
\hline $\begin{array}{c}\text { Escala } \\
1 /\end{array}$ & \multirow{2}{*}{ Classe } & PEC & & $\%$ reprovada & $>10 \% ?$ & $\%$ reprovada & $>10 \% ?$ \\
\cline { 2 - 9 } & & $(\mathrm{mm})$ & $(\mathrm{m})$ & $\mathrm{E}$ & $\mathrm{N}$ & $\mathrm{Ap} / \mathrm{Re}$ & $\mathrm{E}$ & $\mathrm{N}$ & $\mathrm{Ap} / \mathrm{Re}$ \\
\hline \multirow{3}{*}{1.000} & $\mathrm{~A}$ & 0,5 & 0,50 & $30,4 \%$ & $89,3 \%$ & Reprovado & $16,1 \%$ & $16,1 \%$ & Reprovado \\
\cline { 2 - 10 } & $\mathrm{B}$ & 0,8 & 0,80 & $8,9 \%$ & $89,3 \%$ & Reprovado & $7,1 \%$ & $1,8 \%$ & Aprovado \\
\cline { 2 - 10 } & $\mathrm{C}$ & 1,0 & 1,00 & $5,4 \%$ & $89,3 \%$ & Reprovado & $5,4 \%$ & $1,8 \%$ & Aprovado \\
\hline \multirow{3}{*}{2.000} & $\mathrm{~A}$ & 0,5 & 1,00 & $5,4 \%$ & $89,3 \%$ & Reprovado & $5,4 \%$ & $1,8 \%$ & Aprovado \\
\cline { 2 - 10 } & $\mathrm{B}$ & 0,8 & 1,60 & $3,6 \%$ & $89,3 \%$ & Reprovado & $3,6 \%$ & $1,8 \%$ & Aprovado \\
\cline { 2 - 10 } & $\mathrm{C}$ & 1,0 & 2,00 & $1,8 \%$ & $87,5 \%$ & Reprovado & $1,8 \%$ & $1,8 \%$ & Aprovado \\
\hline \multirow{3}{*}{5.000} & $\mathrm{~A}$ & 0,5 & 2,50 & $0,0 \%$ & $64,3 \%$ & Reprovado & $0,0 \%$ & $1,8 \%$ & Aprovado \\
\cline { 2 - 10 } & $\mathrm{B}$ & 0,8 & 4,00 & $0,0 \%$ & $0,0 \%$ & Aprovado & $0,0 \%$ & $0,0 \%$ & Aprovado \\
\cline { 2 - 10 } & $\mathrm{C}$ & 1,0 & 5,00 & $0,0 \%$ & $0,0 \%$ & Aprovado & $0,0 \%$ & $0,0 \%$ & Aprovado \\
\hline
\end{tabular}

Tabela 4.11 - Satisfação ao PEC da faixa 6, antes e após ajustamento.

\begin{tabular}{|c|c|c|c|c|c|c|c|c|c|}
\hline \multicolumn{3}{|c|}{ Comparação com o PEC } & \multicolumn{3}{c|}{ Antes do Ajustamento } & \multicolumn{3}{c|}{ Após Ajustamento } \\
\hline $\begin{array}{c}\text { Escala } \\
1 /\end{array}$ & Classe & PEC & $\%$ reprovada & $>10 \% ?$ & $\%$ reprovada & $>10 \% ?$ \\
\cline { 2 - 9 } & & $(\mathrm{mm})$ & $(\mathrm{m})$ & $\mathrm{E}$ & $\mathrm{N}$ & $\mathrm{Ap} / \mathrm{Re}$ & $\mathrm{E}$ & $\mathrm{N}$ & $\mathrm{Ap} / \mathrm{Re}$ \\
\hline \multirow{3}{*}{1.000} & $\mathrm{~A}$ & 0,5 & 0,5 & $10,2 \%$ & $46,3 \%$ & Reprovado & $13,0 \%$ & $12,0 \%$ & Reprovado \\
\cline { 2 - 10 } & $\mathrm{B}$ & 0,8 & 0,8 & $4,6 \%$ & $46,3 \%$ & Reprovado & $5,6 \%$ & $3,7 \%$ & Aprovado \\
\cline { 2 - 10 } & $\mathrm{C}$ & 1,0 & 1,0 & $1,9 \%$ & $45,4 \%$ & Reprovado & $5,6 \%$ & $2,8 \%$ & Aprovado \\
\hline \multirow{3}{*}{2.000} & $\mathrm{~A}$ & 0,5 & 1,0 & $1,9 \%$ & $45,4 \%$ & Reprovado & $5,6 \%$ & $2,8 \%$ & Aprovado \\
\cline { 2 - 10 } & $\mathrm{B}$ & 0,8 & 1,6 & $1,9 \%$ & $42,6 \%$ & Reprovado & $2,8 \%$ & $0,0 \%$ & Aprovado \\
\cline { 2 - 10 } & $\mathrm{C}$ & 1,0 & 2,0 & $1,9 \%$ & $28,7 \%$ & Reprovado & $0,0 \%$ & $0,0 \%$ & Aprovado \\
\hline \multirow{3}{*}{5.000} & $\mathrm{~A}$ & 0,5 & 2,5 & $0,0 \%$ & $11,1 \%$ & Reprovado & $0,0 \%$ & $0,0 \%$ & Aprovado \\
\cline { 2 - 9 } & $\mathrm{B}$ & 0,8 & 4,0 & $0,0 \%$ & $0,0 \%$ & Aprovado & $0,0 \%$ & $0,0 \%$ & Aprovado \\
\cline { 2 - 9 } & $\mathrm{C}$ & 1,0 & 5,0 & $0,0 \%$ & $0,0 \%$ & Aprovado & $0,0 \%$ & $0,0 \%$ & Aprovado \\
\hline
\end{tabular}

Os resultados comprovam que o ajustamento por transformação afim melhorou a qualidade planimétrica dos levantamentos, quanto à satisfação ao PEC, com relação aos dados brutos. Porém, no teste de precisão houve melhora nos resultados apenas na faixa 6 . Mesmo na avaliação quanto ao PEC, os resultados obtidos através de ajustamento, não obtiveram qualidade tão boa quanto os resultados obtidos através de tratamento estatístico simplificado, que aplica as duas translações. Dessa forma, não se recomenda o método apresentado, neste item por sua complexidade e não haver ganhos efetivos com relação à metodologia anterior (tratamento estatístico). 
4.8. Eliminação de erros grosseiros, minimização de erros sistemáticos, teste de precisão e satisfação ao PEC sobre o conjunto de dados vetorizados pelo método semi-automático

A partir das estatísticas calculadas sobre as discrepâncias, no conjunto de pontos obtidos por vetorização semi-automática, foram realizados testes para detecção de erros grosseiros. Foram eliminados pontos fora do intervalo definido pela média e três vezes o desvio padrão.

Com três iterações, foram eliminados dois pontos discrepantes na faixa 3 e sete pontos discrepantes na faixa 6 .

\begin{tabular}{|l|r|}
\hline \multicolumn{2}{|c|}{ Estatística descritiva E } \\
\hline Média & 0,055 \\
\hline Erro padrão & 0,090 \\
\hline Mediana & 0,073 \\
\hline Modo & - \\
\hline Desvio padrão & 0,672 \\
\hline Variância da amostra & 0,452 \\
\hline Curtose & 2,394 \\
\hline Assimetria & $-0,784$ \\
\hline Intervalo & 3,834 \\
\hline Mínimo & $-2,166$ \\
\hline Máximo & 1,668 \\
\hline Soma & 3,061 \\
\hline Contagem & 56,000 \\
\hline
\end{tabular}

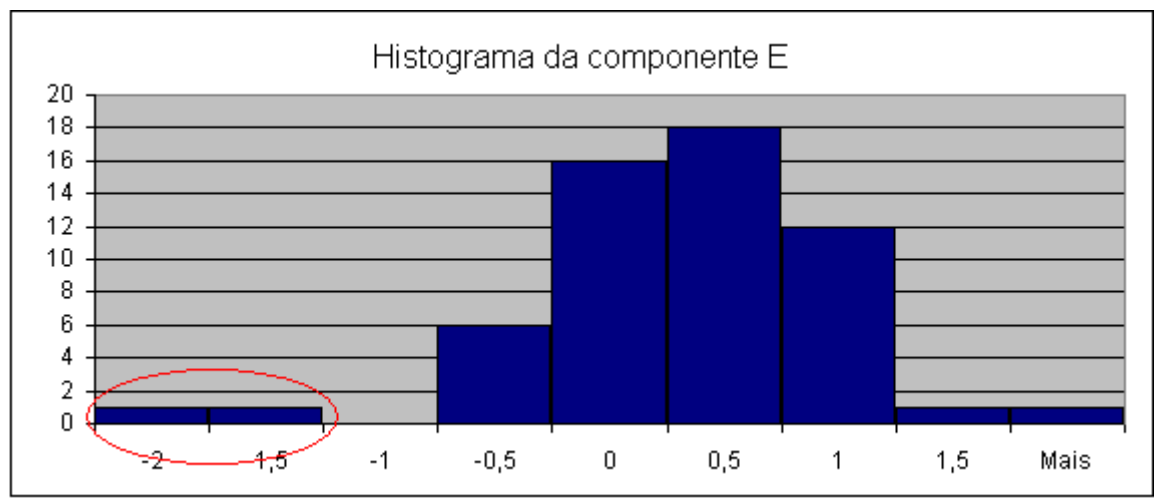

\begin{tabular}{|l|r|}
\hline \multicolumn{2}{|c|}{ Estatística descritiva N } \\
\hline Média & 2,545 \\
\hline Erro padrã̃o & 0,102 \\
\hline Mediana & 2,620 \\
\hline Modo & - \\
\hline Desvio padrẫo & 0,764 \\
\hline Variância da amostra & 0,584 \\
\hline Curtose & 2,444 \\
\hline Assimetria & $-0,961$ \\
\hline Intervalo & 4,268 \\
\hline Mínimo & $-0,267$ \\
\hline Máximo & 4,001 \\
\hline Soma & 142,505 \\
\hline Contagem & 56,000 \\
\hline
\end{tabular}

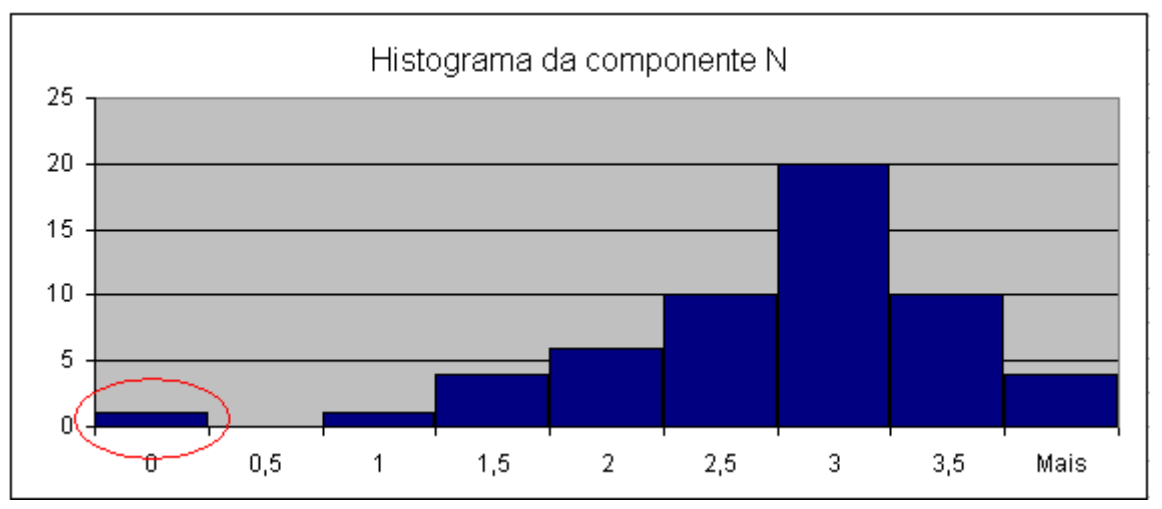

Figura 4.14 - Estatísticas descritivas e histogramas das componentes E e N, da faixa 3, antes da eliminação de erros grosseiros, assinalados em vermelho. 


\begin{tabular}{|l|r|}
\hline \multicolumn{2}{|c|}{ Estatística descritiva E } \\
\hline Média & 0.134 \\
\hline Erro padrão & 0.073 \\
\hline Mediana & 0.091 \\
\hline Modo & - \\
\hline Desvio padrão & 0.540 \\
\hline Variância da amostra & 0.291 \\
\hline Curtose & 0.048 \\
\hline Assimetria & 0.387 \\
\hline Intervalo & 2.476 \\
\hline Mínimo & -0.809 \\
\hline Máximo & 1.668 \\
\hline Soma & 7.211 \\
\hline Contagem & 54.000 \\
\hline
\end{tabular}

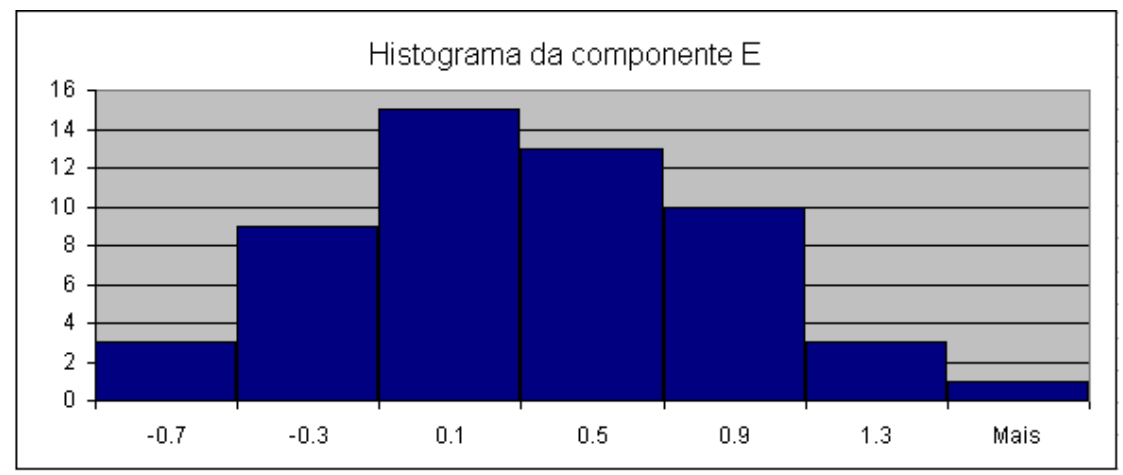

\begin{tabular}{|l|r|}
\hline Estatística descritiva N \\
\hline Média & 2.628 \\
\hline Erro padrẫo & 0.085 \\
\hline Mediana & 2.624 \\
\hline Modo & \multicolumn{1}{|c|}{ \#N/ } \\
\hline Desvio padrão & 0.628 \\
\hline Variância da amostra & 0.394 \\
\hline Curtose & -0.096 \\
\hline Assimetria & -0.061 \\
\hline Intervalo & 2.709 \\
\hline Mínimo & 1.292 \\
\hline Máximo & 4.001 \\
\hline Soma & 141.938 \\
\hline Contagem & 54.000 \\
\hline
\end{tabular}

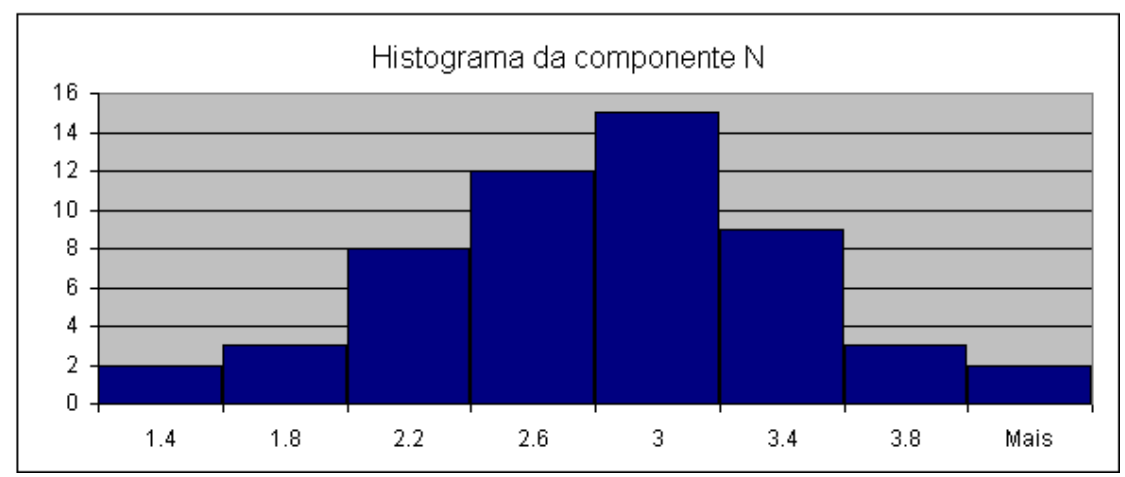

Figura 4.15 - Estatísticas descritivas e histogramas das componentes E e N, da faixa 3, após a eliminação de erros grosseiros

Nos dados brutos percebe-se valores de curtose e assimetria bastante de grandes, além de do comportamento bi-modal encontrado no histograma. Após eliminação dos erros grosseiros, melhoram os valores de curtose e assimetria, aproximando a distribuição da normalidade estatística. Porém, não se observa melhora significativa do desvio padrão.

Foram realizados testes de tendências com os conjuntos de amostras, obtidos por vetorização semi-automática, gerando os seguintes resultados:

Para a faixa $3, t_{n-1, \alpha}=1,674$ (tabelado) e:

$t_{E}=\frac{\overline{\Delta E} \cdot \sqrt{n}}{S_{E}}=\frac{0,134 \cdot \sqrt{54}}{0,540}=1,824$

$t_{E}=1,824>1,674$, rejeita-se $\mathrm{H} 0$ e a amostra apresenta tendências na coordenada Este. 
$t_{N}=\frac{\overline{\Delta N} \cdot \sqrt{n}}{S_{N}}=\frac{2,628 \cdot \sqrt{54}}{0,628}=30,751$

$t_{N}=30,751>1,674$, rejeita-se $\mathrm{HO}$ e a amostra apresenta tendências também na coordenada Norte.

Para faixa $6, t_{n-1, \alpha}=1,660$ (tabelado) e:

$t_{E}=\frac{\overline{\Delta E} \cdot \sqrt{n}}{S_{E}}=\frac{0,353 \cdot \sqrt{101}}{0,689}=5,149$

Como $t_{E}=5,149>1,660$, a amostra apresenta tendência na coordenada Este.

$t_{N}=\frac{\overline{\Delta N} \cdot \sqrt{n}}{S_{N}}=\frac{2,155 \cdot \sqrt{101}}{0,470}=46,080$

Como $t_{N}=46,080>1,660$, a amostra apresenta tendência na coordenada Norte.

Comprovada a existência de tendências em ambos os eixos, foi possível a minimização desses erros sistemáticos, subtraindo a média das discrepâncias das observações.

A partir das amostras tratadas estatisticamente, foram realizados os testes de qualidade cartográfica, segundo o padrão brasileiro.

$\mathrm{Na}$ avaliação segundo o padrão brasileiro (tabelas 4.12 e 4.13), o mapeamento, antes da eliminação dos erros grosseiros, é aprovado apenas na escala 1/5.000, classes B e C, para faixa 3 e 1/5.000, classes A, B e C, para a faixa 6. Após o tratamento estatístico, o produto da faixa 6 é aprovado para todas as escalas e classes, a menos da classe $A$, na escala $1 / 1.000$ e o produto do faixa 3 é aprovado na escala $1 / 2.000$, classe $B$. 
Tabela 4.12 - Satisfação ao PEC, faixa 3.

\begin{tabular}{|c|c|c|c|c|c|c|c|c|c|}
\hline \multicolumn{4}{|c|}{ Comparação com o PEC } & \multicolumn{4}{c|}{ Dados brutos } & \multicolumn{2}{c|}{$\begin{array}{c}\text { Após eliminação de erros } \\
\text { grosseiros e sistemáticos }\end{array}$} \\
\hline $\begin{array}{c}\text { Escala } \\
1 /\end{array}$ & \multirow{2}{*}{ Classe } & \multicolumn{2}{|c|}{ PEC } & \multicolumn{2}{c|}{$\%$ reprovada } & $>10 \% ?$ & $\%$ reprovada & $>10 \% ?$ \\
\cline { 2 - 10 } & & $(\mathrm{mm})$ & $(\mathrm{m})$ & $\mathrm{E}$ & $\mathrm{N}$ & $\mathrm{Ap} / \mathrm{Re}$ & $\mathrm{E}$ & $\mathrm{N}$ & $\mathrm{Ap} / \mathrm{Re}$ \\
\hline \multirow{3}{*}{1.000} & $\mathrm{~A}$ & 0,5 & 0,50 & $35,7 \%$ & $91,1 \%$ & Reprovado & $33,3 \%$ & $37,0 \%$ & Reprovado \\
\cline { 2 - 10 } & $\mathrm{B}$ & 0,8 & 0,80 & $14,3 \%$ & $91,1 \%$ & Reprovado & $14,8 \%$ & $16,7 \%$ & Reprovado \\
\cline { 2 - 10 } & $\mathrm{C}$ & 1,0 & 1,00 & $3,6 \%$ & $91,1 \%$ & Reprovado & $3,7 \%$ & $11,1 \%$ & Reprovado \\
\hline \multirow{3}{*}{2.000} & $\mathrm{~A}$ & 0,5 & 1,00 & $3,6 \%$ & $91,1 \%$ & Reprovado & $3,7 \%$ & $11,1 \%$ & Reprovado \\
\cline { 2 - 10 } & $\mathrm{B}$ & 0,8 & 1,60 & $1,8 \%$ & $85,7 \%$ & Reprovado & $0,0 \%$ & $0,0 \%$ & Aprovado \\
\cline { 2 - 9 } & $\mathrm{C}$ & 1,0 & 2,00 & $0,0 \%$ & $75,0 \%$ & Reprovado & $0,0 \%$ & $0,0 \%$ & Aprovado \\
\hline \multirow{3}{*}{5.000} & $\mathrm{~A}$ & 0,5 & 2,50 & $0,0 \%$ & $58,9 \%$ & Reprovado & $0,0 \%$ & $0,0 \%$ & Aprovado \\
\cline { 2 - 9 } & $\mathrm{B}$ & 0,8 & 4,00 & $0,0 \%$ & $1,8 \%$ & Aprovado & $0,0 \%$ & $0,0 \%$ & Aprovado \\
\cline { 2 - 9 } & $\mathrm{C}$ & 1,0 & 5,00 & $0,0 \%$ & $0,0 \%$ & Aprovado & $0,0 \%$ & $0,0 \%$ & Aprovado \\
\hline
\end{tabular}

Tabela 4.13 - Satisfação ao PEC, faixa 6.

\begin{tabular}{|c|c|c|c|c|c|c|c|c|c|}
\hline \multicolumn{3}{|c|}{ Comparação com o PEC } & \multicolumn{4}{|c|}{ Dados brutos } & \multicolumn{2}{c|}{$\begin{array}{c}\text { Após eliminação de erros } \\
\text { grosseiros e sistemáticos }\end{array}$} \\
\hline $\begin{array}{c}\text { Escala } \\
1 /\end{array}$ & Classe & PEC & $\%$ reprovada & $>10 \% ?$ & $\%$ reprovada & $>10 \% ?$ \\
\cline { 2 - 9 } & & $(\mathrm{mm})$ & $(\mathrm{m})$ & $\mathrm{E}$ & $\mathrm{N}$ & $\mathrm{Ap} / \mathrm{Re}$ & $\mathrm{E}$ & $\mathrm{N}$ & $\mathrm{Ap} / \mathrm{Re}$ \\
\hline \multirow{3}{*}{1.000} & $\mathrm{~A}$ & 0,5 & 0,5 & $11,1 \%$ & $45.4 \%$ & Reprovado & $22,8 \%$ & $12,9 \%$ & Reprovado \\
\cline { 2 - 10 } & $\mathrm{B}$ & 0,8 & 0,8 & $8,3 \%$ & $43,5 \%$ & Reprovado & $8,9 \%$ & $4,0 \%$ & Aprovado \\
\cline { 2 - 10 } & $\mathrm{C}$ & 1,0 & 1,0 & $7,4 \%$ & $43,5 \%$ & Reprovado & $5,9 \%$ & $2,0 \%$ & Aprovado \\
\hline \multirow{3}{*}{2.000} & $\mathrm{~A}$ & 0,5 & 1,0 & $7,4 \%$ & $43,5 \%$ & Reprovado & $5,9 \%$ & $2,0 \%$ & Aprovado \\
\cline { 2 - 9 } & $\mathrm{B}$ & 0,8 & 1,6 & $3,7 \%$ & $37,0 \%$ & Reprovado & $2,0 \%$ & $0,0 \%$ & Aprovado \\
\cline { 2 - 9 } & $\mathrm{C}$ & 1,0 & 2,0 & $3,7 \%$ & $27,8 \%$ & Reprovado & $0,0 \%$ & $0,0 \%$ & Aprovado \\
\hline \multirow{3}{5}{5.000} & $\mathrm{~A}$ & 0,5 & 2,5 & $0,9 \%$ & $8,3 \%$ & Aprovado & $0,0 \%$ & $0,0 \%$ & Aprovado \\
\cline { 2 - 9 } & $\mathrm{B}$ & 0,8 & 4,0 & $0,0 \%$ & $0,9 \%$ & Aprovado & $0,0 \%$ & $0,0 \%$ & Aprovado \\
\cline { 2 - 9 } & $\mathrm{C}$ & 1,0 & 5,0 & $0,0 \%$ & $0,0 \%$ & Aprovado & $0,0 \%$ & $0,0 \%$ & Aprovado \\
\hline
\end{tabular}

Constatou-se que os dois levantamentos atingiram qualidade compatível com produtos na escala 1/5.000, classe B, quando analisados seus dados brutos, eivados de erros grosseiros e sistemáticos. Após a eliminação destes, nota-se grande melhora na qualidade cartográfica da faixa 6 , ficando esta compatível com a escala $1 / 1.000$, classe B. A melhora de qualidade posicional é menos significativa na faixa 3 , onde a qualidade atingida é compatível com a escala $1 / 2.000$, classe $B$

Tais resultados indicam que pontos coletados por vetorização semiautomática apresentam uma quantidade maior de erros grosseiros, apresentam pior precisão e são menos sensíveis a tratamentos de erros sistemáticos. Porém, tal método de coleta de pontos de controle é livre da tendência inerente ao operador 
humano e garante maior agilidade na operação, cerca de metade do tempo gasto com a coleta manual.

\subsection{Coleta de pontos de controle para altimetria}

Para avaliar a qualidade altimétrica foram coletados pontos de controle na área em estudo. Foram utilizados pontos cotados da restituição situados em regiões quase planas, minimizando assim, erros de localização dos mesmos nos levantamentos a LASER. Para determinação de regiões com essas características foram calculados, identificados e apresentados visualmente todos os triângulos com gradiente de elevação entre $0^{\circ}$ e $5^{\circ}$.

Figura 4.14 - Distribuição dos pontos de controle altimétrico. O contorno azul corresponde a faixa 6 e o contorno magenta, a faixa 3. 
Nessas regiões foram coletados 39 pontos, que permitiram 24 observações em cada faixa. Alguns pontos coletados estão presentes em duas faixas e possuem valores distintos de altitude. Sobre cada ponto cotado da restituição foi extraída a elevação do modelo TIN dos dados originais, tratados estatisticamente e ajustados planimetricamente. A distribuição dos pontos é apresentada na figura 4.14. Os valores extraídos e as discrepâncias são apresentados nas tabelas 4.14 e 4.15.

Tabela 4.14 - Altitudes extraídas dos MDS gerados a partir dos dados brutos, tratados estatisticamente e ajustados e suas respectivas discrepâncias (Faixa 3).

\begin{tabular}{|c|c|c|c|c|c|c|c|}
\hline \multirow{2}{*}{ PT } & \multicolumn{4}{|c|}{ Altitude $(\mathrm{m})$} & \multicolumn{3}{c|}{ Discrepância (m) } \\
\cline { 2 - 8 } & Carta & $\begin{array}{c}\text { Dados } \\
\text { Brutos }\end{array}$ & $\begin{array}{c}\text { Trat. } \\
\text { Estatístico }\end{array}$ & $\begin{array}{c}\text { Após } \\
\text { Ajustamento }\end{array}$ & $\begin{array}{c}\text { Dados } \\
\text { Brutos }\end{array}$ & $\begin{array}{c}\text { Trat. } \\
\text { Estatístico }\end{array}$ & $\begin{array}{c}\text { Após } \\
\text { Ajustamento }\end{array}$ \\
\hline A1 & 898,00 & 898,08 & 898,11 & 898,09 & 0,08 & 0,11 & 0,09 \\
\hline A10 & 904,00 & 903,76 & 903,77 & 903,77 & $-0,24$ & $-0,23$ & $-0,23$ \\
\hline A11 & 914,00 & 913,17 & 913,16 & 913,18 & $-0,83$ & $-0,84$ & $-0,82$ \\
\hline A12 & 900,00 & 900,84 & 900,82 & 900,82 & 0,84 & 0,82 & 0,82 \\
\hline A13 & 914,00 & 920,67 & 914,46 & 914,14 & 6,67 & 0,46 & 0,14 \\
\hline A14 & 904,00 & 903,73 & 903,67 & 903,68 & $-0,27$ & $-0,33$ & $-0,32$ \\
\hline A15 & 904,00 & 903,70 & 903,72 & 903,71 & $-0,30$ & $-0,28$ & $-0,29$ \\
\hline A16 & 900,00 & 900,43 & 900,46 & 900,46 & 0,43 & 0,46 & 0,46 \\
\hline A17 & 900,00 & 900,48 & 900,54 & 900,54 & 0,48 & 0,54 & 0,54 \\
\hline A18 & 900,00 & 900,36 & 900,38 & 900,38 & 0,36 & 0,38 & 0,38 \\
\hline A19 & 900,00 & 899,59 & 899,59 & 899,60 & $-0,41$ & $-0,41$ & $-0,40$ \\
\hline A2 & 903,00 & 903,40 & 903,43 & 903,43 & 0,40 & 0,43 & 0,43 \\
\hline A20 & 897,00 & 898,03 & 897,99 & 897,99 & 1,03 & 0,99 & 0,99 \\
\hline A21 & 914,00 & 913,63 & 913,61 & 913,61 & $-0,37$ & $-0,39$ & $-0,39$ \\
\hline A3 & 897,00 & 897,82 & 897,77 & 897,77 & 0,82 & 0,77 & 0,77 \\
\hline A4 & 900,00 & 899,56 & 899,48 & 899,48 & $-0,44$ & $-0,52$ & $-0,52$ \\
\hline A5 & 900,00 & 899,88 & 899,86 & 899,85 & $-0,12$ & $-0,14$ & $-0,15$ \\
\hline A6 & 899,00 & 899,76 & 899,77 & 899,77 & 0,76 & 0,77 & 0,77 \\
\hline A7 & 902,00 & 902,00 & 901,96 & 901,96 & 0,00 & $-0,04$ & $-0,04$ \\
\hline A8 & 913,00 & 912,30 & 912,24 & 912,24 & $-0,70$ & $-0,76$ & $-0,76$ \\
\hline A9 & 913,00 & 912,43 & 912,39 & 912,39 & $-0,57$ & $-0,61$ & $-0,61$ \\
\hline B15 & 913,00 & 913,16 & 913,80 & 913,80 & 0,16 & 0,80 & 0,80 \\
\hline B16 & 914,00 & 913,69 & 913,73 & 913,72 & $-0,31$ & $-0,27$ & $-0,28$ \\
\hline B5 & 900,00 & 899,59 & 899,57 & 899,59 & $-0,41$ & $-0,43$ & $-0,41$ \\
\hline & & & & Média & 0,294 & 0,053 & 0,040 \\
\cline { 5 - 8 } & & & Desvio-padrão & 1,455 & 0,561 & 0,552 \\
\hline
\end{tabular}


Tabela 4.15 - Altitudes extraídas dos MDS gerados a partir dos dados brutos, tratados estatisticamente e ajustados e suas respectivas discrepâncias (Faixa 6).

\begin{tabular}{|c|c|c|c|c|c|c|c|}
\hline \multirow{2}{*}{ PT } & \multicolumn{9}{|c|}{ Altitude $(\mathrm{m})$} & \multicolumn{3}{c|}{ Discrepância (m) } \\
\cline { 3 - 8 } & Carta & $\begin{array}{c}\text { Dados } \\
\text { Brutos }\end{array}$ & $\begin{array}{c}\text { Trat. } \\
\text { Estatístico }\end{array}$ & $\begin{array}{c}\text { Após } \\
\text { Ajustamento }\end{array}$ & $\begin{array}{c}\text { Dados } \\
\text { Brutos }\end{array}$ & $\begin{array}{c}\text { Trat. } \\
\text { Estatístico }\end{array}$ & $\begin{array}{c}\text { Após } \\
\text { Ajustamento }\end{array}$ \\
\hline A1 & 898,00 & 898,08 & 898,08 & 898,09 & 0,08 & 0,08 & 0,09 \\
\hline A13 & 914,00 & 918,46 & 913,61 & 913,63 & 4,46 & $-0,39$ & $-0,37$ \\
\hline A2 & 903,00 & 903,35 & 903,37 & 903,39 & 0,35 & 0,37 & 0,39 \\
\hline A21 & 914,00 & 913,47 & 913,53 & 913,53 & $-0,53$ & $-0,47$ & $-0,47$ \\
\hline A8 & 913,00 & 912,19 & 912,14 & 912,13 & $-0,81$ & $-0,86$ & $-0,87$ \\
\hline A9 & 913,00 & 912,34 & 912,30 & 912,32 & $-0,66$ & $-0,70$ & $-0,68$ \\
\hline B1 & 900,00 & 899,43 & 899,39 & 899,41 & $-0,57$ & $-0,61$ & $-0,59$ \\
\hline B10 & 909,00 & 908,56 & 908,57 & 908,57 & $-0,44$ & $-0,43$ & $-0,43$ \\
\hline B11 & 909,00 & 908,57 & 908,57 & 908,57 & $-0,43$ & $-0,43$ & $-0,43$ \\
\hline B12 & 911,00 & 910,43 & 910,35 & 910,35 & $-0,57$ & $-0,65$ & $-0,65$ \\
\hline B13 & 911,00 & 911,23 & 910,34 & 910,34 & 0,23 & $-0,66$ & $-0,66$ \\
\hline B14 & 911,00 & 910,79 & 910,75 & 910,75 & $-0,21$ & $-0,25$ & $-0,25$ \\
\hline B15 & 913,00 & 913,40 & 913,77 & 913,32 & 0,40 & $-0,23$ & 0,32 \\
\hline B16 & 914,00 & 913,67 & 913,64 & 913,62 & $-0,33$ & $-0,36$ & $-0,38$ \\
\hline B17 & 910,00 & 909,94 & 909,82 & 909,82 & $-0,06$ & $-0,18$ & $-0,18$ \\
\hline B18 & 913,00 & 912,84 & 912,76 & 912,77 & $-0,16$ & $-0,24$ & $-0,23$ \\
\hline B2 & 905,00 & 904,42 & 904,50 & 904,52 & $-0,58$ & $-0,50$ & $-0,48$ \\
\hline B3 & 903,00 & 902,04 & 902,02 & 902,04 & $-0,96$ & $-0,98$ & $-0,96$ \\
\hline B4 & 905,00 & 904,44 & 904,52 & 904,52 & $-0,56$ & $-0,48$ & $-0,48$ \\
\hline B5 & 900,00 & 899,50 & 899,51 & 899,52 & $-0,50$ & $-0,49$ & $-0,48$ \\
\hline B6 & 907,00 & 906,97 & 906,89 & 906,89 & $-0,03$ & $-0,11$ & $-0,11$ \\
\hline B7 & 907,00 & 907,19 & 906,99 & 906,99 & 0,19 & $-0,01$ & $-0,01$ \\
\hline B8 & 909,00 & 908,57 & 908,57 & 908,57 & $-0,43$ & $-0,43$ & $-0,43$ \\
\hline B9 & 908,00 & 918,05 & 907,75 & 907,75 & 10,05 & $-0,25$ & $-0,25$ \\
\hline & & & & Média & 0,330 & $-0,386$ & $-0,358$ \\
\cline { 5 - 8 } & & & Desvio-padrão & 2,315 & 0,298 & 0,330 \\
\hline
\end{tabular}




\subsection{Detecção e eliminação de erros grosseiros e sistemáticos na altimetria}

Analisaram-se as amostras na tentativa de detectar erros grosseiros. $\mathrm{Na}$ faixa 3, detectou-se e eliminou-se um ponto nessas condições nos dados originais. Nos dados tratados estatisticamente e nos dados ajustados, não foram detectados erros dessa natureza. Na faixa 6 , foram detectados e eliminados três erros grosseiros nos dados originais. Nos dados tratados estatisticamente e nos dados ajustados, não foram detectados erros dessa natureza. Este fato comprova a importância da exatidão planimétrica de um MDT ou MDS, na qualidade total do produto. Comprova também, a eficácia dos métodos utilizados para melhoria da qualidade planimétrica.

Posteriormente, foram realizados testes de tendência para detectar e eliminar erros sistemáticos:

Para faixa 3 , dados originais, $t_{n-1, \alpha}=1,715 \mathrm{e}$ :

$t_{H}=\frac{\overline{\Delta H} \cdot \sqrt{n}}{S_{H}}=\frac{0,017 \cdot \sqrt{23}}{0,533}=0,156$

$t_{H}=0,156<1,713$, logo a amostra original não apresenta tendências em elevação.

Para faixa 3, dados tratados estatisticamente, em planimetria $t_{n-1, \alpha}=1,713 \mathrm{e}:$

$t_{H}=\frac{\overline{\Delta H} \cdot \sqrt{n}}{S_{H}}=\frac{0,053 \cdot \sqrt{24}}{0,561}=0,466$

$t_{H}=0,466<1,713$, logo a amostra tratada estatisticamente, não apresenta tendências em elevação. 
Para faixa 3, dados ajustados planimetricamente, $t_{n-1, \alpha}=1,713$ e:

$t_{H}=\frac{\overline{\Delta H} \cdot \sqrt{n}}{S_{H}}=\frac{0,040 \cdot \sqrt{24}}{0,552}=0,359$

$t_{H}=0,359<1,713$, logo a amostra ajustada planimetricamente não apresenta tendências em elevação.

Para faixa 6, dados originais, sem erros grosseiros, $t_{n-1, \alpha}=1,720 \mathrm{e}$ :

$t_{H}=\frac{\overline{\Delta H} \cdot \sqrt{n}}{S_{H}}=\left|\frac{-0,332 \cdot \sqrt{21}}{0,353}\right|=4,420$

$t_{H}=4,420>1,753$, logo a amostra original apresenta tendências em elevação.

Para faixa 6, dados tratados estatisticamente, em planimetria $t_{n-1, \alpha}=1,713$ e:

$t_{H}=\frac{\overline{\Delta H} \cdot \sqrt{n}}{S_{H}}=\left|\frac{-0.386 \cdot \sqrt{24}}{0,298}\right|=6,334$

$t_{H}=6,334>1,753$, logo a amostra tratada estatisticamente apresenta tendências em elevação.

Para faixa 6, dados ajustados planimetricamente, $t_{n-1, \alpha}=1,713$ e:

$t_{H}=\frac{\overline{\Delta H} \cdot \sqrt{n}}{S_{H}}=\left|\frac{-0.358 \cdot \sqrt{24}}{0,330}\right|=5,312$

$t_{H}=5,312>1,753$, logo a amostra ajustada planimetricamente apresenta tendências em elevação.

Os erros sistemáticos detectados no conjunto de dados da faixa 6 foram minimizados subtraindo-se a média das discrepâncias. Após esta operação, todos os conjuntos de dados foram submetidos ao teste do padrão brasileiro (satisfação do PEC).

Nota-se que na faixa 3, nenhum conjunto de dados apresenta tendências em elevação. Na faixa 6 , os dados brutos apresentam tendência em elevação que persistem mesmo após tratamento estatístico e ajustamento planimétrico. Este fato 
pode estar relacionado à degradação da determinação de posição da aeronave, durante o vôo de uma das faixas.

Foi feito um teste com pontos comuns às duas faixas, para verificar se havia diferenças significativas entre suas discrepâncias calculadas (tabela 4.16). Para isso, realizou-se testes de tendência sobre essas diferenças.

Tabela 4.16 - Comparação das discrepâncias altimétricas de pontos comuns a duas faixas. Todas as unidade em metros.

\begin{tabular}{|c|c|c|c|c|c|c|}
\hline \multirow[t]{2}{*}{ PT } & Carta & $\begin{array}{c}\text { LASER } \\
\text { F6 } \\
\end{array}$ & $\begin{array}{l}\text { LASER } \\
\text { F3 }\end{array}$ & \multirow{2}{*}{$\begin{array}{c}\text { Discrepância } \\
\text { F3 }\end{array}$} & \multirow{2}{*}{$\begin{array}{c}\text { Discrepância } \\
\text { F6 }\end{array}$} & \multirow{2}{*}{$\begin{array}{c}\text { Diferença } \\
\text { entre } \\
\text { discrepâncias }\end{array}$} \\
\hline & Altitude & Altitude & Altitude & & & \\
\hline A1 & 898,00 & 898,08 & 898,08 & 0,08 & 0,08 & 0.00 \\
\hline A13 & 914,00 & 918,46 & 920,67 & 6,67 & 4,46 & 2.21 \\
\hline A2 & 903,00 & 903,35 & 903,40 & 0,40 & 0,35 & 0.05 \\
\hline A21 & 914,00 & 913,47 & 913,63 & $-0,37$ & $-0,53$ & 0.16 \\
\hline A8 & 913,00 & 912,19 & 912,30 & $-0,70$ & $-0,81$ & 0.11 \\
\hline A9 & 913,00 & 912,34 & 912,43 & $-0,57$ & $-0,66$ & 0.09 \\
\hline B15 & 913,00 & 913,40 & 913,16 & 0,16 & 0,40 & -0.24 \\
\hline B16 & 914,00 & 913,67 & 913,69 & $-0,31$ & $-0,33$ & 0.02 \\
\hline B5 & 900,00 & 899,50 & 899,59 & $-0,41$ & $-0,50$ & 0.09 \\
\hline & & & & & Média & 0,035 \\
\hline & & & & & Padrão & 0,122 \\
\hline
\end{tabular}

Para pontos comuns, descartando o ponto discrepante A13, $t_{n-1, \alpha}=1,894$ e:

$t_{H}=\frac{\overline{\Delta H} \cdot \sqrt{n}}{S_{H}}=\left|\frac{0,035 \cdot \sqrt{8}}{0,122}\right|=0,257$

$t_{H}=0,257<1,894$, logo a amostra não apresenta tendências em elevação, entre faixas.

Este resultado não sugere que o erro seja ocasionado pela posição do ponto dentro da largura da faixa. Os estudos realizados não foram concludentes para identificar a causa desse erro. 


\subsection{Teste de satisfação ao PEC (padrão brasileiro) na altimetria.}

Para tal, foram calculados os valores do PEC para as diferentes escalas e classes de qualidade e comparados com as discrepâncias altimétricas de cada observação, conforme tabela apresentada na metodologia (tabela 3.2).

Tabela 4.17 - Avaliação das discrepâncias altimétricas perante o PEC.

\begin{tabular}{|c|c|c|c|c|c|c|c|}
\hline \multicolumn{8}{|c|}{ Satisfação ao padrão brasileiro: PEC altimétrico } \\
\hline & Amostra & $\begin{array}{c}1 / 1.000- \\
A\end{array}$ & $\begin{array}{c}1 / 1.000- \\
B\end{array}$ & $\begin{array}{c}1 / 1.000- \\
C\end{array}$ & $\begin{array}{c}1 / 2.000- \\
A\end{array}$ & $\begin{array}{c}1 / 2.000- \\
B\end{array}$ & $\begin{array}{c}1 / 2.000- \\
C\end{array}$ \\
\hline \multirow{6}{*}{ 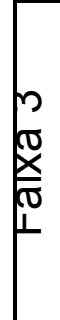 } & Dados Brutos & $66,67 \%$ & $70,83 \%$ & $75,00 \%$ & $91,67 \%$ & $95,83 \%$ & $95,83 \%$ \\
\hline & & Reprovado & Reprovado & Reprovado & Aprovado & Aprovado & Aprovado \\
\hline & Dados tratados & $58,33 \%$ & $66,67 \%$ & $70,83 \%$ & $100,00 \%$ & $100,00 \%$ & $100,00 \%$ \\
\hline & & Reprovado & Reprovado & Reprovado & Aprovado & Aprovado & Aprovado \\
\hline & ajustados & $58,33 \%$ & $66,67 \%$ & $70,83 \%$ & $100,00 \%$ & $100,00 \%$ & $100,00 \%$ \\
\hline & planimetricamente & Reprovado & Reprovado & Reprovado & Aprovado & Aprovado & Aprovado \\
\hline \multirow{6}{*}{$\Phi$} & Dados Brutos & $80,95 \%$ & $90,48 \%$ & $100,00 \%$ & $100,00 \%$ & $100,00 \%$ & $100,00 \%$ \\
\hline & & Reprovado & Aprovado & Aprovado & Aprovado & Aprovado & Aprovado \\
\hline & Dados tratados & $91,67 \%$ & $91,67 \%$ & $100,00 \%$ & $100,00 \%$ & $100,00 \%$ & $100,00 \%$ \\
\hline & estatisticamente & Aprovado & Aprovado & Aprovado & Aprovado & Aprovado & Aprovado \\
\hline & Dados ajustados & $83,33 \%$ & $87,50 \%$ & $100,00 \%$ & $100,00 \%$ & $100,00 \%$ & $100,00 \%$ \\
\hline & & Reprovado & Reprovado & Aprovado & Aprovado & Aprovado & Aprovado \\
\hline
\end{tabular}

Segundo esta análise, o levantamento da faixa 3 obteve qualidade compatível com produtos na escala $1 / 2.000$, classe $A$, em todos os conjuntos de dados. O levantamento da faixa 6 obteve qualidade compatível com produtos cartográficos na escala 1/1.000, classe $B$, para os dados originais. Os dados da faixa 6 , cujo planimetria foi tratada estatisticamente, obtiveram qualidade compatível com escala 1/1.000, classe A. Os dados da faixa 6, ajustados planimetricamente, obtiveram qualidade compatível com escala $1 / 1.000$, classe $\mathrm{C}$.

Os resultados obtidos comprovam melhora não-significativa na qualidade altimétrica na faixa 3 , após tratamento e ajustamento planimétrico dos dados. $\mathrm{Na}$ faixa 6, após a eliminação de erros grosseiros e sistemáticos, os dados originais obtiveram boa qualidade, podendo ser enquadrados na classe $B$, na escala 1/1.000. Os dados após tratamentos estatísticos planimétricos e altimétricos, alcançaram 
qualidade surpreendente: classe $A$, na escala 1/1.000. Porém, o ajustamento planimétrico por transformação afim, degradou a qualidade dos dados originais.

\subsection{Ajustamento com polinômio de $1^{\circ}$ grau na altimetria.}

Com objetivo de tentar refinar as elevações adotou-se um polinômio de $1^{\circ}$ grau, ajustado através do método dos mínimos quadrados. Utilizou-se para o modelo paramétrico, $40 \%$ dos pontos coletados, cuja discrepância mais se aproximava da média das discrepâncias. A equação utilizada no ajustamento foi:
$H_{a}=A 0+A l \cdot H$
Eq. 4.1

O ajustamento gerou os coeficientes, mostrados da tabela 4.18:

Tabela 4.18 - Parâmetros ajustados para as faixas 3 e 6, após a convergência em duas iterações.

\begin{tabular}{|c|c|c|c|}
\hline \multicolumn{4}{|c|}{ Coeficientes } \\
\hline \multicolumn{2}{|r|}{ Amostra } & A0 & A1 \\
\hline \multirow{3}{*}{ 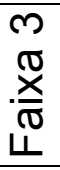 } & Dados Originais & $-13,51123$ & 1,01490 \\
\hline & Dados tratados estatisticamente & $-2,75259$ & 1,00296 \\
\hline & Dados ajustados planimetricamente & $-22,47275$ & 1,02492 \\
\hline \multirow{3}{*}{$\begin{array}{l}0 \\
\mathbb{x} \\
\stackrel{x}{\mathbb{N}} \\
\stackrel{4}{ }\end{array}$} & Dados Originais & 5,88844 & 0,99356 \\
\hline & Dados tratados estatisticamente & $-0,37950$ & 1,00042 \\
\hline & Dados ajustados planimetricamente & 10,01223 & 0,98909 \\
\hline
\end{tabular}

Analisando esses coeficientes, vê-se que A1 está sempre próximo de 1 , indicando que a operação (Eq. 4.1) é, praticamente, uma translação de valor igual a A0.

Os parâmetros ajustados foram aplicados na equação 4.13, para cada ponto de controle altimétrico. As discrepâncias, diferenças entre valores observados no produto a ser avaliado e os valores de referência, calculadas foram utilizadas em testes de tendência, gerando os seguintes resultados: 
Para a faixa 3, dados originais, sem erros grosseiros, $t_{n-1, \alpha}=1,715$ e:

$t_{H}=\frac{\overline{\Delta H} \cdot \sqrt{n}}{S_{H}}=\frac{0,126 \cdot \sqrt{23}}{0,517}=1,172$

$t_{H}=1,172<1,713$, logo a amostra original não apresenta tendências em elevação.

Para a faixa 3 , dados tratados estatisticamente, na planimetria $t_{n-1, \alpha}=1,713 \mathrm{e}:$

$t_{H}=\frac{\overline{\Delta H} \cdot \sqrt{n}}{S_{H}}=\left|\frac{-0,024 \cdot \sqrt{24}}{0,554}\right|=0,208$

$t_{H}=0,208<1,713$, logo a amostra tratada estatisticamente, não apresenta tendências em elevação.

Para a faixa 3, dados ajustados planimetricamente, $t_{n-1, \alpha}=1,713 \mathrm{e}$ :

$t_{H}=\frac{\overline{\Delta H} \cdot \sqrt{n}}{S_{H}}=\frac{0,004 \cdot \sqrt{24}}{0,552}=0,040$

$t_{H}=0,040<1,713$, logo a amostra ajustada planimetricamente não apresenta tendências em elevação.

Para a faixa 6, dados originais, sem erros grosseiros, $t_{n-1, \alpha}=1,720$ e:

$t_{H}=\frac{\overline{\Delta H} \cdot \sqrt{n}}{S_{H}}=\left|\frac{0,049 \cdot \sqrt{21}}{0,363}\right|=0,630$

$t_{H}=0,630<1,753$, logo a amostra original não apresenta tendências em elevação.

Para a faixa 6, dados tratados estatisticamente na planimetria $t_{n-1, \alpha}=1,713$ e:

$t_{H}=\frac{\overline{\Delta H} \cdot \sqrt{n}}{S_{H}}=\left|\frac{-0.006 \cdot \sqrt{24}}{0,296}\right|=0,092$

$t_{H}=0,092<1,753$, logo a amostra tratada estatisticamente não apresenta tendências em elevação. 
Para a faixa 6, dados ajustados planimetricamente, $t_{n-1, \alpha}=1,713$ e:

$t_{H}=\frac{\overline{\Delta H} \cdot \sqrt{n}}{S_{H}}=\left|\frac{0,043 \cdot \sqrt{24}}{0,333}\right|=0,632$

$t_{H}=0,632<1,753$, logo a amostra ajustada planimetricamente não apresenta tendências em elevação.

Esses resultados comprovam que o ajustamento por polinômio de primeiro grau, foi eficiente na eliminação de erros sistemáticos, porém não apresentou vantagem significativa sobre o tratamento estatístico altimétrico. Em seguida, testouse a satisfação dos levantamentos ao PEC, examinando a quantidade de pontos que excedem os limites impostos pelo padrão. Os resultados são exibidos na tabela, a seguir:

Tabela 4.19 - Avaliação das discrepâncias altimétricas perante o PEC, após ajustamento com.polinômio de $1^{\circ}$ grau.

\begin{tabular}{|c|c|c|c|c|c|c|c|}
\hline \multicolumn{8}{|c|}{ Satisfação ao PEC após ajustamento altimétrico } \\
\hline & Amostra & $\begin{array}{c}1 / 1.000- \\
A\end{array}$ & $\begin{array}{c}1 / 1.000- \\
B\end{array}$ & $\begin{array}{c}1 / 1.000- \\
C\end{array}$ & $\begin{array}{c}1 / 2.000- \\
A\end{array}$ & $\begin{array}{c}1 / 2.000- \\
B\end{array}$ & $\begin{array}{c}1 / 2.000- \\
C\end{array}$ \\
\hline & Dados Originais & $73,91 \%$ & $78,26 \%$ & $86,96 \%$ & $95,65 \%$ & $100,00 \%$ & $100,00 \%$ \\
\hline & & Reprovado & Reprovado & Reprovado & Aprovado & Aprovado & Aprovado \\
\hline & Dados tratados & $54,17 \%$ & $62,50 \%$ & $83,33 \%$ & $100,00 \%$ & $100,00 \%$ & $100,00 \%$ \\
\hline & estatisticamente & Reprovado & Reprovado & Reprovado & Aprovado & Aprovado & Aprovado \\
\hline & Dados ajustados & $54,17 \%$ & $66,67 \%$ & $91,67 \%$ & $100,00 \%$ & $100,00 \%$ & $100,00 \%$ \\
\hline & planir & Reprovado & Reprovado & Aprovado & Aprovado & Aprovado & Aprovado \\
\hline \multirow{6}{*}{$\frac{\mathbb{E}}{\bar{\sigma}}$} & Dados Originais & $76,19 \%$ & $95,24 \%$ & $95,24 \%$ & $100,00 \%$ & $100,00 \%$ & $100,00 \%$ \\
\hline & & Reprovado & Aprovado & Aprovado & Aprovado & Aprovado & Aprovado \\
\hline & Dados tratados & $91,67 \%$ & $91,67 \%$ & $100,00 \%$ & $100,00 \%$ & $100,00 \%$ & $100,00 \%$ \\
\hline & & Aprovado & Aprovado & Aprovado & Aprovado & Aprovado & Aprovado \\
\hline & Dados & $83,33 \%$ & $91,67 \%$ & $100,00 \%$ & $100,00 \%$ & $100,00 \%$ & $100,00 \%$ \\
\hline & planir & Reprovado & Aprovado & Aprovado & Aprovado & Aprovado & Aprovado \\
\hline
\end{tabular}

Observa-se que o ajustamento com polinômio de $1^{\circ}$ grau, não apresentou melhora significativa nos resultados, o que não recomenda sua aplicação, pelo menos com os presentes dados.

Os resultados finais deste experimento, considerando planimetria e altimetria, apontam que o MDS oriundo deste levantamento apresenta qualidade compatível com produtos cartográficos na escala $1 / 2.000$, classe $A$, para a faixa 3 e 
escala 1/1.000, classe B, para a faixa 6. Observa-se ainda, coerência entre áreas de sobreposição, como pode ser observado nas tabelas 4.12 e 4.13 .

Parece-nos, em conclusão, que a especificação final para o produto, após todos os tratamentos, deve ser escala 1:2.000, classe A, mesmo porque 0 mapeamento de controle está nessa escala e precisão. Para certificar algo melhor seria preciso contar com um produto de referência mais preciso. Em trabalhos futuros, pretende-se também analisar outros mapeamentos a LASER, para maior garantia dessa conclusão. 


\section{Conclusões e recomendações}

Conclui-se, pelos resultados do experimento feito, que os levantamentos por sistema de varredura a LASER aerotransportado apresentam resultados satisfatórios. Os testes realizados no capítulo 4 apontam qualidade compatível com classe $A$, na escala 1/2.000. Pretende-se realizar testes com outros levantamentos, preferencialmente, com características distintas: altura de vôo e resolução diferentes, outros sistemas de varredura (por exemplo, fibra ótica), etc.

As conclusões e experiências são as seguintes:

1) A metodologia proposta foi eficiente na detecção de bordas de edificações. Uma das vantagens desta metodologia é a detecção das bordas sobre os dados originais (nuvem de pontos). Desta forma, previnem-se erros introduzidos pela interpolação inerente à geração de imagens. Esta proposição abre uma nova área de estudo, adaptando as técnicas de processamento de imagem, a dados em um domínio real tridimensional (R3).

2) As bordas detectadas podem ser usadas para inúmeras aplicações como filtragem de pontos para geração de MDT e utilização como linhas de quebra para geração de MDS/MDT mais fiéis a realidade. Podem ainda, como utilizado no trabalho, ser utilizadas para determinação de pontos de controle planimétrico. Neste caso devem-se realizar mais estudos com relação ao retorno do pulso LASER a ser processado, para garantir a métrica das edificações.

3) Melhorias na qualidade dos levantamentos são alcançadas mediante minimização de erros, através de uma transformação afim plana ou da subtração da média das discrepâncias planimétricas nas coordenadas observadas. No caso estudado, as duas metodologias são equivalentes. Uma explicação para a coerência entre resultados da transformação afim e a simples translação é o grande peso dos coeficientes $\mathrm{A} 0$ e $\mathrm{B} 0$, responsáveis por translações, frente aos coeficientes $\mathrm{A} 1, \mathrm{~B} 1$, A2 e B2, responsáveis pelas rotações e escalas. 
4) A simples subtração da média das discrepâncias nas observações (translações) mostrou-se bastante eficiente, garantindo resultados, ligeiramente melhores que a transformação afim. Além da maior eficiência, o procedimento é mais simples e menos oneroso computacionalmente. Sugere-se aplicar esse método, se não houver alguma circunstância especial.

Recomendações

1) A restituição, usada como documento cartográfico de referência, impediu o teste de transformações afins no espaço, modelo presumidamente mais indicado para ajustamento de levantamentos a LASER. Recomenda-se, para estudos futuros, a coleta de pontos tridimensionais em campo, identificáveis no levantamento a LASER. Levantamentos GPS sobre o topo de vértices de edificações, permitiriam o emprego da transformação afim no espaço e possibilitariam a construção de uma matriz-peso mais adequada, através das precisões das observações.

2) Do ponto de vista altimétrico, a utilização do polinômio de $1^{\circ}$ grau, não apresentou melhora significativa nos resultados em um dos conjuntos de amostras. A simples eliminação de erros grosseiros e sistemáticos nas observações altimétricas, obteve resultados semelhantes, com procedimentos mais simples. Pretende-se realizar testes com outros levantamentos para verificar qual modelo mais se adeqüa ao ajustamento deste tipo de dado.

3) Outros estudos de interesse, para trabalhos futuros seriam:

a) Adaptar a presente metodologia pensando em levantamentos maiores; determinar para esses casos o número de pontos de apoio e verificação necessários, principalmente no caso de não existir mapeamento disponível e ser necessário levantamento de campo, com GPS, por exemplo. 
b) Verificar se a metodologia de extração de bordas proposta é melhor que o processo de extração de bordas sobre imagens de níveis de cinza para dados de sensores que naturalmente não produzem dados com distribuição regular ou como sonares e radares de varredura lateral.

c) Realizar mais testes sobre qual limiar de gradiente utilizar para detecção de bordas sobre triangulação, em dados com distribuição semelhantes como os oriundos de varredura a LASER ou ecobatímetro multi-feixe. Estudar se esta metodologia pode ser utilizada com dados de imageamento ou outros sensores que não gerem dados brutos sob forma de grade regular.

d) Aumentar a automatização do processo de vetorização de bordas detectadas pela metodologia descrita, aperfeiçoando as ferramentas desenvolvidas. 


\section{REFERÊNCIAS BIBLIOGRÁFICAS}

ASPRS Interim Accuracy Standards for Large Scale Maps, 1989. July 1989 PE\&RS, pp. 1038-1040: disponível em http://www.asprs.org/resources/standards.html, último acesso em dez. de 2008

BALTSAVIAS, E.P., Airborne LASER scanning: basic relations and formulas. ISPRS Journal of Photogrammetry and Remote Sensing, v. 54, n. 2-3, p. 199-214, 1999.

BROVELLI, M.; CANNATA, M.; LONGONI, U. LIDAR data filtering and DTM interpolation within GRASS. Transictions in GIS, v.8, p. 155-174, 2004.

BURMAN, H. LASER strip adjustment for data calibration and verification. IAPRS Remote Sensing and Spatial Information Sciences, n 34, p 67-72, 2002.

CAVASSIM JR, I. Utilização de dados derivados do varredor LASER na geração de cartas planimétricas na escala 1:2000. 2004. Dissertação (Mestrado) Universidade Federal do Paraná, Curitiba, 2004, 86p.

CENTENO, J. S. et al. Análise de modelos numéricos de elevação derivados de LASER scanner para o monitoramento urbano. In: Congresso Brasileiro de Cadastro Técnico Multifinalitário, 1, Florianópolis, 2000. Anais.

CINTRA, J. P. Modelagem digital de terrenos. 1985. Tese (Doutorado) - Escola Politécnica da Universidade de São Paulo, São Paulo, 1985, 285p.

CINTRA, J.P.; NERO, M.N. A new method for the cartographic quality control in digital mapping, ISPRS Journal of Photogrammetry \& Remote Sensing, submitted, 2009

DALMOLIN, Q.; SANTOS, D. R.: Sistema LASER Scanner: Conceitos e princípios de funcionamento. Curitiba. Ed. UFPR, 2003, 97p.

ELMQVIST, M. Ground surface estimation from airborne LASER scanner data using active shape models. IAPRS Remote Sensing and Spatial Information Sciences, n. 34, p. 114-118, 2002. 
GEMAEL, G., Introdução ao ajustamento de observações, aplicações geodésicas. Curitiba. Ed. UFPR, 1994, 320p.

GONÇALES, R. Dispositivo de varredura LASER 3D terrestre e suas aplicações na engenharia. 2007. Dissertação (Mestrado) - Escola Politécnica da Universidade de São Paulo, São Paulo, 2007, 98p.

HOFTON, M. A., BLAIR, J. B. An airborne scanning LASER altimetry survey of Long Valley, California. International Journal of Remote Sensing, vol. 21, n 12, p 2413$2437,2000$.

HUISING, E. J.; GOMES, L. M. P. Errors and accuracy estimates of LASER data acquired by various LASER scanning systems for topographic applications. ISPRS Journal of Photogrammetry \& Remote Sensing, v. 53, n. 5, p. 245-261, 1998.

KAPLAN, E. D. Understanding GPS: principles and applications. Boston, Artech House, 1996, 554p.

KILLIAN, J.; HAALA, N.; ENGLICH, M. Capture and evaluation of airborne LASER scanner data. IAPRS Remote Sensing and Spatial Information Sciences, n. 23, p. 383-388, 1996.

LIMA, S. R. S. Integração GPS/INS utilizando sensores inerciais baseados em sistemas microeletromecânicos. 2005. Tese (Doutorado) - Universidade Federal do Paraná, Curitiba, 2005, 136p.

MONICO, J. F. G Posicionamento pelo NAVSTAR-GPS: descrição, fundamentos e aplicações. São Paulo, Ed.UNESP, 2008, 287p.

MERCHANT, D. C. Spatial Accuracy Standards for Large Scale Line Maps, In: Technical congress on surveing and mapping. Proceedings. V. 1, p. 222-231, 1982

MORIN, K. W. Calibration of airborne LASER scanners. 2002. Tesis (PhD) University of Calgary, Alberta, 2002, 125p. 
MORSDORF, F. ET AL. The potential of discrete return, small footprint airborne LASER scanning data for vegetation density estimation. In: ISPRS work group III Workshop, 2005, Enschede, Annals, p.198-203.

NERO, M. A. Estudo comparativo de metodologias de digitalização de mapas e seu controle de qualidade geométrica. 2000. Dissertação (Mestrado) - Escola Politécnica da Universidade de São Paulo, São Paulo, 2000, 233p.

NERO, M. A. Proposta para controle de qualidade de bases cartográficas com ênfase na componente posicional. 2005. Tese (Doutorado) - Escola Politécnica, Universidade de São Paulo, São Paulo 2005, 291p.

PESSOA, L.M.C., GPS - Teoria e Prática. Rio de Janeiro, Ed. Petrobras, 1998, $134 p$.

ROGGERO, M. Airborne LASER scanning: clustering in raw data. IAPRS Remote Sensing and Spatial Information Sciences, n. 34, p. 227-232, 2001.

SITHOLE, G. e VOSSELMAN, G. Experimental comparison of filter algorithms for bare-Earth extraction from airborne LASER scanning point clouds. ISPRS Journal of Photogrametry \& Remote Sensing, v. 59, n. 1-2, p. 85-101, 2004.

STEINLE, E.; VOGTLE, T., Effects of difference LASER scanning modes on the results of buildings recognition and reconstruction. IAPRS Remote Sensing and Spatial Information Sciences, v. 33, part B3, pp. 858-865, 2000.

USBB, 1947 U.S. Bureau of the Budget, National Map Accuracy Standard (NMAS), Revised, June 17, 1947: disponível em http://rockyweb.cr.usgs.gov/ nmpstds/nmas.html, último acesso em dez de 2008

VAUGHN, C. R. et al. Georeferecing of airborne LASER altimeter measurements. International Journal of Remote Sensing, v. 17, n 11, p 2185-2200, 1996.

VOSSELMAN, G. Slope based filtering of LASER altimetry data. IAPRS Remote Sensing and Spatial Information Sciences, v. 33, p. 935-942, 2000. 
WACK, R; WIMMER, A. Digital terrain models from airborne LASER scanner data - a grid based approach IAPRS Remote Sensing and Spatial Information Sciences, n. 34, p. 293-296, 2002.

WEHR A.; LOHR U. Airborne LASER Scanning - An Introduction and Overview. ISPRS Journal of Photogrammetry \& Remote Sensing, v.54, n. 3, pp. 68-82, 1999

ZIOU, D; TABBONE, S.. Edge detection techniques - an overview. International Journal of Pattern Recognition and Image Analysis, n.8, p.:537--559., 1998

\section{BIBLIOGRAFIA CONSULTADA}

BEHAN A..; MAAS H-G.; VOSSELMANN, G. Steps towards Quality Improvement of Airborne LASER Scanner Data. In: ANNUAL CONFERENCE OF THE REMOTE SENSING SOCIETY, 26, 2000, Amsterdam. Proceedings. [s.n.]

HYYPÂ, J. et al. Using individual tree crown approach for forest volume extraction with aerial images and LASER point clouds. In: ISPRS work group III Workshop, 2005, Enschede, Annals, p.144-149.

LIDAR - Light Detection And Ranging: disponível em http:// www.lidar.com, último acesso em dezembro 2008

Optech: disponível em http://www.optech.ca, último acesso em outubro de 2008

Precise Navigation: disponível em http://gge.unb.ca/Research/GeodesyGroup/ tutorial/precision_navigation.htm, último acesso em setembro de 2006

VOSSELMAN, G.; MAAS, H. G., Adjustment and filtering of raw LASER altimetry data. In: OEEPE workshop on Airbone LASERscaning and Interferometric SAR for Detailed Digital Elevation Models, 40, Amsterdam, 2001. Proceedings, pp. 62-72. 